University of Louisville

ThinkIR: The University of Louisville's Institutional Repository

Electronic Theses and Dissertations

$12-2017$

\title{
Role of human arylamine n-acetyltransferase 1 in tumorigenesis and cancer biology.
}

Marcus William Stepp

University of Louisville

Follow this and additional works at: https://ir.library.louisville.edu/etd

Part of the Pharmacy and Pharmaceutical Sciences Commons

\section{Recommended Citation}

Stepp, Marcus William, "Role of human arylamine n-acetyltransferase 1 in tumorigenesis and cancer biology." (2017). Electronic Theses and Dissertations. Paper 2862.

https://doi.org/10.18297/etd/2862

This Doctoral Dissertation is brought to you for free and open access by ThinkIR: The University of Louisville's Institutional Repository. It has been accepted for inclusion in Electronic Theses and Dissertations by an authorized administrator of ThinkIR: The University of Louisville's Institutional Repository. This title appears here courtesy of the author, who has retained all other copyrights. For more information, please contact thinkir@louisville.edu. 
ROLE OF HUMAN ARYLAMINE N-ACETYLTRANSFERASE 1 IN TUMORIGENESIS AND CANCER BIOLOGY

By

\author{
Marcus W. Stepp \\ B.S., Rose-Hulman Institute of Technology, 2010 \\ M.S., University of Louisville, 2014
}

\begin{abstract}
A Dissertation
Submitted to the Faculty of the School of Medicine of the University of Louisville In Partial Fulfillment of the Requirements for the Degree of

Doctor of Philosophy in Pharmacology and Toxicology

Department of Pharmacology and Toxicology

University of Louisville Louisville, KY
\end{abstract}

December 2017 
Copyright 2017 by Marcus William Stepp

All rights reserved 

ROLE OF HUMAN ARYLAMINE N-ACETYLTRANSFERASE 1 IN TUMORIGENESIS AND CANCER BIOLOGY

\author{
By \\ Marcus William Stepp \\ B.S., Rose-Hulman Institute of Technology, 2010 \\ M.S., University of Louisville, 2014 \\ A Dissertation Approved on
}

June $12^{\text {th }}, 2017$

By the following Dissertation Committee

David W. Hein, PhD.

J. Christopher States, PhD.

David J. Samuelson, PhD.

Shirish S. Barve, PhD

Alfred B. Jenson, PhD. 


\section{DEDICATION}

This dissertation is dedicated to my caring parents Mr. Kevin M. Stepp and Mrs.

Wilma K. Stepp for giving me so many opportunities in life, and their continual support and encouragement. Additionally this dissertation is dedicated to my entire family for their support and love. 


\section{ACKNOWLEDGEMENTS}

I would like to thank Dr. Hein, my mentor, for all of his support and guidance in the development of my dissertation. Thank you to Mark Doll for all his dedicated help with several aspects of this dissertation. I would like to acknowledge the help of Dr. Mary Ann Sanders, in teaching me pathology classifications and helping classify the pathology slides. Thank you to Dr. Dennis Warner for instructing me on the isolation and culture of mouse embryonic fibroblasts. Thank you to Jamie Rush for being a helpful neighbor in the laboratory. Thank you to the summer students that I had the pleasure of instructing over the summers of my graduate studies. Additional thanks to my other committee members for their comments and suggestions:

Dr. States, Dr. Samuelson, Dr. Barve, and Dr. Jenson 


\section{ABSTRACT \\ ROLE OF HUMAN ARYLAMINE N-ACETYLTRANSFERASE 1 IN TUMORIGENESIS AND CANCER BIOLOGY \\ Marcus W. Stepp \\ June $12^{\text {th }}, 2017$}

Human arylamine $\mathrm{N}$-acetyltransferase 1 (NAT1) is a well-known phase II metabolic enzyme that has been associated with carcinogenesis. Its role in the biotransformation of aromatic and heterocyclic amine carcinogens has been investigated for many years, but more recent investigations focus on a possible endogenous role of human NAT1 in cancer initiation and progression. To further explore and understand possible endogenous roles for NAT1, we conducted in vitro enzymatic reactions, in vivo studies using homozygous high (rapid) or low (slow) NAT2 activity congenic F344.WKY rats, and genetically modified human breast cancer cell lines. Human NAT1 and rodent NAT2 hydrolyzed acetylcoenzyme $A(A c C o A)$ in a folate-dependent manner. This hydrolytic function of human NAT1 also was measured with an endogenous folate compound dihydrofolate. The rat Nat2 gene is a functional ortholog for the human NAT1 because it has similar sequence and substrate specificity to human NAT1. Rapid acetylator NAT2 congenic rats developed more mammary tumors than the slow acetylator NAT2 congenic rats following administration of the mammary 
carcinogens methylnitrosourea and 7,12-dimethylbenzanthracene, neither of which is metabolized by rat NAT2. Investigations of partial NAT1 knockdown and complete NAT1 knockout were completed in MDA-MB-231 and MCF7 human breast cancer cell lines. Both partial and complete NAT1 knockout reduced ability for colony formation in soft agar compared to parental cell lines. Endogenous AcCoA levels in congenic rat embryonic fibroblasts and in human breast cancer cell lines with partial and complete NAT1 knockout showed increased AcCoA when the level of NAT1 was reduced within the cells. In summary, the findings compliment but do not fully replicate previous reports regarding the effect of reducing NAT1 activity on cancer cell properties. In our studies, partial knockdown or complete removal of NAT1-catalyzed N-acetylation in the MDAMB-231 and MCF7 breast cancer cell line by CRISPR/Cas9 resulted in a significant decrease in anchorage-independent colony formation without affecting overall cell growth and relative invasion ability. NAT1 knockout cell lines had increased endogenous AcCoA levels, about 45\%, compared to the parental cell line. The results warrant further studies to determine mechanisms to understand how reduced NAT1 activity is related to reduced formation of anchorageindependent colonies. Use of this model system further suggests that human NAT1 could serve as a target for the prevention and/or treatment of breast cancer. 


\section{TABLE OF CONTENTS}

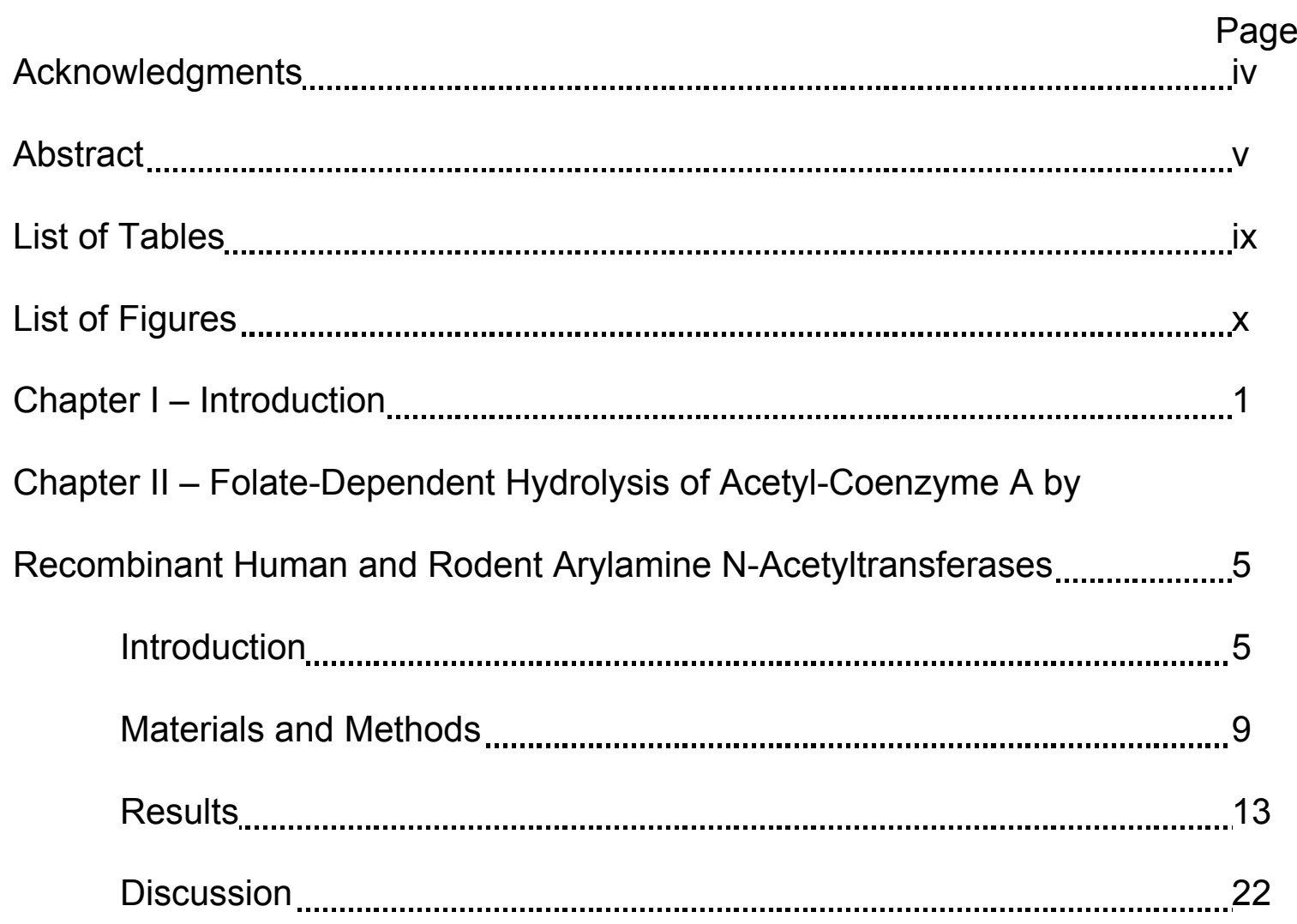

Chapter III - Congenic rats with higher arylamine $\mathrm{N}$-acetyltransferase 2 activity exhibit greater carcinogen-induced mammary tumor susceptibility independent of

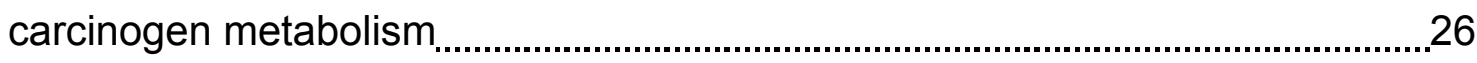

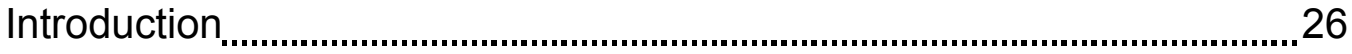

Materials and Methods ................................................................................. 35

Results

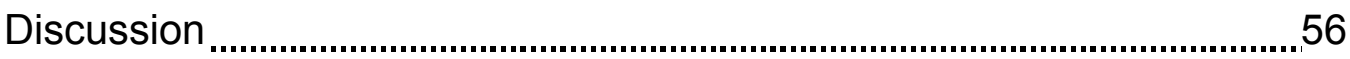


Chapter IV - Inhibition of Arylamine N-acetyltransferase 1 Reduces AnchorageIndependent Growth in Human Breast Cancer Cell Line MDA-MB-231 .............61 Introduction

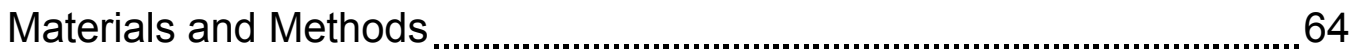

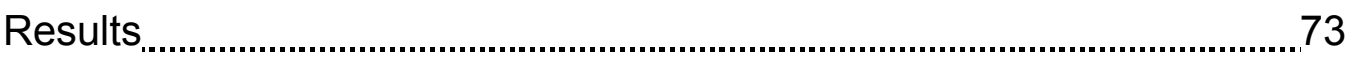

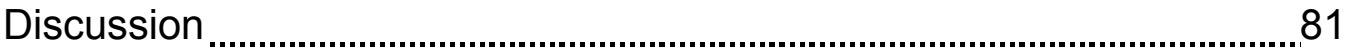

Chapter V - CRISPR/Cas9 mediated knock out of arylamine $N$-acetyltransferase 1 (NAT1) in human adenocarcinoma breast cancer cell lines..............................86

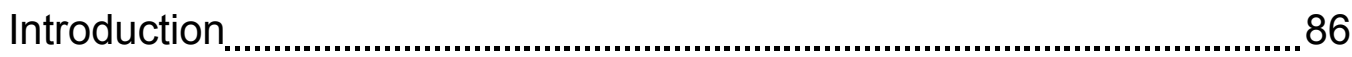
Materials and Methods ............................................................................ 91 Results

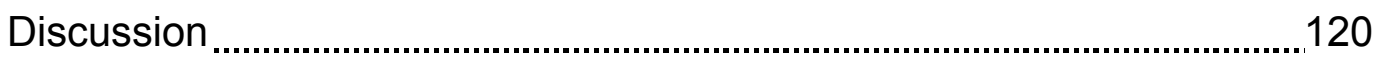

Chapter VI - Summary and Conclusions .........................................................125

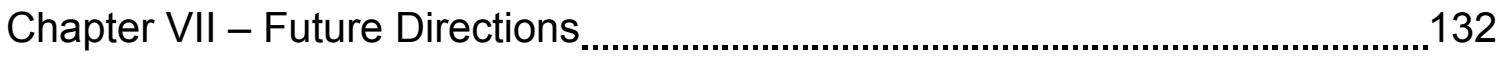

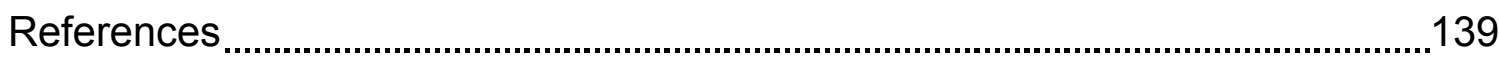

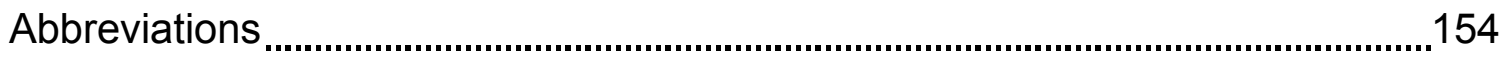

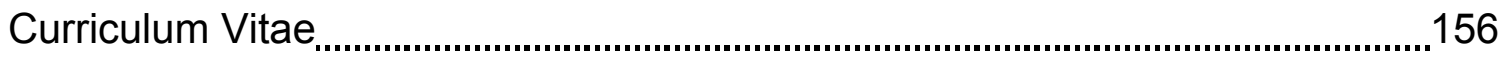




\section{LIST OF TABLES}

\section{TABLE}

1.Table 2.1 - Comparisons of PABA N-acetylation and AcCoA hydrolysis by recombinant human NAT1 and rodent Nat2 enzymes 18

2.Table 3.1 - Mammary tumor totals in rapid and slow acetylator congenic rats administered MNU or DMBA

3.Table 5.1 - Genomic sequence for the NAT1 gene in MDA-MB-231 Parental and NAT1 knockout clones

4.Table 5.2 - Resulting Amino Acid Sequence for MDA-MB-231 Parental and NAT1 knockout clones 103

5.Table 5.3 - Genomic sequence for the NAT1 gene in MCF7 Parental and NAT1 knockout clones 104

6.Table 5.4 - Resulting Amino Acid Sequence for MCF7 Parental and NAT1 knockout clones 105 


\section{LIST OF FIGURES}

FIGURE

PAGE

1.Figure 2.1 - NAT1 enzymatic reactions 8

2.Figure 2.2 - Michaelis-Menton saturation curves for AcCoA hydrolysis with or without folate. 14

3.Figure 2.3 - Michaelis-Menton saturation curves with various concentrations of AcCoA and folate for human NAT1 and rodent NAT2 17

4.Figure 2.4 - AcCoA hydrolysis catalyzed by NAT1 with the addition of folate, MTX, and DHF 20

5.Figure 2.5 - Michaelis-Menton curves showing inhibition by folate or MTX on NAT1 PABA acetylation activity 21

6.Figure 3.1 - Amino acid sequence comparison between human NAT1 and rat Nat2. 29

7.Figure 3.2 - How MNU damages the genetic sequence 32

8.Figure 3.3 - Experimental design for chemical-induced tumor experiments..37

9.Figure 3.4 - Weekly body mass of rapid and slow acetylator Nat2 congenic rats post administration of specified carcinogen or vehicle control. 45

10.Figure 3.5 - Kaplan-Meier plot of palpable mammary tumors in congenic rats

11.Figure 3.6 - Photomicrographs of H\&E stained slides depicting the criteria utilized to classify tumors. .51 
12.Figure 3.7 - Rat NAT2 PABA acetylation and folate-dependent AcCoA

hydrolysis activity

13.Figure 3.8 - NAT2 activity and AcCoA level measured in rat embryonic

fibroblasts (REFs) from rapid and slow rats 55

14.Figure 4.1 - NAT1 catalytic activity and mRNA expression in stably modified

MDA-MB-231 cell lines 74

15.Figure 4.2 - Cell growth properties in shRNA NAT1 knockdown and

overexpression stably modified MDA-MB-231 cell lines. 76

16.Figure 4.3 - Effects of a small molecular inhibitor (5-HDST) on NAT1 activity 79

17.Figure 4.4 - Cell growth properties of MDA-MB-231 cells incubated with 5HDST 80

18.Figure 5.1 - NAT1 PABA acetylation activity and endogenous AcCoA concentration level in genomic modified MDA-MB-231 and MCF7 cell lines 108

19.Figure 5.2 - Cell growth properties in genomic modified MDA-MB-231 and MCF7 cell lines 112

20.Figure 5.3 - Growth curves for MDA-MB-231 cell lines with standard adhesion or in anchorage independent conditions 115

21.Figure 5.4 - Hanging drop assay results for parental and genomic modified

MDA-MB-231 cell lines 116

22.Figure 5.5 - Relative invasion ability for parental and genomic modified MDAMB-231 cell lines 117 
23.Figure 5.6 - Wound closure ability for parental and genomic modified MDA-

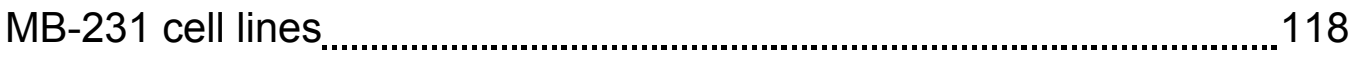

24.Figure 5.7 - Xenograft tumor weight for parental and genomic modified MDAMB-231 cell lines. 119 


\section{CHAPTER I}

\section{INTRODUCTION}

The human genome codes for two functional arylamine $\mathrm{N}$ acetyltransferases (NATs), NAT1 and NAT2, that are located on the short arm of chromosome 8 [1]. Human NAT1 is expressed in nearly all human tissues [2, 3]. Human NAT2 is expressed primarily in the liver and gut [4]. The two NATs differ from each other in substrate specificity, structural stability, and tissue specific expression [5]. There is also an inactive NAT pseudogene known as NATP [6].

The NAT1 protein is a phase II cytosolic isoenzyme responsible for the metabolism of arylamine xenobiotics, including such environmental and occupational carcinogens like 4-aminobiphenyl (ABP)[7]. NAT1 catalyzes both Nacetylation and $\mathrm{O}$-acetylation. The $\mathrm{N}$-acetylation of aromatic and heterocyclic amine xenobiotics results in the inactivation of compounds, and the inactivated compound is removed by urinary excretion. After N-hydroxylation of aromatic and heterocyclic amine xenobiotics by a cytochrome P450, O-acetylation catalyzed by NAT1 produces an unstable highly reactive nitrenium ion. This nitrenium ion is able to react with DNA forming DNA adducts, which if left unrepaired generate mutations leading to cancer initiation. NAT1 is related to several cancer types by its ability to biotransform arylamine procarcinogens to active carcinogen forms. 
However recent findings suggest that human NAT1 activity is involved in cancer by a still unknown mechanism independent of procarcinogen metabolism.

Research in cancer biology has provided insights into the connections of NAT1 and cancer cell proliferation and invasiveness. Overexpressing human NAT1 in non-transformed breast epithelial cells, HB4a, resulted in increased growth and survival. These modified cells also showed a resistance to etoposide treatment [8]. Calu3 cells, a colon carcinoma cell line, that are resistant to gemcitabine have higher expression of NAT1 [9]. In a majority of human immortalized cells assayed there has been endogenous NAT1 expression/activity observed [10]. The use of a lentiviral shRNA expression system for human NAT1 knockdown in a human breast cancer cell line, MDA-MB-231, caused a decrease in cell proliferation and invasiveness $[11,12]$. Similarly, NAT1 knockdown in a human colon cancer cell line, HT-29 showed increased cell-cell contact inhibition [13]. Up-regulation of E-cadherin was associated with knockdown of human NAT1, but there was no change in the transcription factors Snail, Twist, or Slug $[13,14]$. Use of a small molecule inhibitor, Rhod-o-hp, specific for human NAT1 showed that inhibition in MDA-MB-231 cells stops cell proliferation, inhibited anchorage-independent growth, and reduced the invasiveness of the cell [11]. All the cell culture experiments indicate that human NAT1 plays some role in cancer cell proliferation and survival.

Microarray data on many different types of breast cancer showed NAT1 expression was clustered with estrogen receptor expression $[15,16]$. This correlation between positive estrogen receptor (ER) status and human NAT1 was 
confirmed by additional microarray studies [17-20]. Immunohistochemistry showed higher human NAT1 levels in ER+ breast cancer samples when compared to ER- breast cancer [8]. Expression also is affected by the deletion of NAT1's chromosome region in some cancers. The deletion may explain why some cancer subtypes have low expression of NAT1 [21]. Tumors, characterized based on which breast tissue the tumor arose from, showed luminal breast cancers with higher NAT1 expression than basal breast cancer [16, 22, 23]. A significant correlation has been observed between breast carcinomas expressing the highest levels of NAT1 and those that metastasized to the bone [24]. Also, elevated human NAT1 mRNA level has been shown to be associated with more invasive breast cancers [25]. All this evidence for the relationship of NAT1 with some subtypes of breast cancer has led some to state a possible role of NAT1 in classifying cancer molecular subtypes.

Human populations exhibit different NAT1 variant haplotypes. The reference haplotype is termed $N A T 1^{*} 4$. NAT1*10 is known as one of the most common variant haplotypes. NAT1*10 is presently defined by two SNPs $1088 \mathrm{~T}>\mathrm{A} \quad(\mathrm{rs} 1057126)$ and $1095 \mathrm{C}>\mathrm{A} \quad(\mathrm{rs} 15561)$ in the $3^{\prime}$ UTR (http://nat.mbg.duth.gr). NAT1*10 is associated with increased NAT1 activity in human bladder [26], colon [27], and liver [28]. NAT1*10 also is associated with higher cancer risk in some types of cancer. NAT1*10 has been associated with higher risk of developing cancer in the breast [29], colon/rectum [30, 31], lung [32], pancreas [33], and urinary bladder [34]. However, other studies have reported no association between $N A T 1^{*} 10$ and cancer risk $[35,36]$. 
$N A T 1^{*} 14 B$ is the most common variant allele that is associated with a reduced acetylator activity. Allelic frequencies in American, German, French, and Canadian populations are less than 5\% [7]. However the allelic frequency of $N A T 1^{*} 14 B$ in the Lebanese population is about $24 \%$ [37]. NAT1 ${ }^{*} 14 B$ is defined presently by a SNP of nucleotide G560A (rs4986782), which is located in the open reading frame (ORF) (http://nat.mbg.duth.gr). G560A results in an amino acid substitution R187Q. The arginine for glutamine substitution is thought to destabilize the NAT1 structure. The use of homology modeling predicts that the substitution affects NAT1 binding of acetyl-coenzyme A, active site acetylation, catalytic activity, and substrate specificity [38]. NAT1*14B is associated with smoking-induced cancer [39]. 4-Aminobiphenyl (ABP) DNA adducts are elevated in cells that have been stably transfected with $N A T 1^{*} 14 B$ compared with cells transfected with $N A T 1^{*} 4$ (considered the wildtype allele) [40].

In summary human NAT1 is involved in cancer cell proliferation and survival. Human NAT1 has been found to correlate with aggressive forms of cancer and estrogen receptor positive breast cancer. Human NAT1 haplotypes that have the highest activity stand at a higher risk for certain types of cancer. This evidence shows that NAT1 has a role in cancer, but the exact mechanism of how it is involved is unknown. 
CHAPTER II

FOLATE-DEPENDENT HYDROLYSIS OF ACETYL-COENZYME A BY

RECOMBINANT HUMAN AND RODENT ARYLAMINE N-

ACETYLTRANSFERASES

INTRODUCTION

Arylamine N-acetyltransferases (NATs) are phase II cytosolic isoenzymes responsible for the metabolism of arylamine and N-hydroxylarylamine drugs and xenobiotics [41]. The isoenzymes catalyze the transfer of the acetyl group from acetyl-coenzyme A (AcCoA) to the exocyclic amine of an arylamine ( $\mathrm{N}$ acetylation) or the hydroxylated amine of an $\mathrm{N}$-hydroxylated arylamine (Oacetylation) [42-44]. NATs are able to bioactivate procarcinogens like 4aminobiphenyl (ABP), a component of cigarette smoke [41]. Also, NATs metabolize various pharmaceuticals, such as the antibacterial (sulfonamides), antitubercular (isoniazid), and antiarrhythmic (procainamide) drugs [45-47]. Understanding $\mathrm{N}$-acetyltransferase function, expression, and regulation aids in predicting individual drug toxicities or individual tissue-specific cancer susceptibilities associated with environmental and/or occupational carcinogen exposures. 
Amino acid residues at positions 125,127 , and 129 determine substrate specificity of the 290 amino acid NAT1 protein [48]. Comparison of the amino acids at the three mentioned positions in rat Nat2 and mouse Nat2 with human NAT1, shows they share all three amino acids (Phe125, Arg127, and Tyr129). However hamster Nat2 shares only two out of three amino acids (Phe125 and Arg127) with human NAT1. This shared amino acid similarity suggests that these NATs will have similar substrate specificity. The C-terminus undecapeptide tail of the NATs controls the hydrolysis of AcCoA [49]. The C-terminus undecapeptide tail of rat, mouse, and hamster Nat2 and human NAT1 share $100 \%$ identical amino acids suggesting they are orthologs. Conversely rodent Nat1 and human NAT2 do not align as well as rodent Nat2 and human NAT1. Only rat Nat1 (Tyr125, Ser127, and Tyr129) shares a single similar amino acid for the active site in human NAT2 (Ser125, Ser127, Ser129). The mouse and hamster Nat1 (Tyr125, Gly127, Tyr129) share the same active site amino acids with each other, but do not share any similarity to human NAT2. The C-terminus undecapeptide tails for rodent Nat1 and human NAT2 also do not have much in common. Rodents have an active Nat3 enzyme, unlike humans [1, 50].

$\mathrm{N}$-acetyltransferases have been shown to play a role in development [51]. It has been proposed that human NAT1 influences folate homeostasis and thus, affects neural tube development [52]. Human NAT1 acetylates the folate catabolite, para-aminobenzoyl-1-glutamate [53]. Recent studies report that human NAT1 and mouse Nat2 hydrolyze AcCoA into acetate and coenzyme A in 
a folate-dependent fashion [54], a previously unknown function (figure 2.1). In this chapter, our goal was to confirm these findings and determine the apparent Michaelis-Menten kinetic constants (Vmax and $\mathrm{Km}$ ) of the folate-dependent AcCoA hydrolysis for human NAT1/NAT2 and the rodent analogs rat Nat1/Nat2, mouse Nat1/Nat2, and hamster Nat1/Nat2. We also compared apparent Vmax values for AcCoA hydrolysis to $\mathrm{N}$-acetylation of the substrate para-aminobenzoic acid (PABA). 
FIGURE 2.1

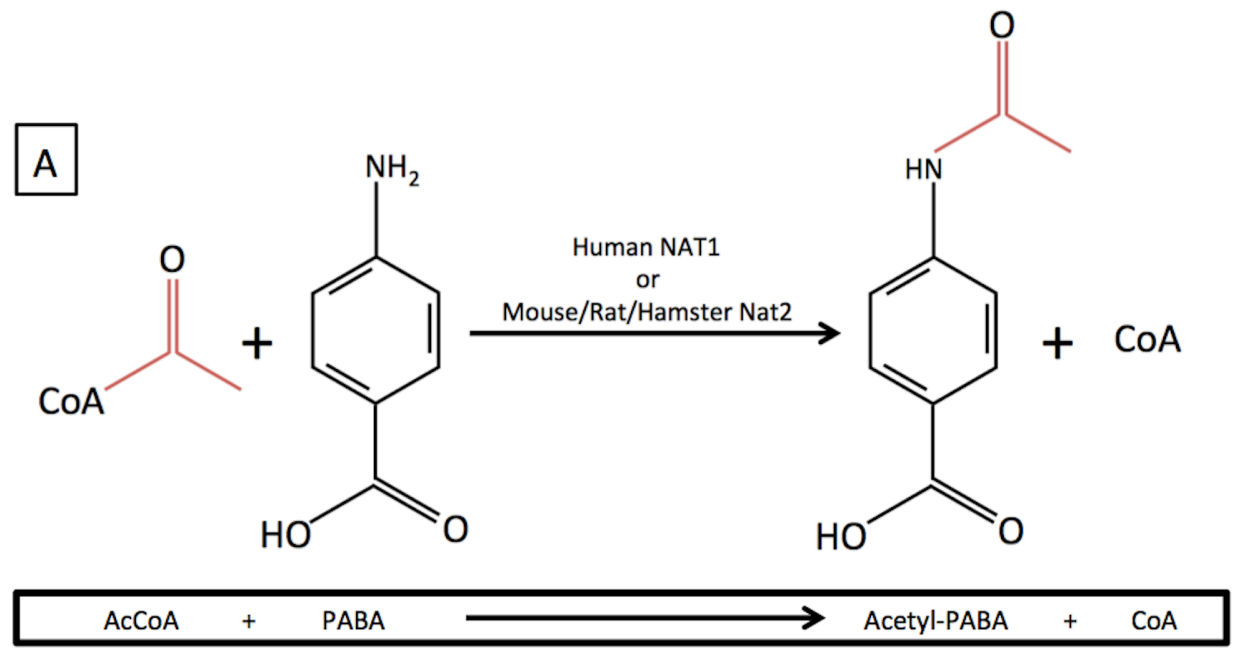

B

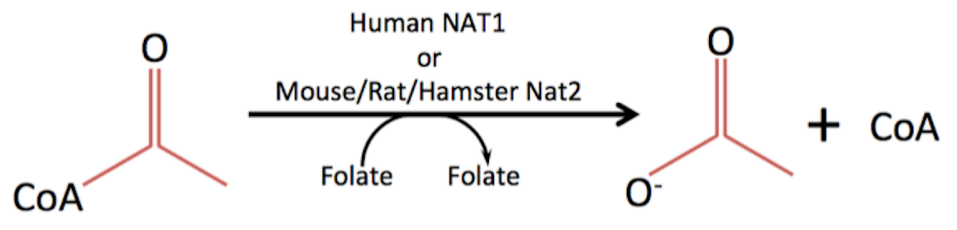

AcCoA

Acetate $+\mathrm{CoA}$

Figure 2.1. NAT1 enzymatic reactions are AcCoA-dependent $N$-acetylation of arylamine substrate $(A)$ and folate-dependent hydrolysis of AcCoA in absence of arylamine acceptor substrate $(B)$. 


\section{MATERIALS AND METHODS}

\section{Arylamine $\mathrm{N}$-acetyltransferases Recombinant Expression}

Methods for the cloning and expression of the recombinant human and rodent arylamine $\mathrm{N}$-acetyltransferases have been reported in previous publications from our laboratory for human [55], rat [56], mouse [57], and hamster [58, 59]. In brief, JM105 Escherichia coli strain was transformed with NAT containing pkk223-3 plasmid. The transformed JM105 E. coli was picked as a single colony and cultured overnight in $50 \mathrm{ml}$ LB media containing ampicillin $(100 \mu \mathrm{g} / \mathrm{ml})$ at $37^{\circ} \mathrm{C}$. The following day, $4 \mathrm{ml}$ of the overnight culture was added to $200 \mathrm{ml}$ fresh sterile LB media containing ampicillin $(100 \mu \mathrm{g} / \mathrm{ml})$ and grown until the optical density $\left(\mathrm{OD}_{600 \mathrm{~nm}}\right)$ reached $0.4-0.6$. Expression of $\mathrm{N}$-acetyltransferases was induced by addition of isopropyl $\beta$-D-thiogalactopyranoside (final concentration $1 \mathrm{mM}$ ) for $3 \mathrm{~h}$. Cells were harvested by centrifugation at $5000 \times \mathrm{g}$ for $10 \mathrm{~min}$ at $4{ }^{\circ} \mathrm{C}$ and the cell pellet was suspended in $10 \mathrm{ml}$ of ice-cold $20 \mathrm{mM}$ sodium phosphate $\mathrm{pH} 7.4,1 \mathrm{mM}$ dithiothreitol, $1 \mathrm{mM}$ EDTA, $0.2 \%$ triton-x-100, $100 \mu \mathrm{M}$ phenylmethylsulfonyl fluoride, $1 \mu \mathrm{M}$ pepstatin $\mathrm{A}$, and $1 \mu \mathrm{g} / \mathrm{ml}$ aprotinin.

The solution was sonicated on ice 6 times for $30 \mathrm{sec}$. The lysate was centrifuged at $15,000 \times \mathrm{g}$ for $20 \mathrm{~min}$ at $4{ }^{\circ} \mathrm{C}$. Aliquots of supernatant were stored at $-80^{\circ} \mathrm{C}$ until use. 


\section{PABA N-acetylation Assays}

PABA N-acetylation assays were done as previously described [60]. Briefly, recombinant lysate was added to a mixture of PABA (Sigma Aldrich) and AcCoA (Amersham Biosciences), whose final concentrations in the reaction were $150 \mu \mathrm{M}$ and $400 \mu \mathrm{M}$, respectively. The mixture was incubated at $37^{\circ} \mathrm{C}$ for 10 min, after which the reaction was quenched with 1/10 volume of $1 \mathrm{M}$ acetic acid. Precipitated proteins were removed by centrifugation. Supernatants were injected on a C18 column and reaction substrates and products separated and

quantitated using Beckman System Gold high performance liquid chromatography (HPLC).

\section{AcCoA Hydrolysis Assays}

Recombinant lysates were added to folate (Sigma-Aldrich) and AcCoA. Initial reactions were carried out at $37^{\circ} \mathrm{C}$ with fixed concentrations of folate (500 $\mu \mathrm{M})$ and $\mathrm{AcCoA}(400 \mu \mathrm{M})$ to determine appropriate enzyme lysate dilutions for subsequent reactions. Next, reactions were performed to determine MichalisMenton constants for AcCoA. Reactions were done at $500 \mu \mathrm{M}$ folate and varying AcCoA concentrations from $0 \mu \mathrm{M}$ to $400 \mu \mathrm{M}$. The third set of reactions was done with AcCoA fixed at $400 \mu \mathrm{M}$ for mouse and hamster and $200 \mu \mathrm{M}$ for human and rat with folate concentrations varied between 0 and $400 \mu \mathrm{M}$. Control reactions were done with the same enzyme and AcCoA concentration but no folate. The amounts of CoA produced in the minus folate reactions were subtracted from reactions containing folate to determine folate-dependent hydrolysis. 
Recombinant human NAT1 lysates were used to compare the ability of AcCoA hydrolysis dependent on folate analogs methotrexate (MTX) (Sigma Aldrich) and dihydrofolate (DHF) (Sigma Aldrich). Reactions were carried out at $37^{\circ} \mathrm{C}$ with fixed concentrations of folate/MTX/DHF $(300 \mu \mathrm{M})$ and AcCoA (500 $\mu \mathrm{M})$ for 10 mins. Control reactions were done with the same enzyme and AcCoA concentration but no folate analogs. The amounts of CoA produced in the minus folate reactions were subtracted from reactions containing folate to determine folate-dependent hydrolysis.

The reaction mixtures were incubated at $37^{\circ} \mathrm{C}$ for $10 \mathrm{~min}$, after which the reaction was quenched by adding $1 / 10$ volume of perchloric acid $(15 \% \mathrm{w} / \mathrm{v})$. The precipitated protein was removed by centrifugation and the supernatant was injected onto a C18 reverse-phase HPLC column $(250 \mathrm{~mm} \times 4 \mathrm{~mm} ; 5 \mu \mathrm{M}$ pore size). Reactants and products were separated and quantitated by HPLC. Separation of CoA, acetyl CoA, and folate was achieved using a linear gradient of $100 \% 55 \mathrm{mM}$ sodium phosphate $\mathrm{pH} 4.0: 0 \%$ methanol to $0 \% 55 \mathrm{mM}$ sodium phosphate $\mathrm{pH}$ 4.0: $100 \%$ methanol over $20 \mathrm{~min}$ and was quantitated by absorbance at $260 \mathrm{~nm}$. The limit of detection for CoA was $0.05 \mathrm{nmoles} / \mathrm{min} / \mathrm{mg}$ of protein.

\section{Inhibition of PABA N-acetylation Activity with Folate Analogs}

Recombinant human NAT1 lysates were added to a mixture of AcCoA $(400 \mu \mathrm{M})$, with varying folate/MTX $(0,100,200,300,400,500 \mu \mathrm{M})$, and varying 
$\operatorname{PABA}(0,50,100,200$, and $400 \mu \mathrm{M})$. The mixtures were incubated at $37^{\circ} \mathrm{C}$ for $10 \mathrm{~min}$, after which the reaction was quenched with $1 / 10$ volume of $1 \mathrm{M}$ acetic acid. Precipitated proteins were removed by centrifugation. Supernatants were injected on a C18 column and reaction substrates and products separated and quantitated using Beckman System Gold high performance liquid chromatography (HPLC) as described above.

\section{Statistics}

All the data are shown as mean \pm SEM from three separate determinations. The Michaelis-Menten constants ( $\mathrm{Km}$ and $\mathrm{Vmax}$ ) were determined by nonlinear regression of the Michaelis-Menten equation (GraphPad Software, Inc, San Diego, CA) 


\section{RESULTS}

\section{Michaelis-Menton Saturation Curves for AcCoA Hydrolysis}

AcCoA hydrolysis with (figure 2.2, solid line) or without (figure 2.2, dash line) the addition of folate (both in the absence of any arylamine NAT1 substrate) was determined for recombinant human NAT1 and rodent Nat2. Some hydrolysis of AcCoA to form CoA was observed in the absence of folate (figure 2.2). Since this folate-independent hydrolysis of AcCoA to form CoA was also observed in bacterial lysates from recombinantly expressed vector controls, this folateindependent hydrolysis of $\mathrm{AcCoA}$ was subtracted from folate-dependent $\mathrm{AcCoA}$ hydrolysis rates in the subsequent measurements described below.

\section{AcCoA Hydrolysis and $\mathrm{N}$-acetylation Activities of Recombinant}

\section{Human NAT1 and NAT2}

For human NAT1 the apparent Vmax and $\mathrm{Km}$ values determined for AcCoA in the AcCoA hydrolysis reaction were $111 \pm 13 \mathrm{nmoles} / \mathrm{min} / \mathrm{mg}$ protein and $54.3 \pm 20.5 \mu \mathrm{M}$, respectively (figure $2.3 \mathrm{~A}$, solid line). For human NAT1 the apparent $V \max$ and $\mathrm{Km}$ values determined for folate in the AcCoA hydrolysis reaction were $200 \pm 18 \mathrm{nmoles} / \mathrm{min} / \mathrm{mg}$ protein and $85.2 \pm 21.5 \mu \mathrm{M}$, respectively (figure 2.3A, dash line). Initial rate constant for PABA $\mathrm{N}$-acetylation activity for recombinant human NAT1 was $20300 \pm 1720 \mathrm{nmoles} / \mathrm{min} / \mathrm{mg}$ protein. Human NAT2 AcCoA hydrolysis activity was below the level of detection (0.05 nmoles/min/mg of protein). 


\section{FIGURE 2.2}

A

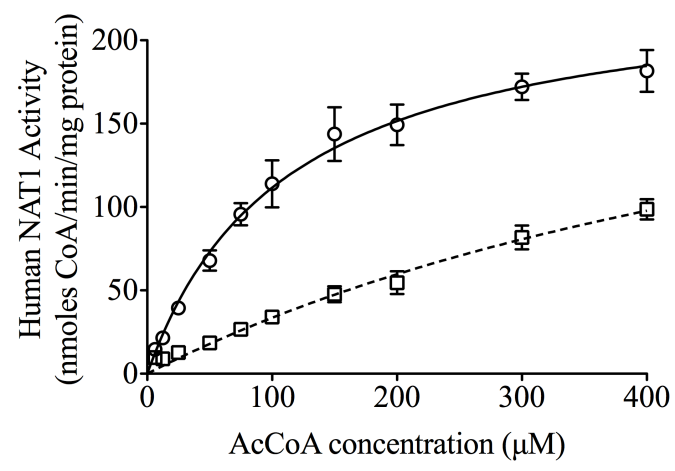

$\mathrm{C}$

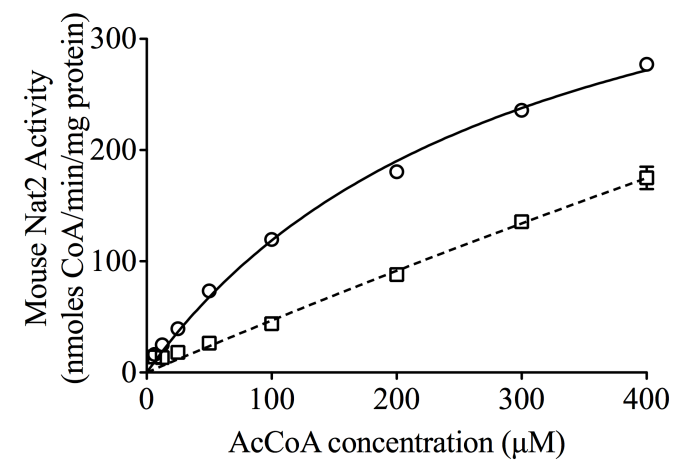

$\mathrm{B}$

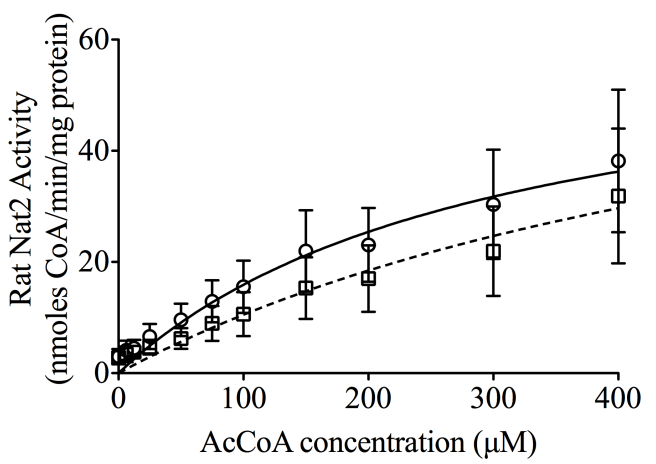

$\mathrm{D}$

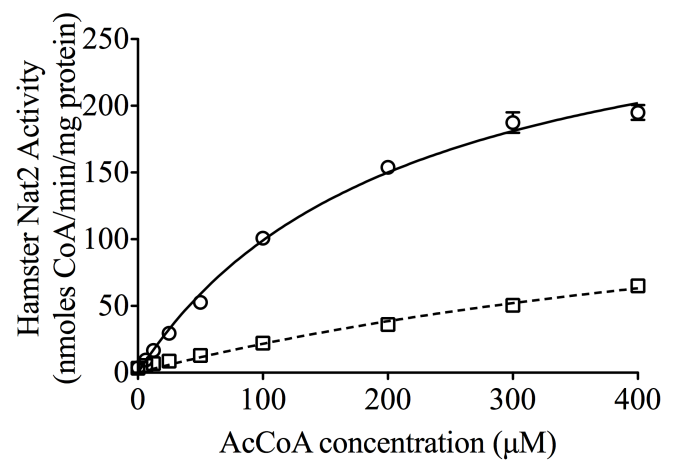

Figure 2.2. Michaelis-Menton saturation curves for AcCoA hydrolysis with (circles with solid line) or without (squares with dashed line) $500 \mu \mathrm{M}$ folate (with no arylamine substrate present). Hydrolysis activity was catalyzed by human NAT1 (A) and rodent Nat2s (B-D). Data points represent results from three separate determinations with mean \pm SEM. 


\section{AcCoA Hydrolysis and $\mathrm{N}$-acetylation Activities of Recombinant Rat}

\section{Nat1 and Nat2}

For rat Nat2 the apparent $\mathrm{Vmax}$ and $\mathrm{Km}$ values determined for AcCoA in the AcCoA hydrolysis reaction were $13.5 \pm 2.6 \mathrm{nmoles} / \mathrm{min} / \mathrm{mg}$ protein and $126 \pm$ $60 \mu \mathrm{M}$, respectively (figure 2.3B, solid line). For rat Nat2 the apparent Vmax and $\mathrm{Km}$ values determined for folate in the AcCoA hydrolysis reaction were $7.61 \pm$ $0.78 \mathrm{nmoles} / \mathrm{min} / \mathrm{mg}$ protein and $29.5 \pm 14.0 \mu \mathrm{M}$, respectively (figure $2.3 \mathrm{~B}$, dash line). Initial rate constant for PABA N-acetylation activity for recombinant rat Nat2 was $3030 \pm 274$ nmoles/min/mg protein. Rat Nat1 AcCoA hydrolysis activity was below the level of detection ( $0.05 \mathrm{nmoles} / \mathrm{min} / \mathrm{mg}$ of protein).

\section{AcCoA Hydrolysis and $\mathrm{N}$-acetylation Activities of Recombinant}

\section{Mouse Nat1 and Nat2}

For mouse Nat2 the apparent $\mathrm{Vmax}$ and $\mathrm{Km}$ values determined for AcCoA in the AcCoA hydrolysis reaction were $130 \pm 9 \mathrm{nmoles} / \mathrm{min} / \mathrm{mg}$ protein and $88.3 \pm$ 18.3 $\mu \mathrm{M}$, respectively (figure $2.3 \mathrm{C}$, solid line). For mouse Nat2 the apparent Vmax and $\mathrm{Km}$ values determined for folate in the AcCoA hydrolysis reaction were $120 \pm 14 \mathrm{nmoles} / \mathrm{min} / \mathrm{mg}$ protein and $77.1 \pm 27.9 \mu \mathrm{M}$, respectively (figure 2.3C, dash line). Initial rate constant for PABA N-acetylation activity for recombinant mouse Nat2 was $32600 \pm 1170$ nmoles $/ \mathrm{min} / \mathrm{mg}$ protein. Mouse Nat1 AcCoA hydrolysis activity was below the level of detection $(0.05 \mathrm{nmoles} / \mathrm{min} / \mathrm{mg}$ of protein). 


\section{AcCoA Hydrolysis and $\mathrm{N}$-acetylation Activities of Recombinant}

\section{Hamster Nat1 and Nat2}

For hamster Nat2 the apparent $\mathrm{Vmax}$ and $\mathrm{Km}$ values determined for AcCoA in the AcCoA hydrolysis reaction were $200 \pm 13 \mathrm{nmoles} / \mathrm{min} / \mathrm{mg}$ protein and $164 \pm 24 \mu \mathrm{M}$, respectively (figure 2.3D, solid line). For hamster Nat2 the apparent $\mathrm{Vmax}$ and $\mathrm{Km}$ values determined for folate in the AcCoA hydrolysis reaction were $186 \pm 5 \mathrm{nmoles} / \mathrm{min} / \mathrm{mg}$ protein and $94.0 \pm 6.5 \mu \mathrm{M}$, respectively (figure 2.3D, dash line). Initial rate constants for PABA N-acetylation activity for recombinant hamster Nat2 was $20700 \pm 1350$ nmoles/min/mg protein. Hamster Nat1 AcCoA hydrolysis activity was below the level of detection (0.05 nmoles/min/mg of protein).

\section{Comparison of AcCoA Hydrolysis to PABA N-acetylation}

Human NAT1 and rodent Nat2 lysates were able to N-acetylate PABA. The percentages of the AcCoA hydrolytic activity (Vmax) for human NAT1 and rodent Nat2 lysates were 0.25 to $1 \%$ relative to the initial rate constant for PABA $\mathrm{N}$-acetylation catalyzed by the same enzyme (table 2.1). 


\section{FIGURE 2.3}
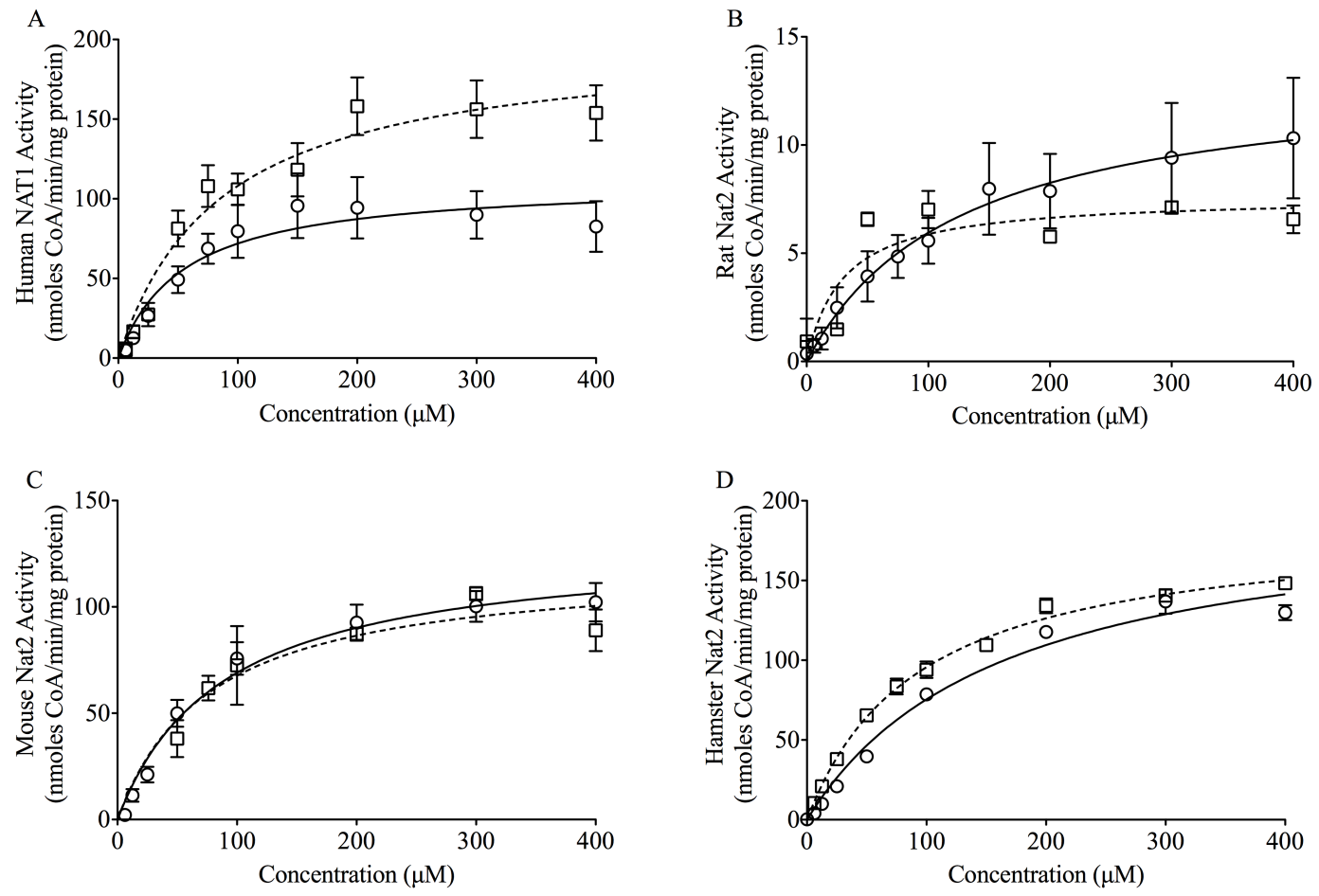

Figure 2.3. Michaelis-Menton saturation curves with various concentrations of AcCoA (solid line) and folate (dashed line) for human NAT1 (A), rat Nat2 (B) mouse Nat2 (C) and hamster Nat2 (D). Hydrolysis activity in $\mathrm{nmol} / \mathrm{min} / \mathrm{mg}$ protein is plotted on the ordinate versus substrate concentration on the abscissae. Folate concentration was fixed at $500 \mu \mathrm{M}$ for AcCoA Vmax and Km determinations.

AcCoA concentration was fixed at $200 \mu \mathrm{M}$ for human NAT1 and rat Nat2 and 400 $\mu \mathrm{M}$ for mouse Nat2 and hamster Nat2 folate Vmax and Km determinations. Data points represent mean \pm SEM from three separate determinations. 
Table 2.1 - Comparisons of PABA N-acetylation and AcCoA hydrolysis by recombinant human NAT1 and rodent Nat2 enzymes.

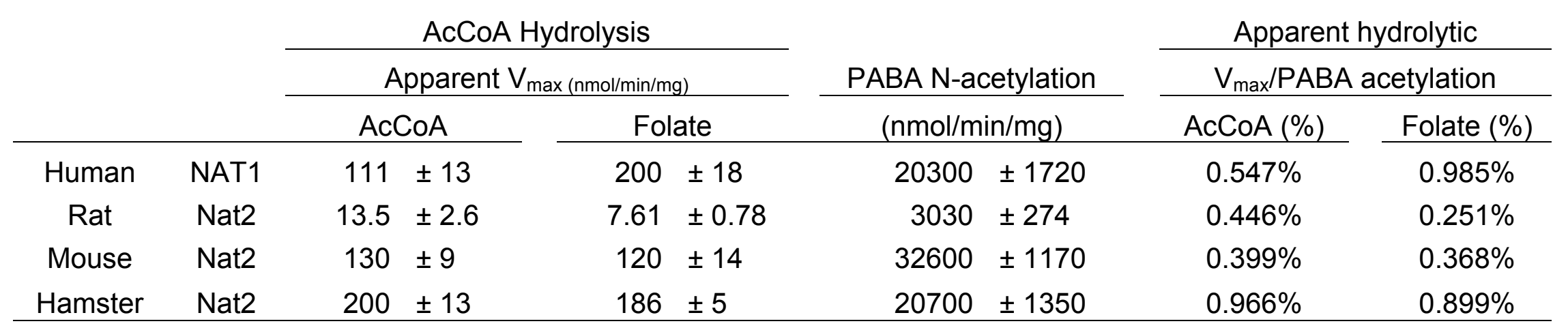


Recombinant Human NAT1 AcCoA Hydrolysis Activity with Folate, MTX, and DHF

Human NAT1 hydrolyzed AcCoA in the presence of folate with a rate of $104 \pm 10.2 \mathrm{nmoles} / \mathrm{min} / \mathrm{mg}$ protein (figure 2.4B). Human NAT1 hydrolyzed AcCoA in the presence of DHF at a rate of $85.6 \pm 9.13 \mathrm{nmoles} / \mathrm{min} / \mathrm{mg}$ protein (figure 2.4B). Human NAT1 hydrolyzed AcCoA in the presence of the folate analog MTX at a very low rate of $2.50 \pm 0.920 \mathrm{nmoles} / \mathrm{min} / \mathrm{mg}$ protein (figure 2.4B). Folate-and DHF-dependent hydrolysis rates did not differ significantly $(p>0.05)$ from each other but both were significantly $(p<0.001)$ elevated compared to the level of MTX-dependent hydrolysis (figure 2.4B).

\footnotetext{
Inhibition of $\mathrm{N}$-acetylation of PABA by Recombinant NAT1 with Folate and MTX

Increasing the folate concentrations served to inhibit human NAT1 PABA acetylation activity in a dose-dependent manner (figure 2.5A). Additionally the increasing MTX concentrations served to inhibit the amount of acetylated PABA produced by human NAT1 (figure 2.5B). The IC50's for folate and MTX were 76.9 and $127 \mu \mathrm{M}$ respectively (figure $2.5 \mathrm{C}$ and $2.5 \mathrm{D}$ ).
} 
FIGURE 2.4
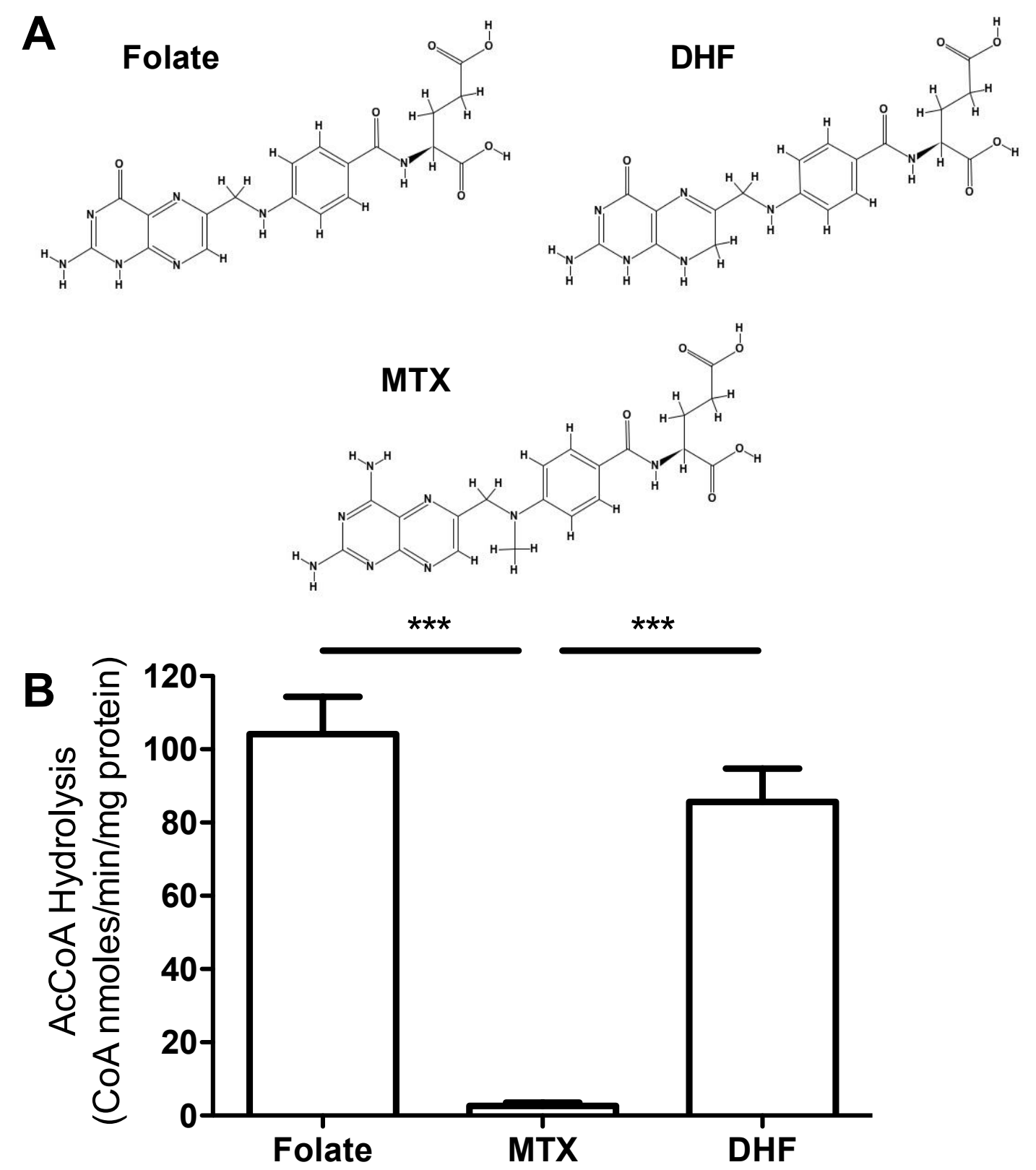

Figure 2.4. The chemical structures (A) depicting folate, DHF, and MTX. Level of AcCoA hydrolysis catalyzed by NAT1 with the addition of folate, MTX, and DHF (B). MTX had significantly lower level of activity than folate or DHF. Data points represent mean \pm SEM from three separate determinations. The number of asterisks corresponds to the $p$-value: ${ }^{* * *}=p<0.001$. 


\section{FIGURE 2.5}
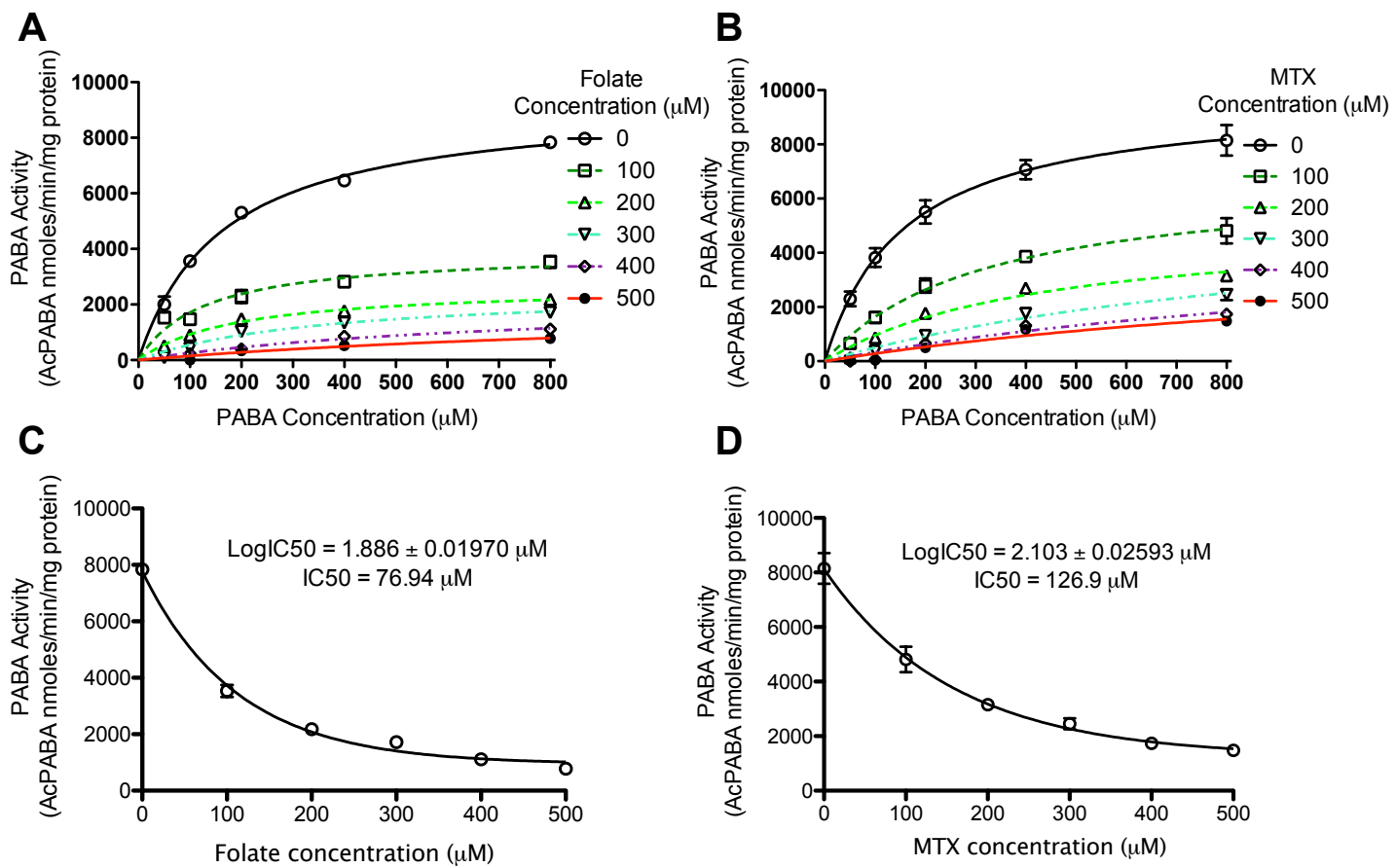

Figure 2.5. Michaelis-Menton curves showing inhibition by folate (A) or MTX (B) on NAT1 PABA acetylation activity with increasing PABA concentration. The concentrations of folate and MTX are $0,100,200,300,400$, and $500 \mu \mathrm{M}$.

Folate (C) and MTX (D) inhibit PABA acetylation activity, when PABA is held constant at $800 \mu \mathrm{M}$. Data points represent mean \pm SEM from three separate determinations. 


\section{DISCUSSION}

Folate is a water soluble B vitamin found in various foods (leafy green vegetables, organ meat, etc.), and is commonly used to fortify foods. Commercial fortification was mandated to prevent developmental defects in early fetal development. However, of growing interest and experimentation is whether folate levels in the body and folic acid supplementation affects tumor induction and progression [61].

Our study has confirmed that human NAT1 and the rodent ortholog mouse Nat2 are capable of AcCoA hydrolysis in the presence of folate but absence of xenobiotic substrate (e.g. PABA) as shown by Laurieri et al. [54]. This study also confirmed that folate is not consumed in the hydrolysis reaction and that human NAT2 and mouse Nat1 do not perform this reaction to any significant degree. In addition, we have shown that hamster and rat Nat2 enzymes also catalyze this AcCoA hydrolysis, while the hamster and rat Nat1 has no detectable AcCoA hydrolysis activity. A new methodology was developed in the study to measure the level of CoA and AcCoA by HPLC. We determined the Michaelis-Menton kinetic constants (Vmax and $\mathrm{Km}$ ) for both $\mathrm{AcCoA}$ and folate using human NAT1 as well as three rodent Nat2 enzymes.

Human NAT1 had Vmax and $\mathrm{Km}$ values similar to hamster and mouse

Nat2 but different from rat Nat2 for both varying AcCoA and folate 
concentrations. Also, when comparing $\mathrm{Vmax}$ and $\mathrm{Km}$ values for folate and AcCoA among the individual human and rodent enzymes they also appeared to be surprisingly similar. The Vmax for AcCoA hydrolytic activity was less than $1 \%$ of the PABA N-acetylation activity for the same enzyme. The total body content of folate is estimated to be 10 to $30 \mathrm{mg}$; about half of this amount is stored in the liver and the remainder is in blood and body tissues [62]. Erythrocyte folate concentrations in the USA and Canada recently were reported from 0.5 to 2.5 $\mathrm{nmol} / \mathrm{L}$ but varied with assay method, diet and supplementation. Modest correlations recently were reported between plasma and breast folate concentrations suggesting that plasma levels may not predict concentrations of folate in various tissues [63]. Future studies with NAT2 knock out mice [52] or congenic Nat2 rapid and slow acetylator rats [64] may help to determine whether changes in level of human NAT1 (rodent Nat2) expression could affect AcCoA levels in vivo and thus possibly affect cellular metabolism. The next chapter describes congenic rat embryonic fibroblasts (REFs) used to compare endogenous AcCoA levels. Slow acetylator congenic REFs showed higher endogenous AcCoA levels than the rapid acetylator congenic REFs [65].

Folate is commonly considered to have a low abundance within the mammalian cell, being reduced to dihydrofolate (DHF) upon entering the cell. DHF is then reduced further resulting in other folate derivatives. Derivatives past DHF are considered unstable and are not readily, commercially available with a high level of purity. The instability of endogenous folate compounds makes the 
measurement of $\mathrm{AcCo} A$ hydrolysis dependent on endogenous folate compounds complex. Fortunately, DHF is commercially available at $90 \%$ or more purity and moderately stable. Human NAT1 is able to hydrolyze AcCoA in the presence of DHF similar to folate, but not with an analog for folate and DHF, MTX. Structurally DHF has one additional hydrogen compared to folate. Folate and DHF compared to MTX differ mainly by the addition of one methyl group and an amine group. MTX being unable to significantly stimulate AcCoA hydrolysis, raises the questions of whether MTX is able to interact with the active site of NAT1 and how similar endogenous folate derivatives stimulate AcCoA hydrolytic activity by NAT1.

While MTX is almost unable to support the hydrolysis of AcCoA by NAT1, it is able to inhibit the $\mathrm{N}$-acetylation of PABA like folate (figure 2.5B). The similar inhibition abilities of folate and MTX suggest that both folate and MTX are able to interact with the active site. This interaction blocks substrates from entering the deep pocket of the NAT1 enzymatic active site. The shared interaction with the active site leaves the question, what chemical structural elements in folate allow for the release the acetyl group from the acetylated cysteine since MTX is unable to perform a similar function.

In summary, our results are consistent with the possibility that human NAT1 and its rodent Nat2 orthologs regulate endogenous AcCoA levels in a folate-dependent reaction. The results suggest associations of human NAT1 
activity with disease or tumor progression may be related to regulation of AcCoA. The regulation of AcCoA levels will be analyzed in the following chapters. Further studies are needed to explore how some folate compounds support the hydrolysis of AcCoA by human NAT1. 
CHAPTER III

CONGENIC RATS WITH HIGHER ARYLAMINE N-ACETYLTRANSFERASE 2

ACTIVITY EXHIBIT GREATER CARCINOGEN-INDUCED MAMMARY TUMOR

SUSCEPTIBILITY INDEPENDENT OF CARCINOGEN METABOLISM

\section{INTRODUCTION}

Human arylamine N-acetyltransferase 1 (NAT1) is a cytosolic isoenzyme responsible for the $\mathrm{N}$-acetylation of arylamine xenobiotics, including environmental and occupational carcinogens such as 4-aminobiphenyl (ABP)[41]. NAT1 is located on the short arm of chromosome $8(8 p 22)$ and is expressed in nearly all human tissues [2, 3]. NAT1 catalyzes both O-acetylation and $\mathrm{N}$-acetylation. One role for NAT1 in carcinogenesis is its ability to biotransform arylamine procarcinogens to active carcinogens [66]. Recent findings in vitro suggest that NAT1 activity level also may influence cancer cell proliferation and survival $[8,10,11,13]$.

NAT1 activity is modified by genetic polymorphism, but also can be regulated by microRNA, epigenetic, and/or translational and post-translational control features [67-70]. NAT1 transcript levels are regulated by extracellular stimuli acting on glucocorticoid receptor or androgen receptor [71, 72]. Exposure to NAT1 substrates can increase NAT1 degradation $[69,70]$. Some polymorphisms in humans destabilize the enzyme, leading to greater 
polyubiquitin-dependent degradation [69]. NAT1*10, the most common haplotype, is associated with increased NAT1 activity in human bladder [26], colon [27], and liver [28]. NAT1*10 has been associated with higher risk of developing cancers of the breast [29], colon/rectum [30, 31], lung [32], pancreas [33], and urinary bladder [34]. However, other studies have reported no association between $N A T{ }^{*} 10$ and cancer risk $[35,36]$.

Rat arylamine $\mathrm{N}$-acetyltransferases are similar in sequence and function to human $\mathrm{N}$-acetyltransferases $[48,50,73]$. Rat models have been used for the study of arylamine N-acetyltransferases [73-75]. Rat NAT2 and human NAT1 active sites both contain Phe125, Arg127, and Tyr129, consistent with their similar arylamine substrate selectivity [48]. The C-terminal undecapeptide, which is involved in controlling acetyl-coenzyme A (AcCoA) hydrolysis [49], is $100 \%$ identical when comparing rat NAT2 and human NAT1. Rat Nat2 and human NAT1 are orthologs as shown by their amino acid sequence similarity (figure 3.1).

Rats, like humans, have different NAT2 haplotypes. Homozygous rapid (F344) and slow (WKY) acetylator inbred rats have been characterized as rapid and slow NAT2 acetylators, respectively $[75,76]$. Slow acetylator WKY inbred rats are homozygous for a rat Nat2 allele with four single nucleotide polymorphisms (SNPs): $\mathrm{G}^{361} \mathrm{~A} \quad\left(\mathrm{Val}^{121} \rightarrow \mathrm{lle}\right), \mathrm{G}^{399} \mathrm{~A}$ (synonymous), $\mathrm{G}^{522} \mathrm{~A}$ (synonymous), and $\mathrm{G}^{796} \mathrm{~A}\left(\mathrm{Val}^{266} \rightarrow \mathrm{lle}\right)$, as compared to the Nat2 allele in the 
F344 strain rapid-acetylator Nat2 allele [56] (figure 3.1). These two inbred rat stains were used in the development of congenic F344.WKY rats with either high (rapid) or low (slow) NAT2 activities [64]. 


\section{FIGURE 3.1}

\begin{tabular}{|c|c|c|c|c|c|}
\hline \multirow[b]{2}{*}{ HUMAN NAT1-1 } & \multicolumn{2}{|c|}{ N-TERMINUS END } & \multirow[b]{2}{*}{ LETLTDILQH } & \multirow[b]{2}{*}{ QIRAVPFENL } & \multirow[b]{2}{*}{ NIHCGDAMDI } \\
\hline & MDIEAYLERI & GYKKSRNKLD & & & \\
\hline RAT NAT2-1 & MDIEAYFERI & GYQSSRNKLD & LEELTEILQH & QIRAIPFENL & NIHCGESMEL \\
\hline HUMAN NAT1-51 & GLEAIFDQVV & RRNRGGWCLQ & VNHLLYWALT & TIGFETTMLG & GYVYSTPAKK \\
\hline RAT NAT2-51 & NLEVIFDQVV & RKKRGGWCLQ & VNHLLYWALT & KMGFEATMLG & GYVFNTPANK \\
\hline HUMAN NAT1-101 & YSTGMIHLLL & QVTIDGRNYI & VDAGFGRS $Y Q$ & MWQPLELISG & KDQPQVPCVF \\
\hline RAT NAT2-101 & YSSGMIHLLV & QVTLSGKDYI & VDAGFGRS $\mathbf{Y} Q$ & MWEPLELTSG & KDQPQVPAIF \\
\hline HUMAN NAT 1-151 & RLTEENGFWY & LDQIRREQYI & PNEEFLHSDL & LEDSKYRKIY & SFTLKPRTIE \\
\hline RAT NAT2-151 & RLTEENGTWY & LDQIRREQYV & PNQEFVNSDL & LEKNKYRKIY & SFTLEPRTIE \\
\hline HUMAN NAT1-201 & DFESMNTYLQ & TSPSSVFTSK & SFCSLQTPDG & VHCLVGFTLT & HRRFNYKDNT \\
\hline RAT NAT2-201 & DFESINTYLQ & TSPASLFTSK & SFCSLQTLEG & VHCLVGSTLT & YRRFSYKDNI \\
\hline HUMAN NAT1-251 & DLIEFKTLSE & EEIEKVLKNI & FNISLQRKLV & PKHGDRFFTI & $290 \mathrm{AA}$ \\
\hline RAT NAT2-251 & DLVEFKSLTE & EEIEDVLKTI & FGVSLERKLV & PKHGDRFFTI & $290 \mathrm{AA}$ \\
\hline & & & C-TERMINUS & & $\sim 83 \%$ \\
\hline
\end{tabular}

Figure 3.1. Amino acid sequence comparison between human NAT1 and rat Nat2. The gray highlighting indicates areas were the amino acids differ between the two enzymes. The two enzymes are $83 \%$ identical to each other. The yellow highlighted regions indicate the areas of importance to the enzymes, the cterminus tail and the three critical amino acids in the active site. The two enzymes share $100 \%$ identity in the active site and c-terminus tail. In the rat amino acid sequence there are two underlined amino acids, $\mathrm{Val}^{121}$ and $\mathrm{Val}^{266}$. Both valines are isoleucines in the slow phenotypic rats, whereas they are valines in rapid, wildtype, rats. 
Breast tumors have been induced for several decades with the administration of methylnitrosourea (MNU). MNU is a simple alkylating agent, which places a methyl group on oxygen and nitrogen of macromolecules, like DNA. It has been shown previously that sexually immature F344 rats (at 3 weeks of age) are more susceptible to mammary carcinogenic effects from MNU than mature rats (8 weeks of age) [77].

The mechanism for how MNU causes cancer is by DNA damage resulting from the alkylation of nitrogen and oxygen in DNA leading to mutations. $\mathrm{N}^{7}$ alkylguanine, $\mathrm{N}^{3}$-alkyladenine, and $\mathrm{O}^{6}$-alkylguanine account for $68 \%, 8 \%$, and $7.5 \%$ of total methylation after MNU treatment, respectively [78]. The $\mathrm{N}^{7}$ atom of guanine is the most vulnerable site for attack by alkylating agents; however $\mathrm{N}^{7}$ alkylguanine alone has no pronounced mutagenic and cytotoxic effect [79]. Alkylation of the $\mathrm{N}^{7}$ atom does cause chemical instability at the $\mathrm{N}$-glycosidic bond, causing spontaneous abasic/apurinic sites to form. Abasic sites also form in the repair of $\mathrm{N}^{7}$-alkylguanine by $\mathrm{N}$-alkylpurine DNA-glycosylases, enzymes in the BER pathway. The mutagenic and toxic effects of abasic sites have been well described previously [80]. $\mathrm{N}^{3}$-alkyladenine is not particularly mutagenic, but it is a cytotoxic DNA lesion because it is able to block replication and able to generate abasic sites [79]. $\mathrm{N}^{3}$-alkyladenine has been shown to cause sister chromatid exchange, chromosome gaps and breaks, S phase arrest, accumulation of p53, and apoptosis in mammalian cells [81]. $0^{6}$-alkylguanine is the primary mutagenic lesion under most conditions of alkylation damage to the genome causing $\mathrm{G} \rightarrow \mathrm{A}$ 
transitions after two replications [79, 82] (figure 3.2). In addition to the point mutations following DNA replication, $\mathrm{O}^{6}$-alkylguanine can also result in mismatch repair-mediated DNA recombination and cell death [83]. Repair by mismatch repair system at $\mathrm{O}^{6}$-alkylG:T can form the "futile cycle". The "futile cycle" occurs when repair enzymes recognize mismatch of G:T and remove the newly incorporated thymidine opposite of $\mathrm{O}^{6}$-alkylguanine. Then, the sequence is replicated again and the $0^{6}$-alkylguanine preferentially pairs with thymine, once more, thus reinitiating the repair and replication cycle $[79,82,84,85]$. This persistent cycling of mismatch repair can generate a stabilized nick or gap in one strand of DNA, which may activate damage signaling pathways and DNA recombination [84]. Even with this futile cycling, it has been found that $\mathrm{O}^{6}$ alkylguanine lesions went from being $10 \%$ mutagenic in cells with repair capability to nearly $100 \%$ mutagenic in cells without DNA repair abilities [86]. In total the resulting alkylation of nitrogen and oxygen in DNA by a simple direct acting carcinogen, MNU, shows how cancer can result without rat NAT2 playing a direct metabolizing role. 


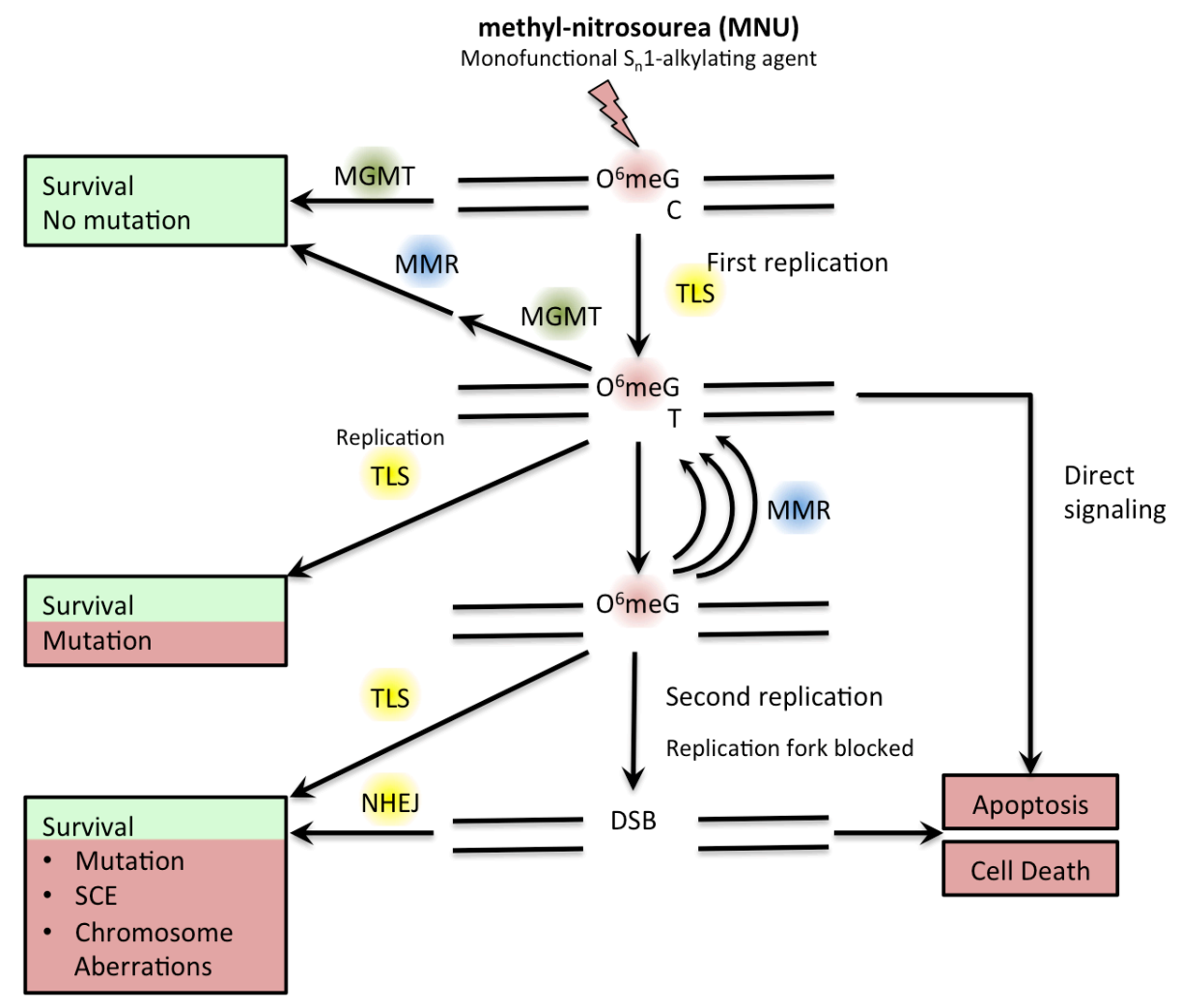

Figure 3.2. Mechanistic diagram for how MNU damages DNA. MNU alkylates guanine, which can be repaired immediately by $0^{6}$-alkylguanine-DNA alkyltransferase (MGMT), also known as $0^{6}$-alkylguanine-DNA alkyltransferase (AGT). However if not repaired before replication, translesion DNA synthesis (TLS) will be done. TLS mismatches the nucleotide causing three possible pathways. The one on the left is that another TLS occurs resulting in a permanent mutation that can allow the cell to survive. The second possibility is on the right and is a direct signaling pathway that tells the cell to undergo apoptosis. The middle one is where the mismatch repair pathway tries to correct the mismatch of G:T and removes the newly incorporated thymidine opposite of $\mathrm{O}^{6}$-alkylguanine. Then, the sequence is replicated again and the $\mathrm{O}^{6}$-alkylguanine preferentially pairs with thymine, once more, thus reinitiating the repair and replication cycle. This reoccurring cycling is termed the "futile cycle" Futile cycle can generate a stabilized nick or gap in one strand of DNA, which can cause replication fork collapse and a double strand DNA break (DSB). The DSB can be repaired by non-homologous end-joining (NHEJ) pathways, which can lead to cell survival but with mutations, sister chromatid exchange (SCE), or chromosomal aberrations. If the DSB is not repaired, cellular programing will be triggered to lead the cell into apoptosis. This figure has been modified from one previously published by Fu et al [87]. 
7,12-dimethylbenzanthracene (DMBA) is a polycyclic aromatic hydrocarbon compound that is known for its carcinogenic properties. DMBA is extensively used in rodent models for breast, skin, and other cancers [88]. DMBA, similar to other polycyclic aromatic hydrocarbon compounds, requires bioactivation to an active carcinogen. DMBA is initially metabolized by cytochrome P450 to DMBA-3,4-oxide, then to DMBA-3,4-diol by epoxide hydrolase, and finally metabolized again by cytochrome P450 to DMBA-3,4-diol1,2-epoxide [89, 90]. The enzymes responsible for this bioactivation of DMBA are cytochrome P4501B1 (CYP1B1) and microsomal epoxide hydrolase (EPHX1) [91]. CYP1B1 is thought of as the main enzyme in DMBA metabolism for humans and rodents [92]. DMBA-3,4-diol-1,2-epoxide is the active metabolite of DMBA that results in DNA adduct formation. The resulting DNA adducts are associated with DNA mutations and malignant transformation [93, 94]. As with MNU, DMBA has an established mechanism for cancer development without rat NAT2 playing a direct metabolizing role.

In this chapter, rapid (F344.WKY-Nat2 ${ }^{\text {rapid }}$ ) and slow (F344.WKY-Nat2 ${ }^{\text {slow }}$ ) acetylator rat strains were utilized to investigate mammary cancer risk following the administration of methylnitrosourea (MNU) or 7,12-dimethylbenzanthracene (DMBA), neither of which is biotransformed by rat NAT2 [89, 95-97]. The two carcinogens are extensively researched and characterized. MNU is known to be a direct acting carcinogen, which will eliminate any differences caused by 
metabolism of a pro-carcinogen. DMBA is a well characterized pro-carcinogen that has no evidence of being metabolized by human NAT1 or rat NAT2. 


\section{MATERIALS AND METHODS}

\section{Rapid and Slow Acetylator Rats Congenic at the Nat2 Locus}

Rapid and slow acetylator Nat2 congenic Fischer 344 (F344.WKY) rats were housed in the University of Louisville animal facility and the experiments were reviewed and approved by the University's Institutional Animal Care and Use Committee. The construction of rapid and slow acetylator Nat2 congenic rats was previously reported [64]. Briefly, F344 (homozygous Nat2 rapid) males were mated to WKY (homozygous Nat2 slow) females to produce the obligate heterozygous $F_{1}$ generation. $F_{1}$ females were then backcrossed with $F 344$ males. Heterozygous acetylator female progeny from each successive backcross were identified by rat Nat2 genotype and were mated with F344 rapid acetylator males. After ten generations of backcrossing, heterozygous acetylator brother/sister progeny were mated to produce the homozygous rapid and slow acetylator congenic rat Nat2 lines. The congenic F344.WKY rats have been confirmed for rapid and slow acetylator phenotype across multiple tissues and substrates [64].

\section{Methylnitrosourea Administration}

Forty-two female rapid acetylator congenic rats and thirty-four female slow acetylator congenic rats, at 3 weeks of age, were administered methylnitrosourea (MNU; CAS\#: 684-93-5)(Ash-Stevens, Detroit, MI) by a single intraperitoneal (IP) injection of $50 \mathrm{mg} / \mathrm{kg}(10 \mathrm{mg} / \mathrm{ml})$ solution dissolved in saline $\mathrm{pH} 5.0$, acidified with

glacial acetic acid (figure 3.3) [98-100]. Six rapid and six slow acetylator control female rats were injected with vehicle. During the twenty-three week experiment, 
one rapid (17 weeks) and two slow acetylator rats (18 and 18 weeks) were euthanized due to tumor burden and/or size. These data were incorporated into the statistical analysis.

Twenty-four rapid acetylator female congenic rats and thirty-three slow acetylator female congenic rats, at 8 weeks of age, were administered MNU by a single IP injection of $50 \mathrm{mg} / \mathrm{kg}(10 \mathrm{mg} / \mathrm{ml}$ ) as above (figure 3.3). Three rapid and four slow acetylator control female rats were injected with vehicle. During the study one rapid female acetylator rat was euthanized (16 weeks) because of tumor burden and/or size. This sample was included in the statistical analysis.

\section{7,12-dimethylbenzanthracene Administration}

Twenty-eight rapid acetylator female congenic rats and thirty-three slow acetylator female congenic rats were given a single dose of 7,12dimethylbenzanthracene dissolved in sesame seed oil (DMBA; CAS\#: 57-976)(Acros Organics, New Jersey, USA) (65 mg/kg) by oral gavage at 8 weeks of age (figure 3.3)[101, 102]. Three rapid and three slow acetylator control female rats were injected with vehicle. During the study four rapid female acetylator rats were euthanized $(14,17,20$, and 21 weeks) because of weight loss or tumor burden issues. Additionally six slow acetylator females were euthanized $(9,17$, $14,20,21$, and 21 weeks) for weight loss or tumor burden issues. These data were still utilized for statistical analysis. 


\section{FIGURE 3.3}

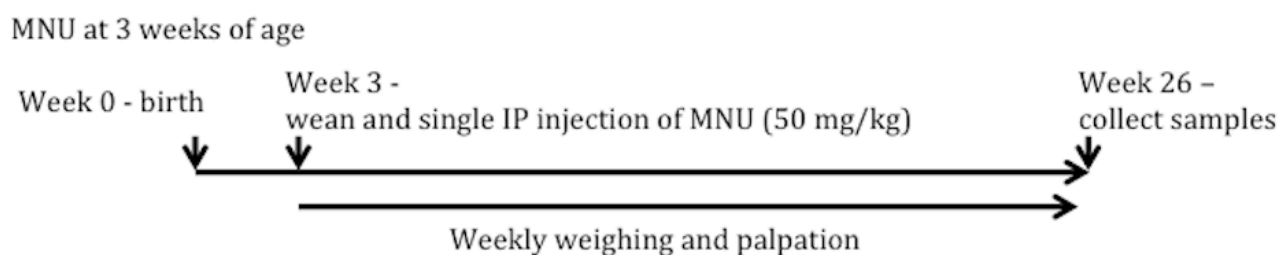

MNU at 8 weeks of age

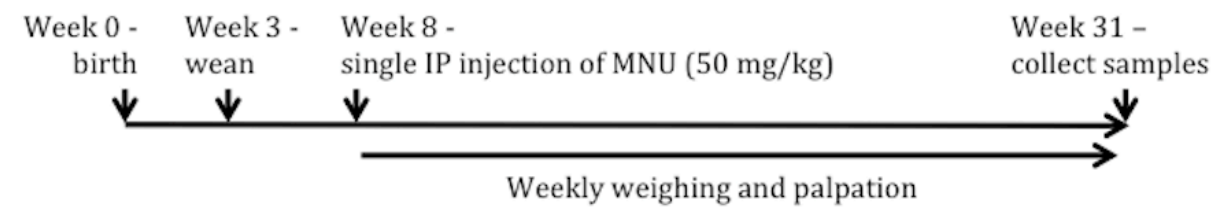

DMBA at 8 weeks of age

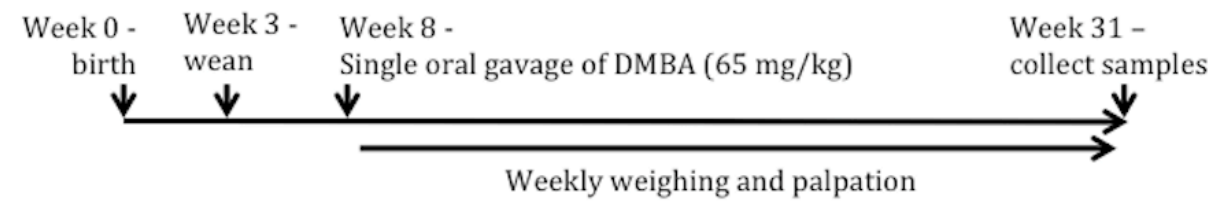

Figure 3.3. Experimental design for chemical-induced tumor experiments. Top shows the dosing of MNU at 3 weeks of age. The middle displays the dosing of MNU at 8 weeks of age. The bottom depicts the dosing of DMBA at 8 weeks of age. 


\section{Weekly Monitoring of Animal Weight and Palpable Mammary Tumors}

Rats were weighed weekly following carcinogen administration. Rats that displayed bradykinesia/fatigue, a tumor size $=10 \%$ of body weight, or tumors that were ulcerated (any break in skin observed) were euthanized. Rats were palpated weekly. The number of weeks post-carcinogen exposure of first palpable mammary tumor was recorded.

\section{Mammary Tissue and Tumor Collection}

Twenty-three weeks after administration of a carcinogen, rats were euthanized by $\mathrm{CO}_{2}$ asphyxiation followed by cervical dislocation. The rats were immediately dissected to count mammary tumors that were $\geq 3 \mathrm{~mm}$ in any direction, collect samples, and record any abnormalities. Mammary tumor and adjacent mammary-tissues were removed and fixed in 10\% neutral buffered formalin.

\section{Pathology}

Tissue samples described above were processed and stained by the Special Procedure Laboratory at the University of Louisville. In brief, tissue was paraffin embedded and sections cut at $5 \mu \mathrm{m}$. Sections were stained using hematoxylin and eosin (H\&E). H\&E stained slides were evaluated and categorized, based on histomorphology, into the following groups: Normal, Benign, Low Grade Carcinoma In Situ (CIS), Intermediate Grade CIS, High Grade CIS and Invasive Carcinoma. If a mammary tumor demonstrated multiple 
features of more than one category, the most malignant category was used for classification. Rats with multiple tumors were categorized by the most severe classification. These evaluations and classifications were performed blind to rat treatment and phenotype.

\section{Rapid and Slow Acetylator Rat NAT2 Recombinant Expression and}

\section{Enzymatic Activity}

Recombinant rapid and slow acetylator rat NAT2 proteins were expressed in JM105 E. coli as described $[56,103]$. Total bacterial lysate protein concentration was determined for each expression using the Bio-Rad protein assay kit (Bio-Rad, Hercules, CA). Bacterial lysates were assayed for $\mathrm{N}$ acetylation of para-aminobenzoic acid (PABA) and folate-dependent AcCoA hydrolysis.

For determination of PABA $\mathrm{N}$-acetylation activity, lysates (in triplicate) were incubated with $1 \mathrm{mM} \mathrm{AcCoA}$ and $300 \mu \mathrm{M}$ PABA for $10 \mathrm{~min}$ at $37^{\circ} \mathrm{C}$, and the reaction was stopped by addition of $1 / 10$ volume of $1 \mathrm{M}$ acetic acid. The reaction tubes were centrifuged to remove precipitated protein, and supernatant was injected onto a LiChrospher $100 \mathrm{RP}-18(125 \mathrm{~mm}$ X $4 \mathrm{~mm}$; $5 \mu \mathrm{m})$ reverse-phase column. Reactants and products were separated by high-performance liquid chromatography (HPLC)(Beckman Coulter, Fullerton, CA). N-Acetyl-PABA product was quantitated by its absorbance at $280 \mathrm{~nm}$ as described [103]. 
Bacterial lysates were assayed for folate-dependent AcCoA hydrolytic activity as reported [103]. In brief, lysates (in triplicate) were incubated with 500 $\mu \mathrm{M}$ AcCoA in the presence or absence of $300 \mu \mathrm{M}$ folate for $10 \mathrm{~min}$ at $37^{\circ} \mathrm{C}$, and the reaction was quenched by adding $1 / 10$ volume of perchloric acid (15\% w/v). The precipitated protein was removed by centrifugation and the supernatant was injected onto a C18 reverse-phase HPLC column (250 mm X $4 \mathrm{~mm} ; 5 \mu \mathrm{m})$. Reactants and products were separated and quantitated by HPLC. Separation of CoA, acetyl CoA, and folate was achieved using a linear gradient of $100 \% 100 \%$ $55 \mathrm{mM}$ sodium phosphate $\mathrm{pH} 4.0$ : $0 \%$ methanol to $0 \% 55 \mathrm{mM}$ sodium phosphate pH 4.0: $100 \%$ methanol over 20 mins and was quantitated by absorbance at 260 $\mathrm{nm}$. The amounts of CoA produced in the minus folate reactions were subtracted from reactions containing folate to determine folate-dependent hydrolysis. Control reactions without the addition of protein lysate also were included. The limit of detection for CoA was $0.05 \mathrm{nmoles} / \mathrm{min} / \mathrm{mg}$ protein.

\section{Rapid and Slow Congenic Rat Tissue Lysate Preparation and}

\section{Enzymatic Activity}

Liver, lung, colon, and mammary tissues were collected from 8 week old female rapid and slow NAT2 congenic rats. Tissues were homogenized in $20 \mathrm{mM}$ sodium phosphate $(\mathrm{pH} 7.4), 1 \mathrm{mM}$ EDTA, $0.2 \%$ triton $\mathrm{X}-100,1 \mathrm{mM}$ dithiothreitol, $100 \mu \mathrm{M}$ phenylmethanesulfonyl fluoride, $10 \mu \mathrm{g} / \mathrm{ml}$ aprotinin, and $1 \mu \mathrm{M}$ pepstatin. Homogenates were centrifuged at $15,000 \times \mathrm{g}$ for $10 \mathrm{~min}$, and aliquots of supernatants were stored at $-80^{\circ} \mathrm{C}$ until used. Protein concentrations were determined using the Bio-Rad protein assay kit. 
To measure PABA $N$-acetylation activity, reactions containing tissue lysate (<2 mg of protein/ml), $300 \mu \mathrm{M} \mathrm{PABA}$ and $1 \mathrm{mM} \mathrm{AcCoA}$ were incubated at $37^{\circ} \mathrm{C}$ for $10 \mathrm{~min}$. Reactions were terminated by the addition of $1 / 10$ volume of $1 \mathrm{M}$ acetic acid. Activity was quantified by HPLC as described above.

To measure folate-dependent AcCoA hydrolytic activity, reactions containing tissue lysate ( $<2 \mathrm{mg}$ of protein $/ \mathrm{ml}$ ), $300 \mu \mathrm{M}$ folate and $500 \mu \mathrm{M}$ AcCoA were incubated at $37^{\circ} \mathrm{C}$ for $10 \mathrm{~min}$. Reactions were terminated by the addition of $1 / 10$ volume of perchloric acid $(15 \% \mathrm{w} / \mathrm{v})$. Activity was quantified by HPLC as described above.

\section{Rat Embryonic Fibroblasts Isolation}

Rat embryonic fibroblasts (REFs) were isolated from congenic rats by adapting procedures described previously for mouse embryonic fibroblasts [104]. Dams were euthanized by $\mathrm{CO}_{2}$ asphyxiation and cervical dislocation on E13.5 (13.5 days post copulation) and embryos removed by Caesarean section. Embryonic brain tissue and organs were removed. The resultant tissue was dissociated by gentle enzymatic digestion [0.05\% trypsin (w/v) for $15 \mathrm{mins}]$ and cells were plated into $10 \mathrm{~cm}$ dishes (one embryo per dish) in DMEM (Dulbecco's modified Eagle's medium; high glucose, Lonza, Walkersville, MD, USA) supplemented with 10\% FBS (fetal bovine serum), $2 \mathrm{mM}$ L-glutamine, 100 units $/ \mathrm{ml}$ penicillin, $100 \mathrm{mg} / \mathrm{ml}$ streptomycin and $0.25 \mathrm{mg} / \mathrm{ml}$ amphotericin. Passaging was by cell dissociation from plates [0.05\% trypsin (w/v) for 15 mins] 
and re-plating $5 \times 10^{5}$ cells on fresh $10 \mathrm{~cm}$ dishes. Resulting REF cell lines at passage 4 were characterized for their PABA $\mathrm{N}$-acetylation activities as described above.

\section{REFs Endogenous Cellular AcCoA Concentration Measurements}

Endogenous acetyl-CoA levels within REFs were determined by HPLC. On passage 4 , the REFs were plated at $5 \times 10^{5}$ per $10 \mathrm{~cm}$ plate and allowed to grow for 96 hours. After 96 hours, media were aspirated from each plate, and washed with $5 \mathrm{ml}$ phosphate-buffered saline (PBS). Then cells were gently dissociated from the plate with $0.5 \mathrm{ml}$ trypsin $[0.05 \%(\mathrm{w} / \mathrm{v})$ for $15 \mathrm{~min}]$. Cells were suspended in $4 \mathrm{ml}$ of diluted complete media (20\% medium and $80 \%$ PBS). Aliquots of $0.5 \mathrm{ml}$ were used to count the number of cells per $\mathrm{ml}$. In the subsequent steps all cells and lysates were kept on ice or in $4^{\circ} \mathrm{C}$ conditions. Collected cells were washed with ice cold PBS, and transferred to a $1.5 \mathrm{ml}$ microcentrifuge tubes. The suspended cells were collected by centrifugation and the supernatants discarded. Having removed any residual PBS, the cells were lysed in $100 \mu \mathrm{l}$ of ice-cold 5\% 5-sulfosalicylic acid with a $1 \mathrm{ml} \mathrm{BD} \mathrm{Insulin} \mathrm{Syringe}$ with permanently attached 28 gauge needle (BD Franklin Lakes, NJ, USA). The cellular lysate was then centrifuged at $13,000 \times \mathrm{g}$ for $10 \mathrm{~min}$. Supernatant was filtered through a syringe filter $(13 \mathrm{~mm}, 0.20 \mu \mathrm{m}$ pore size $)$. Filtrate was collected and separated on a C18 reverse-phase HPLC column $(250 \mathrm{~mm} \times 4 \mathrm{~mm} ; 5 \mu \mathrm{m}$ pore size). HPLC separation and quantitation of AcCoA was achieved using the same method described above for folate-dependent AcCoA hydrolysis. 


\section{Statistics}

Weights were compared over time by a two-way analysis of variance followed by Bonferroni post hoc test. Latency and incidence of first palpable mammary tumors over time were tested by logrank (Mantel-Cox) test. MannWhitney tests were used to compare mammary tumor multiplicity. Terminal tumor incidence was tested by a Fischer's exact test. Enzymatic activities and endogenous AcCoA concentrations were compared by unpaired t-tests. All statistical tests were done using Prism software by GraphPad (La Jolla, CA). Data are displayed and presented as the average \pm standard error of mean (SEM) for each respective group. 


\section{RESULTS}

\section{Weight Gain}

Rapid and slow acetylator congenic rats administered vehicle at either 3 or 8 weeks demonstrated normal weight gain. Initially, all MNU-treated rats experienced hindered weight gain post administration, but then recovered to a rate of weight gain similar to vehicle-treated rats. MNU-treated rats never reached the same weight as the vehicle-treated counterparts (figure 3.4). No statistically significant $(p>0.05)$ differences in weight gain were noted between MNU-treated rapid and slow acetylator congenic rats.

DMBA-treated rats displayed no initial hindrance in weight gain; however, during the time following DMBA administration, DMBA-treated rats tended to have lower body weight than vehicle-treated rats (figure 3.4). No statistically significant $(p>0.05)$ differences in weight gain were noted between DMBA-treated rapid and slow acetylator congenic rats. 


\section{FIGURE 3.4}
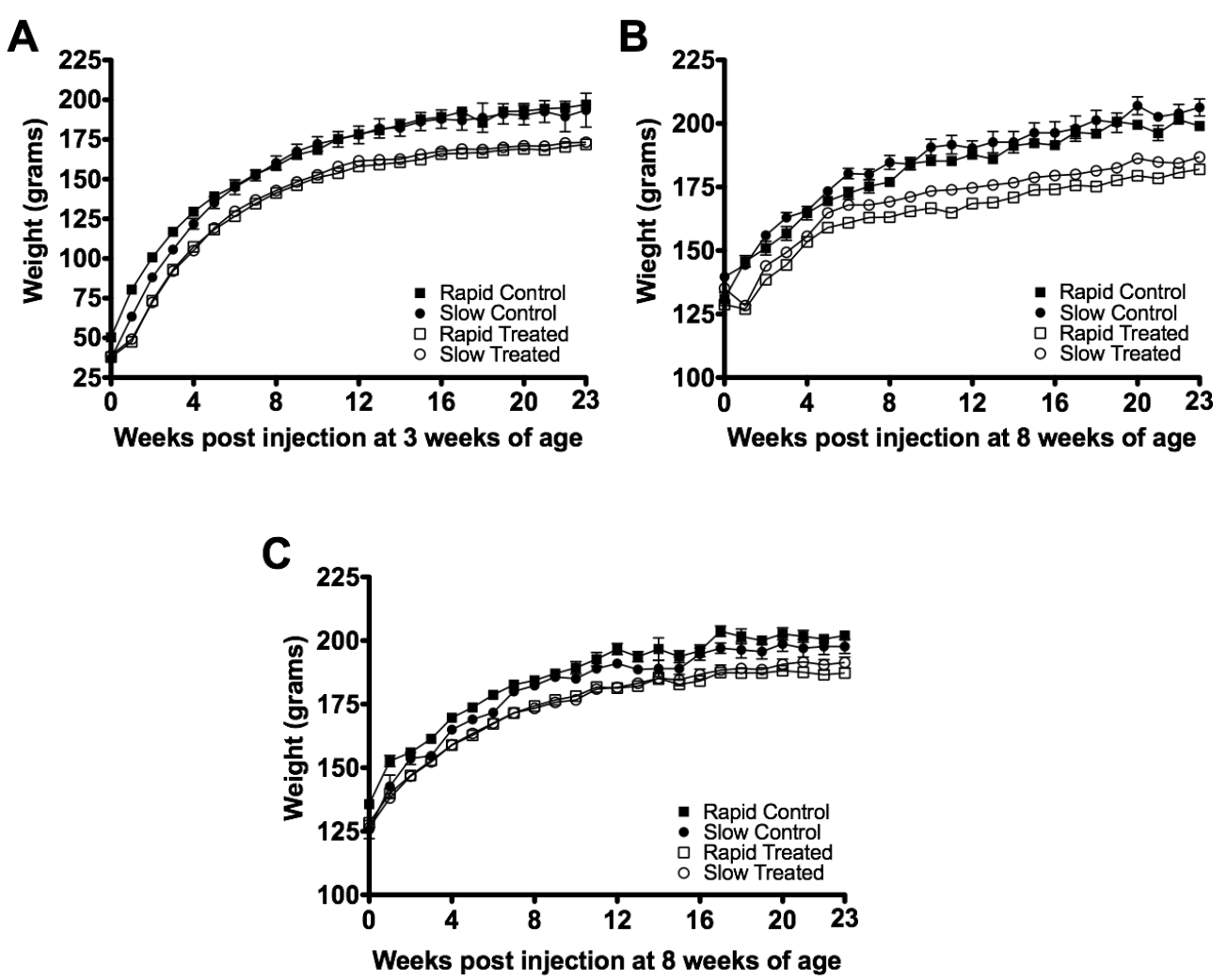

Figure 3.4. Weekly body mass (mean grams \pm SEM) of rapid and slow acetylator Nat2 congenic rats post administration of specified carcinogen or vehicle control. In all three panels squares represent rapid acetylator and circles represent slow acetylator congenic rats. Filled-shapes represent vehicle-treated and unfilledshapes represent MNU or DMBA-treated. Weights for rats treated with MNU at 3 weeks of age (A). The difference between weights of the vehicle-treated and MNU-treated is statistically significant by two-way ANOVA with Bonferroni post hoc test $(p<0.05)$. Weights for rats treated with MNU at 8 weeks of age $(B)$. The weights of the vehicle-treated and MNU-treated rats were statistically significant by two-way ANOVA with Bonferroni post hoc test $(p<0.05)$. Weights for rats administrated DMBA at 8 weeks of age (C). The weights of the vehicle-treated and DMBA-treated rats were not statistically significant by two-way ANOVA with Bonferroni post hoc test $(p>0.05)$. In all panels, weights of MNU/DMBA-treated rats were not significantly different between rapid and slow NAT2 acetylator rat strains. 


\section{Palpable Mammary Tumor Latency and Incidence}

As shown in figure 3.5 , rapid acetylator congenic rats had significantly shorter latency for development of their first palpable mammary tumor compared to slow acetylator NAT2 congenic rats after administration of MNU in females treated at either 3 or 8 weeks of age. Rapid acetylator rats showed significantly higher tumor incidence compared to slow acetylator rats after MNU administration at 3 or 8 weeks of age.

DMBA-treated rapid acetylator rats displayed a higher tumor incidence over the course of the treatment than DMBA-treated slow acetylator rats, although logrank test analysis provides a $p$-value $(p=0.065)$ slightly greater than our established $p$-value threshold of significance $(p=0.050)$.

\section{Terminal Mammary Tumor Incidence and Multiplicity}

As shown in table 3.1 , female congenic rats, administered MNU at 3 weeks of age, developed tumors in $66.7 \%$ of the rapid acetylator congenic rats with an average $1.00 \pm 0.17$ tumors per rat. In contrast, tumors were found in $52.9 \%$ of slow acetylator congenic rats with an average of $0.67 \pm 0.12$ tumors per rat. These mammary tumor incidence and multiplicity results were not significantly different between rapid and slow acetylator rats administered MNU at 3 weeks of age. 


\section{FIGURE 3.5}
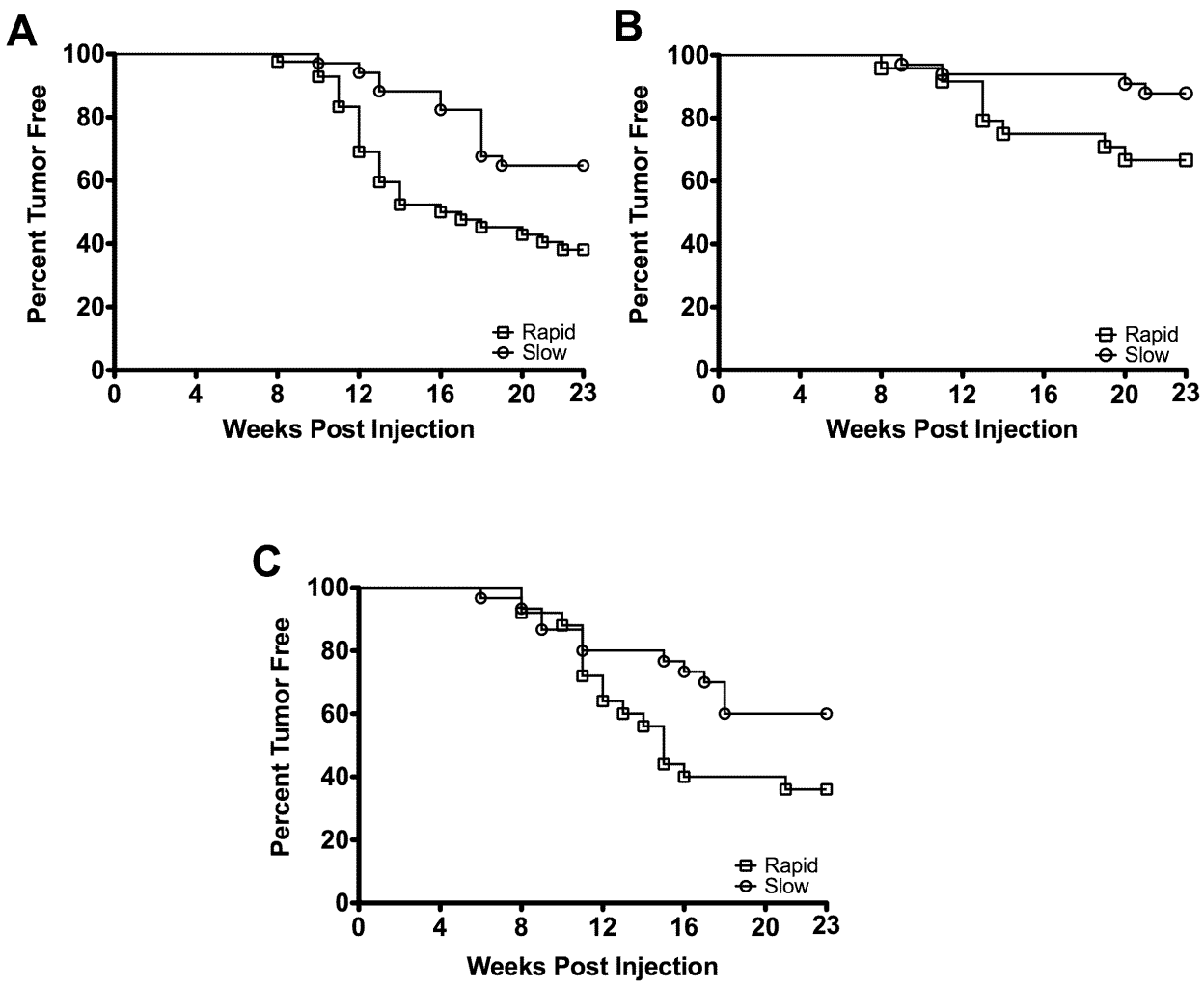

Figure 3.5. Kaplan-Meier plot of palpable mammary tumors in congenic rats. Onset of tumors in rats exposed to MNU at 3 weeks of age (A), MNU at 8 weeks of age (B), and DMBA at 8 weeks of age (C). Squares illustrate rapid and circles illustrate slow acetylator Nat2 congenic rats. Rapid acetylator congenic rats had a significantly $(p<0.05)$ shorter latency for development of first palpable mammary tumor compared to slow acetylator congenic rats after MNU administration at either 3 or 8 weeks of age. Similar findings were obtained after DMBA administration at 8 weeks of age although the difference was not significant $(p=0.065)$ 
As shown in table 3.1, female congenic rats administered MNU at 8 weeks of age developed tumors in $41.6 \%$ of rapid acetylators with $0.50 \pm 0.14$ average tumors per rat. Slow acetylators developed tumors in $15.2 \%$ of those given MNU, with $0.24 \pm 0.12$ tumors per rat. Thus, rapid acetylator rats exhibited significantly higher mammary tumor incidence $(p=0.035)$ and multiplicity $(p=0.050)$ compared to slow acetylator rats.

No other tissue/organ tumors besides mammary tumors were observed in either MNU- or vehicle-treated rats. A few rats displayed discoloration of the eyes, thought to be an onset of cataracts. Cataracts and retinal degradation can occur in rats following MNU administration [105].

As shown in table 3.1, female congenic rats exposed to DMBA developed mammary tumors in $76.0 \%$ of rapid acetylators with $1.20 \pm 0.16$ average tumors per rat. Slow acetylators developed tumors in $43.3 \%$ of those given DMBA, with $0.57 \pm 0.14$ tumors per rat. Rapid acetylator rats had significantly higher mammary tumor incidence $(p=0.027)$ and multiplicity $(p=0.004)$ compared to slow acetylator rats. No other tissue/organ tumors besides mammary tumors were observed in DMBA- or vehicle-treated rats. 
Table 3.1 - Mammary tumor totals in rapid and slow acetylator congenic rats administered MNU or DMBA

\begin{tabular}{|c|c|c|c|c|c|c|}
\hline $\begin{array}{l}\text { Treatment } \\
\text { Protocol }\end{array}$ & $\begin{array}{l}\text { Acetylator } \\
\text { phenotype }\end{array}$ & $\begin{array}{l}\text { Rats treated } \\
\text { and } \\
\text { necropsied }\end{array}$ & $\begin{array}{l}\text { Rats with tumors } \\
(\%)^{a}\end{array}$ & $\begin{array}{l}\text { Total } \\
\text { tumors }\end{array}$ & $\begin{array}{l}\text { Total tumors } \\
\text { per rat }{ }^{b, c}\end{array}$ & $\begin{array}{l}\text { Total tumors per rat in } \\
\text { tumor- bearing rats }\end{array}$ \\
\hline $\begin{array}{c}\text { MNU } \\
3 \text { weeks }\end{array}$ & Rapid & 42 & $28(66.7 \%)$ & 42 & $1.00 \pm 0.17$ & $1.50 \pm 0.20$ \\
\hline $\begin{array}{c}\text { MNU } \\
3 \text { weeks }\end{array}$ & Slow & 34 & $18(52.9 \%)$ & 23 & $0.67 \pm 0.12$ & $1.28 \pm 0.11$ \\
\hline $\begin{array}{c}\text { MNU } \\
8 \text { weeks }\end{array}$ & Rapid & 24 & $10(41.6 \%)^{*}$ & 12 & $0.50 \pm 0.14^{*}$ & $1.20 \pm 0.20$ \\
\hline $\begin{array}{c}\text { DMBA } \\
8 \text { weeks }\end{array}$ & Rapid & 25 & $19(76.0 \%)^{*}$ & 30 & $1.20 \pm 0.16^{* *}$ & $1.58 \pm 0.12$ \\
\hline $\begin{array}{c}\text { DMBA } \\
8 \text { weeks }\end{array}$ & Slow & 30 & $13(43.3 \%)^{*}$ & 17 & $0.57 \pm 0.14^{* *}$ & $1.31 \pm 0.17$ \\
\hline
\end{tabular}

a Tumor incidence

${ }^{\mathrm{b}}$ Tumor multiplicity

${ }^{c}$ Mean \pm SEM. Total mammary tumors differed significantly * $(p<0.05){ }^{* *}(p<0.01)$ between rapid and slow acetylator rats 


\section{Pathology}

A majority of the mammary tumors that developed in carcinogen-treated rats were classified as non-invasive (figure 3.6). More tumors classified as benign were noted in rats administered MNU at 3 weeks compared to 8 weeks of age $(15 \%$ and $0 \%$, respectively).

Among the rapid and slow congenic rat strains administrated MNU at 3 weeks of age, $\sim 11 \%$ of tumors were classified as invasive carcinomas in the rapid acetylators $(3 / 28)$ versus none in the slow acetylators (0/18). Low grade $\mathrm{CIS}$ tumors were the most common histomorphological classification of tumors in both rapid and slow rat Nat2 congenic strains.

Rats administered MNU at 8 weeks of age exhibited similar percentages of mammary tumors classified as low grade CIS in rapid (5/10) and slow (2/5) acetylators. Mammary tumors classified as high grade $C / S$ tumors were observed in 3 rapid acetylator congenic rats (3/10), and the only tumor classified as invasive was found in one slow acetylator rat (1/5).

In general, rats administered DMBA displayed a very similar distribution pattern of tumor pathology. The rapid NAT2 congenic rats had more benign tumors $(4 / 19$ or $21 \%)$ than slow NAT2 congenic rats $(1 / 13$ or $8 \%)$. The slow congenic rats had a higher percentage of tumors with an invasive classification than the rapid congenic rats $(31 \%[4 / 13]$ vs $11 \%[2 / 19])$. 


\section{FIGURE 3.6}

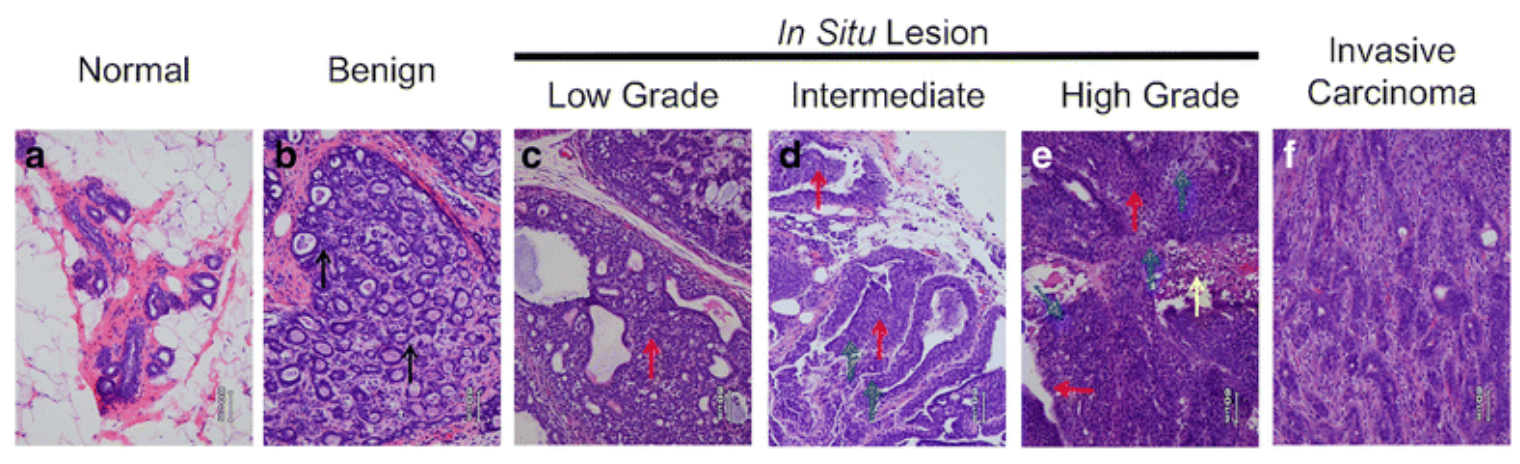

Figure 3.6. Photomicrographs of H\&E stained slides depicting the criteria utilized to classify tumors. Normal mammary tissue (a). Benign tumor (b) showing proliferative disease with no cytologic atypia and minimal to no overgrowth of the epithelial or myoepithelial component (black arrows). CIS lesions (c-e) with overgrowth of the epithelial and/or myoepithelial component (red arrows). Low grade CIS lesion (c) with low grade cytologic atypia and occasional mitoses or single cell apoptosis. Intermediate grade CIS lesion (d) with intermediate to high grade cytologic atypia with increased mitoses (blue arrows) or single cell apoptosis. High grade CIS lesion (e) with intermediate to high grade cytologic atypia with tumor necrosis (yellow dashed arrow) and increased mitoses (blue arrows). Invasive carcinoma (f) with glands or single cells infiltrating through stroma. 


\section{Enzymatic Activities of Recombinant Rapid and Slow Rat NAT2}

PABA $N$-acetylation velocities for rat arylamine $N$-acetyltransferase 2 catalyzed by recombinant rapid acetylator NAT2 was significantly $(p=0.005)$ higher than by recombinant slow acetylator NAT2 (figure 3.7A). The folatedependent AcCoA hydrolysis catalyzed by rat NAT2 was significantly $(p=0.005)$ higher for recombinant rapid acetylator NAT2 than recombinant slow acetylator NAT2 (figure 3.7B).

\section{Rapid and Slow Acetylator Rat NAT2 Activities in Tissue Lysates}

The PABA $N$-acetylation activities of $N a t 2$ congenic rats measured in lysates from several tissue-types was significantly higher in rapid than slow acetylators: liver $(p<0.001)$, lung $(p<0.001)$, colon $(p=0.007)$, and mammary gland $(p<0.001)$ (figure $3.7 \mathrm{C})$. The folate-dependent AcCoA hydrolysis was significantly higher in rapid acetylator than slow acetylator lung $(p=0.002)$ and colon $(p=0.002)$ (figure 3.7D). No detectable folate-dependent AcCoA hydrolysis activity was observed in liver and mammary tissue lysates (threshold of detection $0.05 \mathrm{nmoles} / \mathrm{min} / \mathrm{mg}$ protein). 
FIGURE 3.7
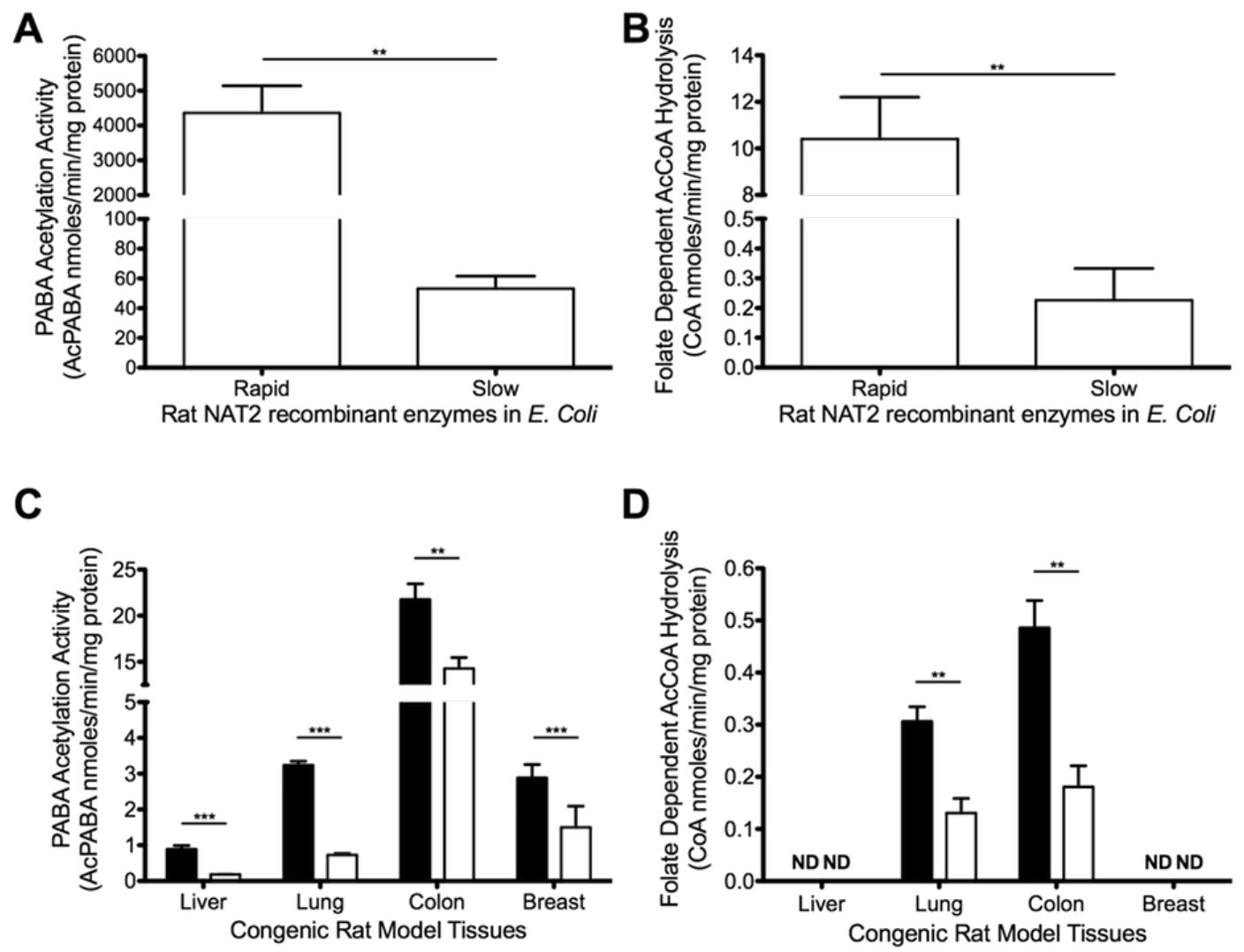

Figure 3.7. Rat NAT2 PABA acetylation $(A, C)$ and folate-dependent AcCoA hydrolysis activity $(B, D)$. The same recombinant lysates were used in triplicate for each activity (A, B).. Lysates of individual tissues collected from either 5 rapid (closed bars) or 5 slow (open bars) acetylator NAT2 F344 congenic rats (C, D). "ND" = not detectable. The number of asterisks corresponds to the $p$-value: ${ }^{* * *}=$ $p<0.001 ;{ }^{* *}=p<0.01$. 
NAT2 Activity and Endogenous AcCoA Concentrations in Isolated Congenic REFs

The REFs isolated from the congenic rat strains were characterized for their ability to acetylate PABA and their endogenous AcCoA concentrations after the fourth passage. PABA N-acetylation in rapid NAT2 REFs was significantly higher than in slow NAT2 REFs $(p=0.002)$ (figure 3.8A). Endogenous AcCoA concentrations levels in the rapid NAT2 REFs were lower compared to that of the slow NAT2 REFs $(p=0.003)$ (figure 3.8B). 


\section{FIGURE 3.8}
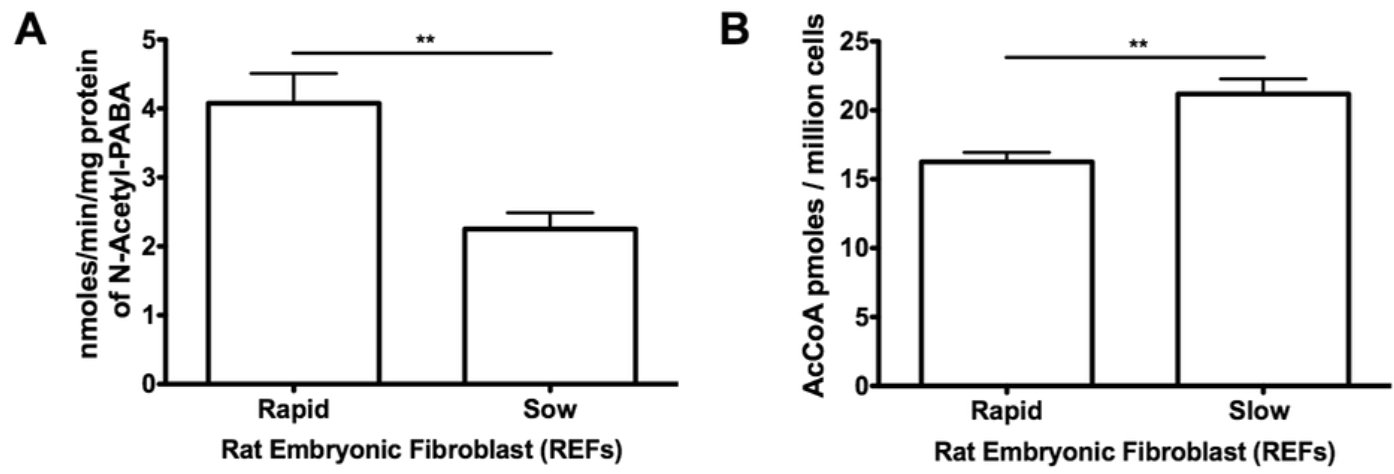

Figure 3.8. NAT2 activity and AcCoA level measured in rat embryonic fibroblasts (REFs) from rapid and slow rats. Rapid NAT2 REFs $(N=7)$ have a higher level of PABA acetylation activity than slow NAT2 REFs $(N=9)(A)$. The amount of AcCoA per million cells is lower in rapid NAT2 REFs $(\mathrm{N}=8)$ than in slow NAT2 REFs $(N=10)(B)$. The number of asterisks corresponds to the $p$-value $\left(^{* *}, p<0.01\right)$. 


\section{DISCUSSION}

This study is the first to utilize a functional animal model to look at tumorigenic differences between rapid and slow rat NAT2 activity using carcinogens that do not require NAT2 activity for activation/deactivation. This functional animal model mimics human populations. Rat NAT2 is the ortholog of human NAT1. Genetic variants and other factors influence human NAT1 activity levels. The NAT1*10 haplotype is associated with increased NAT1 activity in human tissue samples [26-28]. Other polymorphic haplotypes encode a less stable NAT1, leading to a decrease in enzymatic activity. Our results in Nat2 congenic rats suggest that human genetic variation resulting in differential NAT1 activity may influence human breast cancer. Furthermore, our findings suggest that $N A T 1^{*} 10$ human haplotypes may have a higher risk of breast cancer compared to the reference $N A T 1^{*} 4$ haplotype. Also, polymorphic variants that decrease NAT1 activity would likely have a reduced cancer risk.

In the present study, we investigated whether chemical carcinogens induced tumors more rapidly or in greater abundance in rapid than slow Nat2 congenic rat strains. MNU was administered at either a pre-pubescent age (3 weeks) or a post-pubescent age (8 weeks). Additionally DMBA was administered at only post-pubescent age ( 8 weeks). We observed decreased latency and increased incidence of palpable mammary tumors in congenic rapid acetylator rats than in congenic slow acetylator rats treated with either MNU or DMBA. 
Terminal multiplicity and incidence also were higher in rapid than slow acetylator rats administered MNU or DMBA.

The role of human NAT1 in cancer is not well understood, but the current understanding of NAT1's potential importance in cancer is expanding. Several microarray studies have shown that elevated NAT1 expression is correlated with estrogen receptor positive $(E R+)$ breast cancer samples $[8,10,16]$. Human NAT1 expression in breast cancer is predicted to be a valuable indicator for antiestrogen responsiveness [106] and an indicator of a positive prognosis, particularly in ER+ breast cancer [107]. Normal human mammary luminal epithelial cell lines (HB4a) engineered to overexpress NAT1 continue growing compared to normal HB4a cells that reach a growth plateau [8]. The present study adds to the developing and complex narrative of NAT1 in cancer, by providing the first animal model data that show an association between NAT1 activity levels and tumorigenesis independent of carcinogen metabolism.

Rapid acetylator rats displayed elevated risk of mammary tumors compared to slow acetylator $\mathrm{MNU}$-treated rats regardless of whether treatment occurred when immature or mature. Pre-pubescent exposure to MNU, regardless of NAT2 activity phenotype, resulted in greater palpable tumor incidence, as well as increased terminal mammary tumor incidence and multiplicity (table 3.1 and compare panels in figure 3.5). This increase with earlier age of MNU-exposure is consistent with the known elevated breast cancer susceptibility of prepubescent 
female breasts to cancer induced by ionizing radiation [108]. MNU, a simple alkylating agent, is radiomimetic [109]. Humans are exposed to alkylating chemical carcinogens in diet, tobacco products, cosmetics, drugs, and chemotherapy [110]. The results reported in the current study suggest that the human NAT1 (an ortholog of rat NAT2) phenotype and prepubescent carcinogen exposure should be studied as additional factors in human breast cancer susceptibility.

The role rat NAT2 activity plays in increased tumorigenesis is poorly understood. Our hypothesis is that a more active rat NAT2 might lower vital compounds needed for DNA repair to a greater extent than a less active rat NAT2. Rat NAT2 and human NAT1 are orthologous enzymes that, in addition to their acetylation capacity, catalyze the hydrolysis of AcCoA to acetate and coenzyme $A$ in the presence of folate $[54,103]$. Thus, rapid rat NAT2 (or more active human NAT1) can reduce intracellular levels of AcCoA to a greater extent than slow rat NAT2, affecting crucial pathways supporting DNA repair (e.g. histone and p53 acetylation). In support of this hypothesis, measurement of NAT2 activity in rapid acetylator rat tissues showed higher levels of PABA Nacetylation and folate-dependent AcCoA hydrolysis than in slow acetylator rat tissues. These differences were also reflected in recombinant rapid and slow acetylator NAT2 expressed in bacteria. As shown with congenic rat tissues and recombinant NAT2 proteins, REFs isolated from rapid NAT2 rats had a higher PABA N-acetylation activity level than REFs isolated from the slow NAT2 
congenic rats. Furthermore, rapid NAT2 REFs had lower levels of AcCoA compared to the slow NAT2 REFs. This observation parallels the findings with folate-dependent AcCoA hydrolysis, in that rapid acetylator NAT2 is able to hydrolyze AcCoA at greater rates than slow acetylator NAT2 and thus more likely to reduce endogenous AcCoA levels.

The study of intracellular AcCoA concentration levels has not been well characterized after DNA insult. Some studies have shown AcCoA concentrations control cell growth, cellular autophagy, and histone acetylation [111-113]. Other studies have shown reduced acetylation of downstream targets if acetyl-CoA carboxylase, ATP-citrate lyase, or pantothenate kinase are knocked out [113115]. Future studies will further explore human NAT1 activity in relation to intracellular AcCoA concentrations and associated differences in acetylation targets. As shown in Chapters 4 and 5, human NAT1 knockdown and knockout cancer cell lines have elevated $\mathrm{AcC} \mathrm{C} A$ concentrations compared to their wildtype counterparts.

Breast cancer is one of the most common types of cancer. It is estimated that in 2016 breast cancer will be the most diagnosed type of cancer in United States women, excluding basal and squamous cell skin cancers [116]. It is also expected that breast cancer will be one of the leading causes of death from cancer in women, with only lung cancer ranking higher [116]. Breast cancer's persistence as one of the most formidable cancers in women illuminates the 
need to understand differences in cancer susceptibility and discover novel avenues for prevention and treatment. The studies in this chapter primarily focus on breast cancer. However given ubiquitous expression of NAT1, the findings here are likely to be observed in other cancer sites such as lung, colon, urinary bladder, and prostate. 
CHAPTER IV

INHIBITION OF ARYLAMINE N-ACETYLTRANSFERASE 1 REDUCES ANCHORAGE-INDEPENDENT GROWTH IN HUMAN BREAST CANCER CELL

LINE MDA-MB-231

INTRODUCTION

Arylamine $\mathrm{N}$-acetyltransferase 1 (NAT1) historically is identified as a phase II drug and carcinogen metabolizing enzyme which catalyzes the transfer of an acetyl group from acetyl-coenzyme A (AcCoA) to the amine nitrogen of arylamine and hydrazine compounds. Recently, human NAT1 has been shown to catalyze hydrolysis of AcCoA in the presence of folate [54, 103].

NAT1 expression is elevated in invasive and lobular breast carcinomas when compared to normal breast tissue [8]. This overexpression of NAT1 was confirmed at the mRNA level and by immunohistological analysis in 108 breast cancer samples that demonstrated a strong association of NAT1 staining and estrogen receptor-positive tumors [8]. Elevated NAT1 expression in estrogen receptor-positive tumors has been observed in multiple studies [20,67]. Also, elevated NAT1 expression is associated with breast cancer bone metastasis [24, 117]. Adam et al. demonstrated that overexpression of NAT1 in a normal luminal epithelial-derived cell line conferred enhanced growth properties and etoposide 
resistance compared to control cells that had been transfected with an empty vector [8]. Subsequent studies demonstrated that a small molecule inhibitor of NAT1 activity caused decreased cell growth and reduced ability of MDA-MB-231 human breast cancer cells to grow in soft agar [11]. A lentiviral-based NAT1 shRNA, which reduced NAT1 activity by $74 \%$, reduced cell invasion by $50 \%$ in MDA-MB-231 human breast cancer cells [11]. NAT1 activity is cell-cycle phasedependent showing an association between high NAT1 activity and accelerated progression through the cell cycle in HaCaT keratinocytes [118]. Tiang et al. showed in the colon cancer cell line HT-29 that RNAi mediated knockdown of NAT1 by approximately $85 \%$ led to increased cell-cell contact inhibition, loss of cell viability at confluence, and attenuation of anchorage-independent cell growth [13]. Overall these previous studies have shown a relationship between NAT1 activity and cancer cell proliferation, anchorage-independent growth abilities, and invasiveness.

Human NAT1 activity is modified by polymorphism, but can also be regulated by microRNA, epigenetic, and/or translational and post-translational control features [67-70]. NAT1 transcript levels can be regulated by extracellular stimuli acting on glucocorticoid or androgen receptors [71, 72]. Exposure to NAT1 substrates can increase NAT1 degradation, which results in decreased NAT1 activity $[69,70]$. Oxidative stress can reversibly or irreversibly inactivate NAT1 [119, 120]. NAT1 inhibitors have been reported including cisplatin [121], curcumin [122, 123], disulfiram [124], and rhodanine derivatives [125, 126]. The 
ability to control the level of NAT1 activity and expression by various means may reduce cancer growth or metastasis.

To better understand how variation in NAT1 activity can affect cancer cell growth and invasion properties, we utilized RNAi technology and a small molecule inhibitor of NAT1 in the human breast cancer cell line MDA-MB-231. We used the Sure Silencing ${ }^{\mathrm{TM}}$ shRNA plasmid described previously [13], and a rhodanine derivative (5E)-[5-(4-hydroxy-3,5-diiodobenzylidene)-2-thioxo-1,3thiazolidin-4-one] (5-HDST) similar to the small molecule NAT1 inhibitor reported previously [126]. 


\section{MATERIALS AND METHODS}

\section{Cell Line Generation and Culturing Conditions}

The breast adenocarcinoma cell line, MDA-MB-231, was purchased from ATCC (Manassas, Virginia). Cells were cultured in DMEM media, high glucose with the addition of fetal bovine serum to $10 \%$ and glutamine to $2 \mathrm{mM}$. SureSilencing $^{\mathrm{TM}}$ Predesigned shRNA and NAT1 knockdown shRNA plasmids were purchased from SA Biosciences. Initial screening found that the NAT1 shRNA Clone 1 reduced NAT1 catalytic activity by $29 \%$ while NAT1 shRNA Clone 3 reduced NAT1 catalytic activity by $50 \%$. Further studies were conducted with NAT1 shRNA Clone 3 because it was used in previous experiments [10] and resulted in the greatest reduction in NAT1 expression. The shRNA sequence for the scrambled shRNA and NAT1 shRNA clone 3 were transferred from the pGeneclip $^{\mathrm{TM}}$ vector to the pcDNA5/FRT vector. The NAT1 overexpression plasmid NATb/NAT1*4 in pcDNA5/FRT was previously described [127].

A MDA-MB-231 breast cancer cell line with a single FRT site was constructed using the Flp-In System (Life Technologies, Grand Island, NY) as described previously [128]. Once an MDA-MB-231 cell line was constructed with a single FRT site in a transcriptionally active region, we transfected the shRNA plasmids and the NAT1 overexpression plasmid to deliver the cassettes to the same genetic location. The pcDNA5/FRT plasmids containing the scrambled shRNA, NAT1 specific shRNA plasmid or the NAT1 overexpression plasmid 
NATb/NAT1*4 [127] were co-transfected with pOG44 (Life Technologies), a Flp recombinase expression plasmid, using Amaxa Cell Line Nucleofector Kit V (Lonza, Basel, Switzerland) following the manufacturer's recommendations. Since the pcDNA5/FRT vector contains a hygromycin resistance cassette, cells were passaged in complete DMEM containing $500 \mu \mathrm{g} / \mathrm{ml}$ hygromycin to select for cells with the pcDNA5/FRT plasmid stably integrated into their genomic DNA. Hygromycin-resistant colonies were selected approximately 2 weeks after transfection and isolated using cloning cylinders. Unless otherwise stated experiments using cell lines were performed with cells in log phase of growth.

In summary, the following MDA-MB-231 cell lines were constructed:

1. Scrambled shRNA cell line stably transfected with scrambled shRNA as a control cell line to which other cell lines are compared.

2. NAT1 knockdown cell line stably transfected with NAT1 specific shRNA.

3. NAT1 overexpression cell line stably transfected with the NATb/NAT1*4 cassette.

\section{In Vitro and In Situ NAT1 $\mathbf{N}$-acetyltransferase Assays for Cell Lines}

In vitro assays using the NAT1 selective substrate para-aminobenzoic acid (PABA) were conducted and the $\mathrm{N}$-acetyl-PABA product was separated and quantitated as described [129]. Briefly, cells were scraped from the plate, washed in 1X phosphate-buffered saline (PBS), and lysed in $20 \mathrm{mM}$ sodium phosphate 
$\mathrm{pH} 7.4,1 \mathrm{mM}$ ethylenediaminetetraacetic acid (EDTA), $0.2 \%$ triton $\mathrm{X}-100,, 1 \mathrm{mM}$ dithiothreitol (DTT), $100 \mu \mathrm{M}$ phenylmethanesulfonyl fluoride (PMSF), $1 \mu \mathrm{g} / \mathrm{ml}$ aprotinin, and $2 \mu \mathrm{M}$ pepstatin A. Cell lysate was centrifuged at $15,000 \times g$ for 10 min and supernatant tested for NAT1 activity. Enzymatic reactions containing 50 $\mu \mathrm{L}$ suitably diluted cell lysate, PABA $(300 \mu \mathrm{M})$ and acetyl coenzyme A (1 mM) were incubated at $37^{\circ} \mathrm{C}$ for $10 \mathrm{~min}$. Reactions were terminated by the addition of $1 / 10$ total reaction volume of $1 \mathrm{M}$ acetic acid and centrifuged at $15,000 \mathrm{X} g$ for 10 min. Three independent measurements $(\mathrm{N}=3)$ performed in triplicate were completed for each cell line.

Measurement of $\mathrm{N}$-acetylation in situ was determined by spiking media with a known concentration of PABA as described [130]. The cells were incubated at $37^{\circ} \mathrm{C}$ for $48 \mathrm{~h}$ with media containing $500 \mu \mathrm{M}$ PABA. Media were collected and 1/10 total collected media volume of $1 \mathrm{M}$ acetic acid was added. The acidified media were centrifuged at $15,000 \times \mathrm{g}$ for $10 \mathrm{~min}$. There were four independent measurements $(\mathrm{N}=4)$ performed in triplicate for each cell line.

Resulting supernatants from in vitro and in situ NAT1 activity assays was injected into a reverse phase C18 column (125 mm $\times 4 \mathrm{~mm} ; 5 \mu \mathrm{M}$ pore size). Reactants and products were eluted using a Beckman System Gold high performance liquid chromatography (HPLC) system. HPLC separation of $\mathrm{N}$ acetyl-PABA was achieved using a gradient of 96:4 sodium perchlorate $\mathrm{pH} 2.5$ : acetonitrile at $280 \mathrm{~nm}$. The data for scrambled shRNA, knockdown and 
overexpression cell lines are represented as mean \pm SEM and analyzed statistically by a one-way ANOVA and Bonferroni post- test.

\section{Endogenous Cellular Acetyl-Coenzyme A (AcCoA) Levels for Cell}

\section{Lines}

Endogenous AcCoA levels within modified MDA-MB-231 cancer cell lines (scrambled shRNA, knockdown, and overexpression) were determined by HPLC. Cell growth conditions were strictly monitored because it was observed that cellular confluence and period of growth affected the consistency of data obtained for the endogenous AcCoA concentrations. Cells were plated at $1 \times 10^{6}$ per $10 \mathrm{~cm}$ plate ( 3 plates per $\mathrm{N}$ ) with fresh complete culturing media with no selection antibiotic added, and allowed to grow for $72 \mathrm{~h}$. After $72 \mathrm{~h}$, the cells were $70 \%$ confluent and collected. Media were aspirated from the plates, and each plate was washed with $5 \mathrm{ml}$ PBS. Then cells were dissociated from the plate with $0.5 \mathrm{ml}$ trypsin $[0.25 \%(\mathrm{w} / \mathrm{v})]$. Cells were suspended in $4 \mathrm{ml}$ of diluted complete media (20\% medium and $80 \%$ PBS) and counted in $0.5 \mathrm{ml}$ aliquots. In the subsequent steps all cells and lysates were kept on ice or at $4^{\circ} \mathrm{C}$. Collected cells were centrifuged, supernatant removed, and ice-cold PBS was added. Again, cells were centrifuged, supernatant removed, suspended in $1 \mathrm{ml}$ of ice-cold PBS, and transferred to $1.5 \mathrm{ml}$ microcentrifuge tubes. The suspended cells were collected by centrifugation and the supernatants discarded. Having removed any residual PBS, the cells were lysed in $100 \mu \mathrm{L}$ ice-cold 5\% 5-sulfosalicylic acid with a $1 \mathrm{ml} \mathrm{BD} \mathrm{Insulin} \mathrm{Syringe} \mathrm{with} \mathrm{permanently} \mathrm{attached} 28$ gauge needle (BD 
Franklin Lakes, NJ, USA). The needle selection is important to insure complete cell lysis without loss of volume or cellular masses within the syringe/needle. The cellular lysate was then centrifuged at $13,000 \times g$ for $10 \mathrm{~min}$. Supernatant was filtered through a syringe filter $(13 \mathrm{~mm}, 0.20 \mu \mathrm{m}$ pore size $)$. Filtrate was collected and separated on a C18 reverse-phase HPLC column $(250 \mathrm{~mm} \times 4 \mathrm{~mm} ; 5 \mu \mathrm{m}$ pore size). HPLC separation and quantitation of AcCoA was achieved using a linear gradient of $100 \% 55 \mathrm{mM}$ sodium phosphate $\mathrm{pH} 4.0: 0 \%$ methanol to $0 \% 55$ $\mathrm{mM}$ sodium phosphate $\mathrm{pH}$ 4.0: $100 \%$ methanol over 20 min and was quantitated by absorbance at $260 \mathrm{~nm}$. The data for individual determinations of scrambled shRNA, knockdown and overexpression cell lines ( $N=8,7$, and 7 respectively) are represented as mean \pm SEM, and were analyzed by a one-way ANOVA and Bonferroni post-test.

\section{Quantitation of NAT1 mRNA Levels}

NAT1 mRNA levels were measured as described previously [130]. Briefly, total RNA was isolated from the constructed MDA-MB-231 cell lines using the RNeasy Mini kit (Qiagen, Germantown, MD) following manufacturer's instructions. cDNA was made using the High Capacity Reverse Transcriptase kit (Life Technologies) following manufacturer's instructions. mRNA was quantitated via Real-time PCR using Taqman primers and probe (Life Technologies) 5'gaattcaagccaggaagaagca-3' 5'tccaagtccaatttgttcctagact-3' FAM-5'caatctgtcttctggattaa3'-MGB and PCR conditions suggested by the manufacturer. The data for scrambled shRNA, knockdown and overexpression cell lines are represented as mean \pm SEM from three separate determinations performed in 
triplicate $(\mathrm{N}=3)$, and were analyzed statistically by a one-way ANOVA and Bonferroni post-test.

\section{Determination of Doubling Time of Cell Lines}

Twenty-five thousand cells were plated in triplicate in 6-well plates and allowed to grow for 5 consecutive days. Cells were plated on day 1 and allowed to equilibrate for $24 \mathrm{~h}$ before making the first count on day 2 followed by counts on days 3, 4, 5 and 6 using a cell counter. A cell doubling rate was calculated for each day using Equation 1 (shown below) and then rates were averaged over the 5 day time period to get a final cell doubling rate.

Equation 1: Cell Doubling Rate $=1 /\left(((\log (b)-\log (a)) \times 3.32) /\left(t_{b}-t_{a}\right)\right)$

In the equation, $\mathrm{b}=$ cell number on day $\mathrm{n}, \mathrm{a}=$ cell number on day $\mathrm{n}-1, \mathrm{t}_{\mathrm{b}}=$ hours passed since plating when cells were counted on day $n$, and $t_{a}=$ hours passed since plating when cells were counted on day $n-1$. This assay was performed in triplicate for each cell line $(\mathrm{N}=3)$. The data for the cell lines are represented as mean \pm SEM from three separate determinations performed in triplicate, and were analyzed statistically by a one-way ANOVA and Bonferroni post-test.

Measuring the Effect of a Small Molecule Inhibitor on In Situ NAT1 Activity and Cell Growth

The ability of the small molecule inhibitor (5E)-[5-(4-hydroxy-3,5diiodobenzylidene)-2-thioxo-1,3-thiazolidin-4-one] (5-HDST, CAS\# 336171-85-8) (Ryan Scientific, Mount Pleasant, SC) to inhibit NAT1 activity was measured in 
situ and its effects on cell growth measured as a percentage of untreated cells. Scrambled shRNA MDA-MB-231 cells were incubated with a single dose of 5HDST (ranging from 0-87.5 $\mu \mathrm{M}$ ) for up to 6 days. Briefly, all cells were plated on day 0 and the varying concentrations of 5-HDST were added to the respective cells on day 1 . Cells were plated in 12-well plates so that every successive day would have roughly the same number of cells to enable accurate measurement of PABA $N$-acetylation in situ and cell number. PABA $(10 \mu \mathrm{M})$ was added to the media and incubated with the cells and 5-HDST for $24 \mathrm{~h}$ prior to measurements. After $24 \mathrm{~h}$, media were removed from the cells and amounts of PABA and $\mathrm{N}$ acetyl-PABA were measured by HPLC as described above. Cells were washed once with 1X PBS, scraped off the plate and counted using a cell counter. Three separate determinations performed in triplicate for PABA $\mathrm{N}$-acetylation and cell number were carried out every $24 \mathrm{~h}$ for 6 days $(\mathrm{N}=3)$. The in situ NAT1 data, represented as means \pm SEM, were analyzed statistically by a one-way ANOVA and Bonferroni post-test on day 6 . The cell number data, represented as means \pm SEM, were analyzed statistically by a two-way ANOVA and Bonferroni posttest.

\section{Anchorage-Dependent and Anchorage-Independent Growth Assays}

Anchorage-dependent growth assays were performed by plating cells (300 cells/well) in triplicate in 6-well plates and allowing them to grow for 2 weeks $(\mathrm{N}=3)$. For small molecule NAT1 inhibitor assays, 5-HDST (ranging from 0 to $87.5 \mu \mathrm{M})$ was added to triplicate wells at the time of plating $(\mathrm{N}=3)$. Colonies were 
counted following staining with crystal violet. The data are represented as means \pm SEM from three separate determinations performed in triplicate and were analyzed statistically by a one-way ANOVA and Bonferroni post-test.

The anchorage-independent growth assays were performed by plating the cells in low-melting temperature agarose. The cells were grown in normal growth media where the bottom layer was $1.5 \mathrm{ml}$ (noble agar, $0.5 \%$ ) and the top layer was $1.5 \mathrm{ml}$ (low-melting temperature agarose, $0.3 \%$ ), so the total volume was 3 $\mathrm{ml}$ in each well of a 6 well plate. Cells (6000 cells/well) were plated in triplicate in 6-well plates and grown for 2 weeks. Colonies were counted following staining with crystal violet. For the anchorage-independent growth assay investigating effect of the small molecule NAT1 inhibitor, 5-HDST (ranging from 0 to $87.5 \mu \mathrm{M}$ ) was added at the time of plating of the cells. Three separate determinations performed in triplicate were completed for each assay $(\mathrm{N}=3)$. The data are represented as means \pm SEM and were analyzed statistically by a one-way ANOVA and Bonferroni post- test.

\section{Transwell Assays to Assess Relative Invasive Ability}

Transwell assays were performed by depositing $1 \times 10^{5}$ cells in $100 \mu \mathrm{L}$ of DMEM containing $0.2 \%$ FBS in the top chamber of the transwell and $600 \mu \mathrm{L}$ of complete media in the bottom chamber. 5-HDST (ranging from 0 to $100 \mu \mathrm{M}$ ) was added to media on both sides of the membrane. Cells were allowed to invade across a membrane of Matrigel (Life Technologies). After $24 \mathrm{~h}$, cells on the top side of the membrane were removed with a sterile cotton swab. Cells that 
invaded across the membrane were quantified using the Alamar Blue cell quantitation assay. Three separate determinations performed in triplicate were made $(\mathrm{N}=3)$. The data are represented as means $\pm \mathrm{SEM}$, and were analyzed statistically by one-way ANOVA and Bonferroni post-test. 


\section{RESULTS}

NAT1 Catalytic Activity, Endogenous AcCoA Levels, and mRNA

\section{Expression}

The stable partial knockdown of NAT1 reduced in vitro PABA NAT1 Nacetylation to $61 \%$ of the scrambled shRNA cell line (figure $4.1 \mathrm{~A}$ ) and in situ PABA $N$-acetylation to $62 \%$ of the scrambled shRNA cell line (figure $4.1 \mathrm{~B}$ ). Stable overexpression of NAT1 increased the $\mathrm{N}$-acetylation of PABA in vitro and in situ by 12 -and 11 -fold, respectively, compared to the scrambled shRNA cell line (figure $4.1 \mathrm{~A} \& \mathrm{~B}$ ). The partial knockdown of NAT1 in NAT1 shRNA knockdown MDA-MB-231 breast cancer cells increased endogenous AcCoA levels about $35 \%$ compared to the scrambled shRNA cell line $(p<0.005)$ (figure 4.1C). Endogenous AcCoA levels in the NAT1 overexpression MDA-MB-231 cell line did not differ significantly $(p>0.05)$ compared to the scrambled shRNA cell line but were significantly below the AcCoA levels of the partial NAT1 knockdown cell line $(p<0.05)$ (figure 4.1C). NAT1 mRNA expression in the stable knockdown was $47 \%$ of the scrambled shRNA cell line, and was 31 -fold higher than the scrambled shRNA cell line in the stable NAT1 overexpression cell line (figure 4.1D). 
FIGURE 4.1
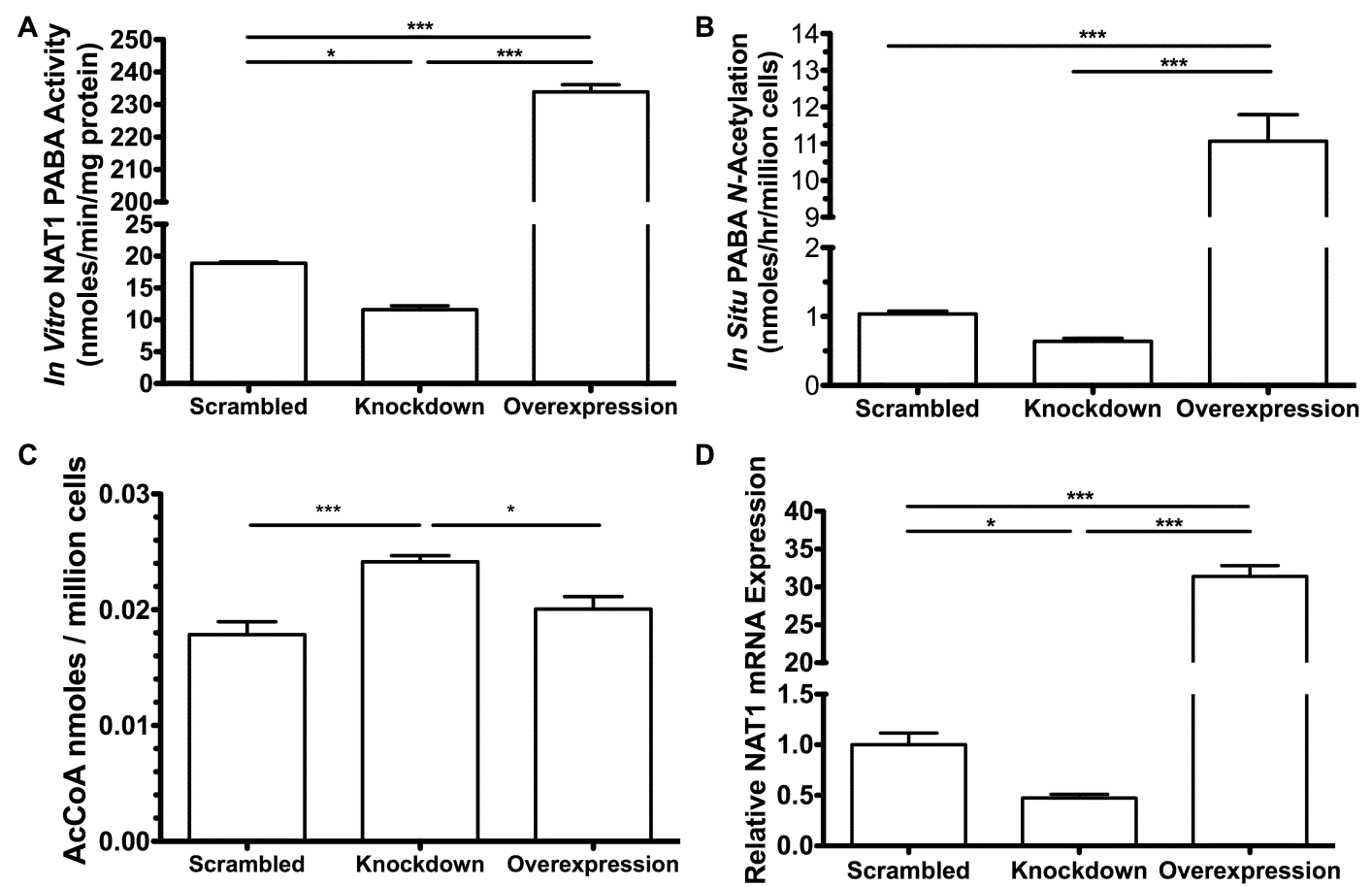

Figure 4.1. NAT1 catalytic activity and mRNA expression in stably modified MDA-MB-231 cell lines. Each bar illustrates mean \pm SEM. The in vitro PABA $N$ acetylation activity $(A)$ in cell line lysates $(N=3)$. The in situ PABA $N$-acetylation $(B)$ in cell lines cultured in PABA spiked media (N=4). The endogenous AcCoA levels $(\mathrm{C})$ for scrambled shRNA $(\mathrm{N}=8)$, NAT1 shRNA knockdown $(\mathrm{N}=7)$, and NAT1 overexpression ( $N=7$ ). NAT1 mRNA levels $(D)$ in cell lines normalized to scrambled shRNA cell line $(\mathrm{N}=3)$. Differences between cell lines were significantly different $\left({ }^{*} p \leq 0.05 ;{ }^{* * *} p \leq 0.001\right)$ following one-way ANOVA with a Bonferroni post-test. 


\section{Cell Growth}

The doubling times for the scrambled shRNA cell line, NAT1 knockdown cell line and NAT1 overexpression cell line were 27.4, 27.2 and 23.4 hours respectively (figure 4.2A). Neither the knockdown nor overexpression of NAT1 significantly $(p=0.26)$ affected the doubling time compared to the scrambled cell line.

Anchorage-Dependent Cell Growth, Anchorage-Independent Cell Growth, and Relative Invasive Ability

Neither the knockdown nor overexpression of NAT1 significantly affected anchorage-dependent growth (figure 4.2B). However, the knockdown of NAT1 caused a significant 7 -fold decrease $(p<0.0001)$ in anchorage-independent growth, whereas the overexpression of NAT1 had no significant effect (figure 4.2C). Neither knockdown of NAT1 with shRNA nor overexpression of NAT1 had a significant effect on relative invasive ability (figure 4.2D). 
A

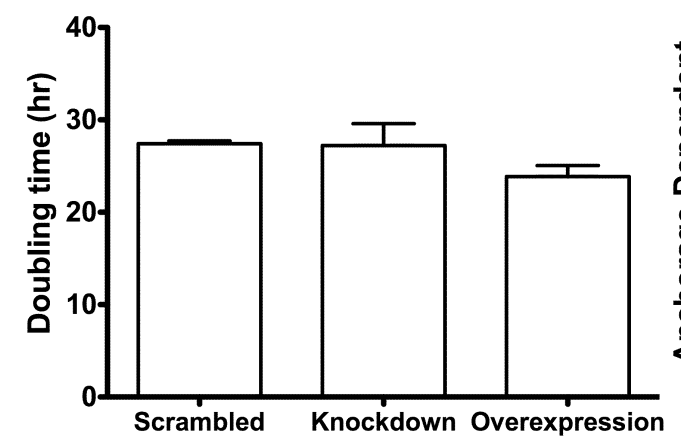

C

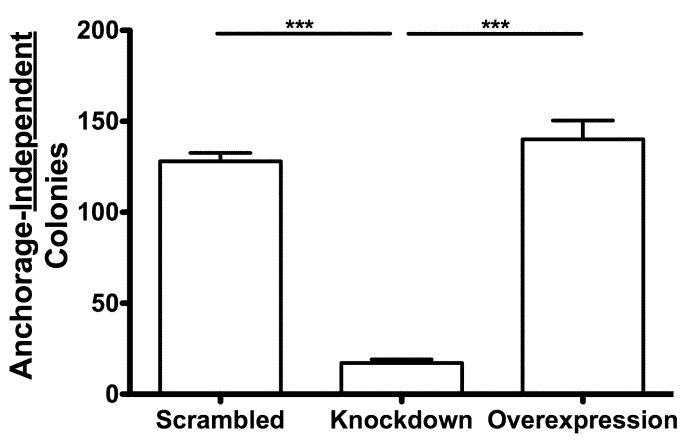

B

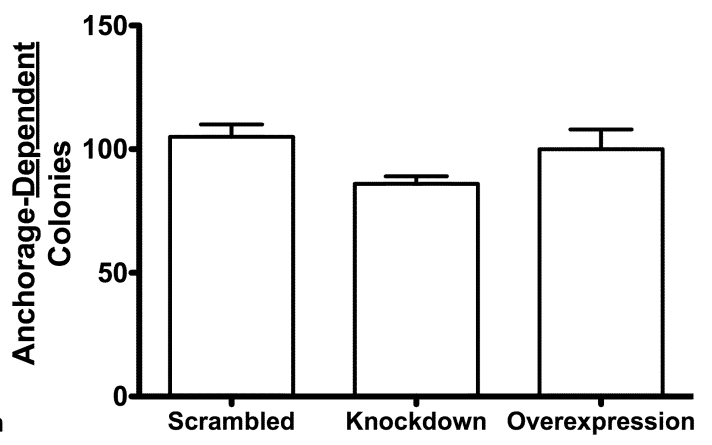

D

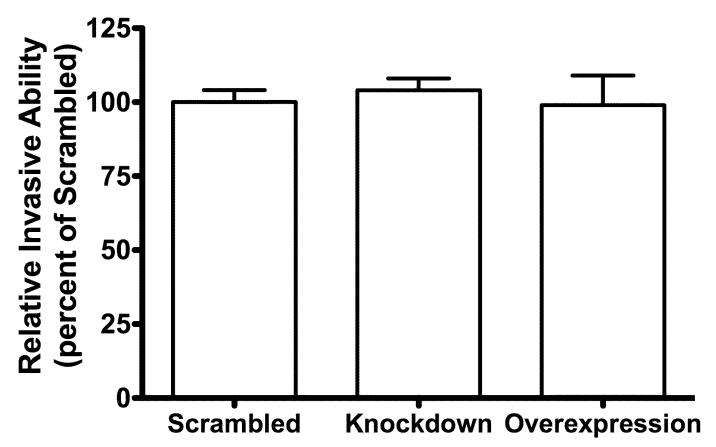

Figure 4.2. Cell growth properties in shRNA NAT1 knockdown and overexpression stably modified MDA-MB-231 cell lines. Each bar illustrates mean \pm SEM. Cell doubling times $(A)$ in the scrambled shRNA, NAT1 knockdown and NAT1 overexpression cell lines did not differ significantly following one-way ANOVA $(p>0.05)(N=3)$. The anchorage-dependent growth $(B)$ did not differ significantly among the scrambled shRNA, NAT1 knockdown and NAT1 overexpression cell lines following one-way ANOVA $(p>0.05)(N=3)$. The NAT1 knockdown cell line formed significantly less anchorage-independent colonies (C) compared to scrambled shRNA and NAT1 overexpressing cell lines following one-way ANOVA followed by a Bonferroni post-test $\left({ }^{* * *} p \leq 0.001\right)(N=3)$. No significant differences in relative invasion ability (D) among the scrambled shRNA, NAT1 knockdown and NAT1 overexpression cell lines were observed following one-way ANOVA $(p>0.05)(N=3)$. 
Effects of Small Molecule NAT1 Inhibitor on MDA-MB-231 Breast

\section{Cancer Cells}

To demonstrate that the effects of NAT1 knockdown on cell growth and invasion ability were due to reduced NAT1 activity, we tested the effects of a small molecule inhibitor of NAT1 that does not depend on decreased NAT1 expression for reduced NAT1 catalytic activity.

\section{N-acetylation In Situ}

5-HDST (figure 4.3A) reduced PABA $N$-acetylation in situ in a concentration-dependent manner $(p<0.0001)($ figure 4.3B). A single dose of 5 HDST reduced PABA $N$-acetylation in situ for at least 6-days (figure 4.3B). The $\mathrm{IC}_{50}$ for inhibition of PABA $N$-acetylation in situ on day 6 was $47.6 \pm 1.07 \mu \mathrm{M}$ (figure 4.3C).

\section{Cell Growth}

Cells exposed to concentrations of 5-HDST ranging from 0 to $50 \mu \mathrm{M}$ over a period of up to 6 days produced no significant effects on cell growth (figure 4.4A). Concentrations of 5 -HDST greater than $50 \mu \mathrm{M}$ caused a concentrationand time-dependent decrease in cell growth $(p<0.0001)$ (figure 4.4A). 
Anchorage-Dependent and -Independent Cell Growth, and Relative Invasive Ability

Incubation with 5-HDST reduced anchorage-dependent cell growth, but the effect was marginal below $50 \mu \mathrm{M}$ (figure 4.4B). Incubation with 5-HDST markedly reduced anchorage-independent cell growth at $12.5 \mu \mathrm{M}$ (figure 4.4C). Incubation with 5-HDST had no effect on relative invasion ability until concentrations of 5-HDST exceeded $75 \mu \mathrm{M}(p<0.05)$ (figure 4.4D). 


\section{FIGURE 4.3}

A

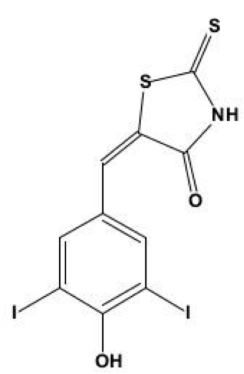

B

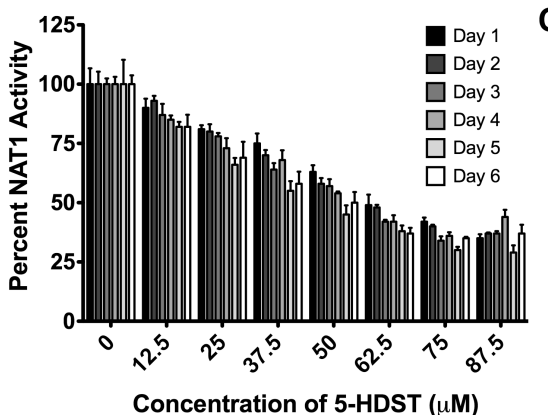

C

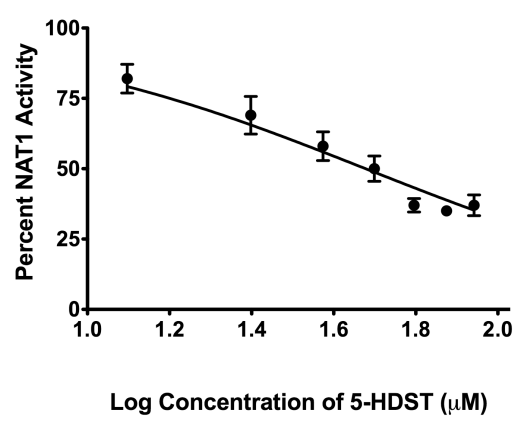

Figure 4.3. Effects of a small molecular inhibitor (5-HDST) on NAT1 activity. Chemical structure of 5-HDST (A). The percentage of NAT1 activity remaining after incubation with 0 to $87.5 \mu \mathrm{M} 5$-HDST $(\mathrm{B})$ for $1-6$ days $(\mathrm{N}=3)$. 5-HSDT inhibition of NAT1 activity curve $(\mathrm{C})$ used to calculate the $\mathrm{IC}_{50}$ for 5 -HSDT inhibition of NAT1 at day $6(\mathrm{~N}=3)$. The $\mathrm{IC}_{50}$ was $47.6 \pm 1.07 \mu \mathrm{M}$. 


\section{FIGURE 4.4}

A

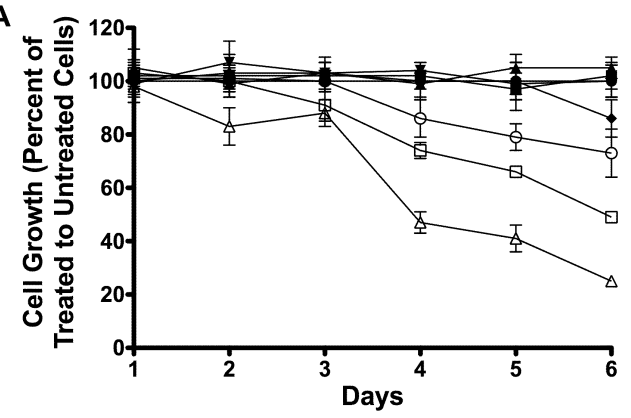

C

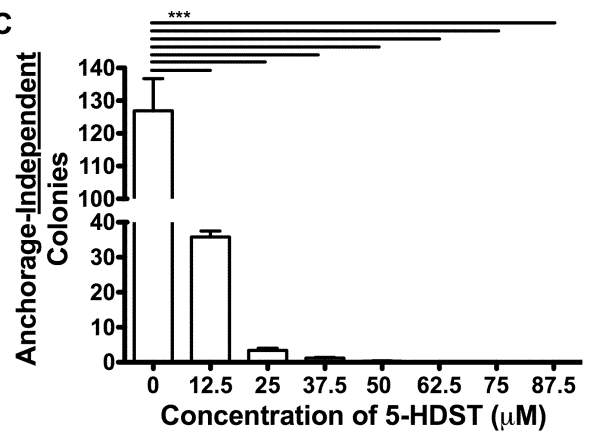

B
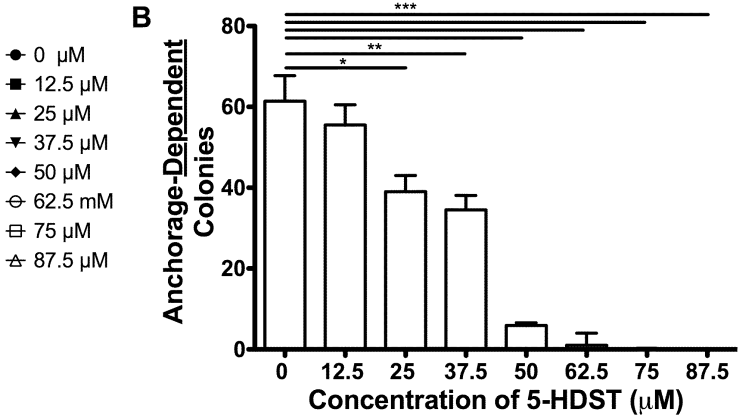

D

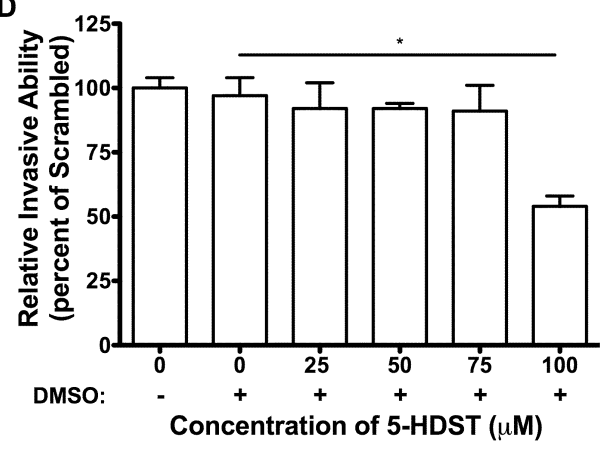

Figure 4.4. Cell growth properties of MDA-MB-231 cells incubated with 5-HDST. Bars/symbols represent means \pm SEM from three separate determinations performed in triplicate $(\mathrm{N}=3)$. Cell number (percent of vehicle) measured after incubation (1-6 days) with 5-HDST (A). Anchorage-dependent colongy formation following incubation with 5-HDST after 14 days (B). Anchorage-independent colony formation following incubation with 5-HDST after 14 days (C). Transwell assays to measure migratory ability of scrambled shRNA cell line incubated with 5-HDST (D). One-way ANOVA was conducted to compare relative invasion ability between groups $(p<0.05)$. The scrambled shRNA cell line incubated with $100 \mu \mathrm{M} 5$-HDST had significantly $(p<0.05)$ less invasion ability compared to scrambled shRNA cell line incubated with vehicle following one-way ANOVA and Bonferroni post-test $(p<0.05)$. 


\section{DISCUSSION}

Understanding how heterogeneity in gene expression affects cancer cell growth characteristics is very important. As outlined in the introduction, differences in human NAT1 expression have been reported to alter cancer cell growth properties. The goal of this study was to replicate previous findings and investigate further whether differences in human NAT1 expression affect breast cancer cell growth and metastatic properties. We knocked-down and overexpressed NAT1 using a FRT system (Life Technologies), which facilitates investigations of decreased or increased NAT1 expression independent of chromosomal position effects because all the expression cassettes were inserted into the same genomic location.

NAT1 knockdown using shRNA resulted in approximately $39 \%$ reduction in NAT1 in vitro catalytic activity, a comparable $35 \%$ increase in cellular AcCoA levels, and a 7-fold decrease in anchorage-independent growth compared to the scrambled shRNA cell line. However the NAT1 shRNA knockdown did not yield significant changes $(p>0.05)$ in cell doubling time, anchorage-dependent growth or relative invasion ability. Previous studies, using the same NAT1 shRNA knockdown plasmid in a colon adenocarcinoma cell line achieved an $80-90 \%$ knockdown of NAT1 [13] with significant changes in cell growth and invasion but only a $15 \%$ reduction in anchorage-independent cell growth. The differences observed between the present study and the previous NAT1 knockdown study 
[13] could be due to the different cell line used or the level of NAT1 knockdown. It is possible there is a threshold knockdown of NAT1 required to observe effects on cell growth and cell invasion that is tissue or cell-type specific.

Despite a 12-fold overexpression of NAT1 in vitro activity, significant $(p>0.05)$ changes in endogenous AcCoA levels, cell doubling time, anchoragedependent growth, anchorage-independent cell growth, or relative invasion ability were not observed. In contrast a previous study using HB4a cells reported that NAT1 overexpression resulted in enhanced growth properties [8]. The MDA-MB231 cells used in the present study are a claudin-low, triple-negative breast cancer cell line whereas the HB4a cell line is derived from normal luminal mammary epithelial cells. Thus, the lack of differences between scramble shRNA and NAT1 overexpression MDA-MB-231 cell lines may be a result of the cell line utilized.

Recent reports that NAT1 catalyzes the hydrolysis of AcCoA in the presence of folate suggests that NAT1 may affect endogenous levels of AcCoA [54]. Consistent with this concept, we found that partial NAT1 knockdown by $39 \%$ elevated endogenous AcCoA levels by $35 \%$ (figure 4.1C). Although this finding is consistent with AcCoA hydrolysis catalyzed by NAT1, it does not provide evidence this is the primary or sole mechanism for the elevation of AcCoA. Rat embryonic fibroblasts from rapid acetylator congenic rats have lower levels of AcCoA than rat embryonic fibroblasts derived from slow acetylator congenic rats 
[65]. Thus while a direct connection for physiological differences in AcCoA levels cannot be drawn to NAT1 AcCoA hydrolysis, accumulating data suggest that NAT1 may influence endogenous AcCoA levels. Differences in AcCoA levels could provide an explanation for differences in metabolites of fatty acid synthesis and amino acids [131]. The effects of NAT1 knockdown on anchorageindependent cell growth and endogenous AcCoA levels may provide insight into why congenic rapid NAT2 (ortholog to human NAT1) activity rats developed more mammary tumors than congenic slow NAT2 rats following administration of mammary carcinogens that are not metabolized by rat NAT2 [65].

A second objective of this study was to compare inhibition of NAT1 via a small molecule inhibitor to NAT1 knockdown using shRNA. We selected a small molecule inhibitor (5-HDST) similar to that identified and characterized previously [126]. The scrambled shRNA cell line was utilized as the control in both the small molecular inhibitor and shRNA knockdown experiments to facilitate this comparison.

5-HDST decreased the ability of the breast cancer cell line to $\mathrm{N}$-acetylate PABA in situ. Cell growth was reduced in a concentration dependent manner above $50 \mu \mathrm{M}$ (figure 4.4A). Our experiments did not provide evidence that the reduction in cell growth was solely caused by NAT1 inhibition; but did show that the concentration-dependent effects on NAT1 catalytic activity and cell growth were similar in trend on day six. In the scrambled shRNA cell line incubated with 
5-HDST, we observed a decrease in both anchorage-dependent and anchorageindependent cell growth. It is possible that the reduction in anchorage-dependent growth reflects cellular toxicity of the small molecule inhibitor. The reduction in anchorage-independent growth reflects a combination of cellular toxicity and ability of the 5-HDST to inhibit NAT1 and thereby reduce anchorage-independent growth in the breast cancer cell line MDA-MB-231.

The $\mathrm{IC}_{50}$ value for the small molecule inhibitor 5 -HDST was $47.6 \pm 1.07$ $\mu \mathrm{M}$ by in situ PABA $N$-acetylation inhibition assay. A previous study determined an $\mathrm{IC}_{50}$ value of $101 \pm 11 \mu \mathrm{M}$ for (Z)-5-(2-hydroxybenzylidene)-2thioxothiazolidin-4-one (Rhod-o-hp), which is structurally similar to 5-HDST, by an in situ PABA $\mathrm{N}$-acetylation inhibition assay [11]. The $\mathrm{IC}_{50}$ for 5 -HDST also was lower than the $\mathrm{IC}_{50}$ for both folate and $\mathrm{MTX}(76.9 \pm 1.05 \mu \mathrm{M}$ and $127 \pm 1.06 \mu \mathrm{M}$, respectively). Thus, 5-HDST was a more potent NAT1 inhibitor than folate, MTX, and Rhod-o-hp.

Previous studies using a different small molecule inhibitor of NAT1 in a different cell line reduced cell growth, relative invasion ability and anchorageindependent cell growth similar to those observed with NAT1 knockdown using shRNA $[11,13]$. We assessed relative invasion ability using a transwell assay and observed no change in the scrambled shRNA cell line treated with the small molecule inhibitor 5-HDST until the concentration exceeded $75 \mu \mathrm{M}$. 
Concentrations of 5-HDST as high as $87.5 \mu \mathrm{M}$ showed no effects on cell viability at the $24 \mathrm{hr}$ time point.

In summary, our findings compliment but do not fully replicate previous reports regarding the effect of NAT1 knockdown on cancer cell properties. In our studies, approximately $40 \%$ inhibition of NAT1-catalyzed N-acetylation in the MDA-MB-231 breast cancer cell line by either shRNA knockdown or 5-HDST resulted in a significant decrease in anchorage-independent growth without affecting overall cell growth and relative invasion ability. NAT1 shRNA partial knockdown increased endogenous AcCoA levels 35\% compared to the scrambled shRNA and NAT1 overexpression. The results of our study strongly confirm that further studies are needed. Rather than carrying out more extensive mechanistic studies on a cell line with a very modest NAT1 knock down (39\%), we are now utilizing a new model system, CRISPR/Cas9, that makes permanent deletions at the NAT1 gene open reading frame causing $100 \%$ knockout of NAT1. Use of this model, as discussed in the following chapter, has confirmed the findings of this study that further suggests that human NAT1 could serve as a target for the prevention and/or treatment of breast cancer. 


\section{CHAPTER V \\ CRISPR/CAS9 MEDIATED KNOCK OUT OF ARYLAMINE N- \\ ACETYLTRANSFERASE 1 (NAT1) IN HUMAN ADENOCARCINOMA BREAST \\ CANCER CELL LINES \\ INTRODUCTION}

Modifications of human NAT1 expression within a human cancer cell line have mostly either been to overexpress or to knockdown expression partially [8, 11, 13]. In order to obtain a complete knock out of cellular NAT1 activity CRISPR/ Cas9 was utilized to alter the genomic sequence of NAT1 within a cell. There are many benefits and some disadvantages in using this rapidly adopted experimental technique, however the end result is a novel genomic knockout for NAT1.

An initial publication from Ishino et al. in 1987 detailed an observation of a cluster of repeat sequences arranged with a spacer sequence, but stated the biological significance was unknown [132]. This sequence, with an unknown significance, would later be known as Clustered Regularly Interspaced Palindromic Repeats (CRISPR). In 2005, the spacer sequences were determined to be foreign in origin, and considered to play a role in the organism's adaptive defense system [133-135]. A major requirement was a group of CRISPR- 
associated (Cas) genes/enzymes. The Cas9 gene encodes an RNA guided nuclease that targets DNA introduced from phage infections.

Years of work from several groups resulted in understanding the mechanism by which the adaptive immunity works, and the functional ability of the system within mammalian cells. The mechanism for CRISPR/Cas9 activity involves a pair of RNAs that work together to target a specific sequence and a large multi-subunit endonuclease complex (Cas9) to cleave the non-host DNA. The two RNAs are: "crRNA" that is a processed spacer/repeat sequence and "tracrRNA" that shares a complementary region with "crRNA" $[136,137]$. When these separate RNA sequences bind together they are able to guide Cas9 to a specific target site encoded by the spacer sequence. Beside the complementary sequence to spacer sequence the DNA sequence must have a protospacer adjacent motif (PAM) follow the target site for the cleavage of DNA. The two RNA sequences "crRNA" and "tracrRNA" were simplified in 2012 by Jinek et al. when they showed that a chimeric transcript, was able to take Cas9 to the target sequence and cleave the DNA [138].

The Cas9/guide RNA (gRNA) complex interacts with complementary genomic DNA sequence, and this interaction causes the Cas9 to engage its twonuclease domains. The nuclease domains form a double strand break (DSB) about 3 nucleotides before the PAM site. The PAM site commonly used is 'NGG' from Streptococcus pyogenes Cas9 (SpCas9). This PAM site, which occurs 
frequently in the genome, generally imposes only minimal constraints on target site selection and gRNA design.

The cell's DNA repair pathways repair DNA DSB cleavage resulting from Cas9. Those DNA repair pathways are either homologous recombination (homology directed-repair (HDR)) or non-homologous end joining (NHEJ). HDR repairs a DSB precisely with the aid of a DNA template. While the cell is in cell cycle the sister chromatid would serve as the template, however an exogenous DNA sequence can allow for a new sequence to be introduced into the genomic DNA. The NHEJ is the main DSB repair pathway within most mammalian cells with the pathway being active in all phases of the cell cycle. As opposed to HDR, NHEJ does not require a homologous DNA sequence to direct the repair of the $\mathrm{DSB}$, and this difference often results in genomic insertions/deletions, termed indels, after NHEJ repair of DSB. Indels range in size, and if indels occur within the protein-coding region of a gene then a frameshift mutation can result. A frameshift mutation can produce an amino acid sequence that is terminated early. This type of frameshift mutation can effectively produce a knocking out of the gene.

To summarize, CRISPR/Cas9 system is composed of three parts. The first is the gRNA with a spacer sequence (like from a "crRNA") to target a DNA sequence and a sequence to complex with the Cas9 (like from a "tracrRNA"). Cas9 when guided by the gRNA uses the two nuclease-domains to form a DSB 
just before the PAM site. The PAM site is required for the CRISPR/Cas9 system to cleave the targeted DNA sequence. The relative simplicity of the mechanism explains the wide and rapid adoption of the technique.

The CRISPR/Cas9 system has some disadvantages that are often under represented. The precision of the Cas9 complex (in particular SpCas9) has been reported several times to cleave the genomic DNA in unintended sites [139-144]. Some gRNAs can act on more than 100 off-target sites [145]. These off target breaks have the potential to result in multiple mutations and genomic rearrangement, which could alter cellular properties different from that of the desired target of the Cas9 complex.

While groups around the world work to improve the precision of individual Cas9 complexes, the present study uses two separate gRNAs that target separate sequences within the early portion of the NAT1 gene. If an off-target event takes place with one gRNA then it will not likely happen in the other gRNA. In this scheme for a phenotype to be related to NAT1 knockout both gRNAs must display the same phenotype.

This study utilizes two human breast cancer cell lines MDA-MB-231 and MCF7. The cell lines originate from separate pleural effusions of different malignant breast cancer patients, and have been used for decades in breast cancer research. Claudin-low MDA-MB-231 are estrogen receptor negative, 
progesterone receptor negative, and HER2 negative. MDA-MB-231 cells also have little to no cohesion, and are stellate in structure. Luminal A MCF-7 cells are estrogen receptor positive, progesterone receptor positive, and HER2 negative. MCF7 cell line can form tightly cohesive structures, which show more cell-cell adhesions. In using two different cell lines, we are trying to establish if the knock out of NAT1 will show similar effects across different breast cancer classifications.

To understand better how knocking out NAT1 activity can affect cancer cell growth and invasion properties, this study utilized CRISPR/Cas9 technique with two unique gRNA sequences for the early portion of the 5' region of the open reading frame for NAT1 gene in human breast cancer cell lines MDA-MB231 and MCF7. 


\section{MATERIALS AND METHODS}

\section{Cell Line Generation and Culturing Conditions}

The cell lines utilized within this study were the MDA-MB-231 and MCF7 breast adenocarcinoma cell lines obtained from ATCC (Manassas, Virginia). Cells were cultured in DMEM media, high glucose with the addition of fetal bovine serum to $10 \%$ and glutamine to $2 \mathrm{mM}$. The cell lines were grown in a humidified incubator set at $37{ }^{\circ} \mathrm{C}$ with $5 \% \mathrm{CO}_{2}$. Horizon Discovery Group (Cambridge CB525 9TL, United Kingdom) designed the 5 different gRNAs for NAT1 and DNA2.0 Inc (Menio Park, CA) cloned the gRNAs into a Cas9 expressing vector expressing a dasher-GFP tag. Separately, each of the $5 \mathrm{gRNA}$ /Cas9 vectors were transiently transfected in MDA-MB-231 cells using the Amaxa Nucleofector II (Lonza, Allendale, NJ). Forty-eight hours after transfection cells were harvested and DNA isolated. We used the Transgenomic (Omaha, NE) SURVEYOR Mutation Detection Kit to determine the effectiveness of each gRNA's ability to cut the genomic and induce DNA strand breaks effectively. The gRNAs \#2 and \#5 were the most effective at inducing DNA strand breaks, and where chosen to separately knockout the function of NAT1 in the following studies.

MDA-MB-231 cells were transfected with either \#2 or \#5 gRNA /Cas9 vectors as above, and 48 hours after transfection cells were sorted for GFP fluorescence. MCF7 was transfected with either \#2 or \#5 gRNA /Cas9 with Lipofectamine 3000 (Invitrogen, California, USA), and 48 hours after 
transfections cells were sorted for GFP fluorescence. The fluorescent positive cells were collected, and plated at a very dilute cell concentration so that individual unique clones could be isolated. After several weeks individual cells grew into large enough colonies to utilize cloning cylinders to trypsin cells off the plate and transfer to a 96-well culture plate. Clones were passaged into a $10 \mathrm{~cm}$ dish and tested for NAT1 activity. A low number of clones with knockout of NAT1 activity were selected for further characterization. Knockout clones for NAT1 activity were screened by sequencing of the NAT1 open reading frame to find clones that had deleted/inserted nucleotides that resulted in a frame-shift mutation and early protein termination signals resulting in nonfunctional NAT1. The individual cloned knockout cell lines representing the knockout of NAT1 activity for either gRNA \#2 or \#5 were chosen based upon the measurement of NAT1 acetyltransferase activity and genomic sequence.

\section{Sequencing of the NAT1 Gene in the gRNAs \#2 and \#5 Knockout}

\section{Clones}

Genomic DNA was isolated from both MDA-MB-231 and MCF7 cloned knockout cell lines. The NAT1 open reading frame was TOPO cloned using pcDNA $^{\text {TM }}$ 3.1/N5-His TOPO® TA Expression Kit (Invitrogen, California, USA) following manufacture's recommendations. The TOPO Cloning reaction for the individual cell lines was transformed into One Shot TOP10 Chemically Competent E. coli. For each NAT1 knockout cell line, five transformed E. coli colonies were selected and grown overnight. Cultures of bacteria were then 
harvested for plasmid purification. Purified plasmids and primers were sent for DNA sequencing (Eurofins, Louisville, KY, USA). Sequence data was analyzed and aligned with SeqMan Pro ${ }^{\mathrm{TM}}$ (Version 12.0, DNASTAR, Madison, WI.)

\section{In Vitro and In Situ NAT1 N-acetyltransferase Assays}

In vitro assays using the NAT1 selective substrate para-aminobenzoic acid (PABA) were conducted and acetylated products were separated and quantitated as described [129]. Briefly, cells were scraped from the plate, washed in 1X phosphate-buffered saline (PBS), and lysed in $20 \mathrm{mM}$ sodium phosphate $\mathrm{pH} 7.4,1 \mathrm{mM}$ ethylenediaminetetraacetic acid (EDTA), 0.2\% triton X-100,, $1 \mathrm{mM}$ dithiothreitol (DTT), $100 \mu \mathrm{M}$ phenylmethanesulfonyl fluoride (PMSF), $1 \mu \mathrm{g} / \mathrm{ml}$ aprotinin, and $2 \mu \mathrm{M}$ pepstatin A. Cell lysate was centrifuged at $15,000 \times g$ for 10 min and supernatant tested for NAT1 activity. Enzymatic reactions containing 50 $\mu \mathrm{L}$ suitably diluted cell lysate, PABA $(300 \mu \mathrm{M})$ and acetyl coenzyme A (1 mM) were incubated at $37^{\circ} \mathrm{C}$ for $10 \mathrm{~min}$. Reactions were terminated by the addition of $1 / 10$ total reaction volume of $1 \mathrm{M}$ acetic acid and centrifuged at $15,000 \times g$ for 10 min. Three independent measurements $(\mathrm{N}=3)$ performed in triplicate were completed for each cell line.

Measurement of $\mathrm{N}$-acetylation in situ was determined by spiking media with a known concentration of PABA as described [130]. The cells were incubated at $37^{\circ} \mathrm{C}$ for $48 \mathrm{~h}$ with media containing $500 \mu \mathrm{M}$ PABA. Media were collected, and 1/10 total collected media volume of $1 \mathrm{M}$ acetic acid was added. 
Then the acidified media were centrifuged at $15,000 \times g$ for $10 \mathrm{~min}$. There were three independent measurements $(\mathrm{N}=3)$ for MDA-MB-231 and four independent measurements $(\mathrm{N}=4)$ for MCF7 all performed in triplicate.

Resulting supernatants from in vitro and in situ NAT1 activity assays were injected into a reverse phase C18 column (125 mm $\times 4 \mathrm{~mm} ; 5 \mu \mathrm{M}$ pore size). Reactants and products were eluted using a Beckman System Gold high performance liquid chromatography (HPLC) system. HPLC separation of $\mathrm{N}$ acetyl-PABA was achieved using a gradient of $96: 4$ sodium perchlorate $\mathrm{pH} 2.5$ : acetonitrile at $280 \mathrm{~nm}$. The data for scrambled shRNA, knockdown and overexpression cell lines are represented as mean \pm SEM and analyzed statistically by a one-way ANOVA and Bonferroni post hoc test.

\section{Endogenous Acetyl-Coenzyme A (AcCoA) Levels}

Endogenous AcCoA levels within modified MDA-MB-231 and MCF7 cancer cell lines were determined by HPLC-UV. Cell growth conditions were strictly monitored because it was observed that cellular confluence and period of growth affected the consistency of data obtained for the endogenous AcCoA concentrations. Cells were plated at $1 \times 10^{6}$ per $10 \mathrm{~cm}$ plate $(3$ plates per $\mathrm{N})$ with fresh complete culturing media with no selection antibiotic added, and allowed to grow for $72 \mathrm{~h}$. After $72 \mathrm{~h}$, the cells were $70 \%$ confluent and collected. Media were aspirated from the plates, and each plate was washed with $5 \mathrm{ml}$ PBS. Then cells were dissociated from the plate with $0.5 \mathrm{ml}$ trypsin $[0.25 \%(\mathrm{w} / \mathrm{v})]$. Cells were 
suspended in $4 \mathrm{ml}$ of diluted complete media (20\% medium and $80 \%$ PBS) and counted in $0.5 \mathrm{ml}$ aliquots. In the subsequent steps all cells and lysates were kept on ice or at $4^{\circ} \mathrm{C}$. Collected cells were centrifuged, supernatant removed, and ice-cold PBS was added. Again, cells were centrifuged, supernatant removed, suspended in $1 \mathrm{ml}$ of ice-cold PBS, and transferred to $1.5 \mathrm{ml}$ microcentrifuge tubes. The suspended cells were collected by centrifugation and the supernatants discarded. Having removed any residual PBS, the cells were lysed in $100 \mu \mathrm{L}$ ice-cold 5\% 5-sulfosalicylic acid with a $1 \mathrm{ml} \mathrm{BD}$ Insulin Syringe with permanently attached 28 gauge needle (BD Franklin Lakes, NJ, USA). The needle selection is important to insure complete cell lysis without loss of volume or cellular masses within the syringe/needle. The cellular lysate was then centrifuged at $13,000 \times g$ for $10 \mathrm{~min}$. Supernatant was filtered through a syringe filter (13 mm, $0.20 \mu \mathrm{m}$ pore size). Filtrate was collected and separated on a C18 reverse-phase HPLC column $(250 \mathrm{~mm} \times 4 \mathrm{~mm} ; 5 \mu \mathrm{m}$ pore size $)$. HPLC separation and quantitation of AcCoA was achieved using a linear gradient of 100\% $55 \mathrm{mM}$ sodium phosphate $\mathrm{pH} 4.0$ : $0 \%$ methanol to $0 \% 55 \mathrm{mM}$ sodium phosphate $\mathrm{pH}$ 4.0: $100 \%$ methanol over $20 \mathrm{~min}$ and was quantitated by absorbance at $260 \mathrm{~nm}$. The data for individual determinations of CRISPR clones are represented as mean \pm SEM with eight independent measurements $(\mathrm{N}=8)$ for MDA-MB-231 and twelve independent measurements $(\mathrm{N}=12)$ for MCF7. Data were analyzed by a one-way ANOVA and Bonferroni post test. 


\section{Determination of Doubling Time}

Twenty-five thousand cells were plated in triplicate in 6-well plates and allowed to grow for 5 consecutive days. Cells were plated on day 1 and allowed to equilibrate for $24 \mathrm{~h}$ before making the first count on day 2 followed by counts on days 3, 4, 5 and 6 using a cell counter. A cell doubling rate was calculated for each day using Equation 1 (shown below) and then rates were averaged over the 5 day time period to get a final cell doubling rate.

Equation 1: Cell Doubling Rate $=1 /\left(((\log (b)-\log (a)) \times 3.32) /\left(t_{b}-t_{a}\right)\right)$

In the equation, $\mathrm{b}=$ cell number on day $\mathrm{n}, \mathrm{a}=$ cell number on day $\mathrm{n}-1, \mathrm{t}_{\mathrm{b}}=$ hours passed since plating when cells were counted on day $\mathrm{n}$, and $\mathrm{t}_{\mathrm{a}}=$ hours passed since plating when cells were counted on day $n-1$. This assay was performed in triplicate for each cell line $(\mathrm{N}=3)$. The data for the cell lines are represented as mean \pm SEM from three separate determinations performed in triplicate, and were analyzed statistically by a one-way ANOVA and Bonferroni post hoc test.

\section{Anchorage-Dependent and Anchorage-Independent Growth Assay}

Anchorage-dependent growth assays were performed by plating cells ( 300 cells/well) in triplicate in 6-well plates and allowing them to grow for 2 weeks. Colonies were counted following staining with crystal violet. The data are represented as means \pm SEM from six independent measurements $(N=6)$ for 
MDA-MB-231 and seven independent measurements $(\mathrm{N}=7)$ for MCF7 all performed in triplicate, and were analyzed statistically by a one-way ANOVA and Bonferroni post test.

The anchorage-independent growth assays were performed by plating the cells in low-melting temperature agarose. The cells were grown in normal growth media where the bottom layer was $1.5 \mathrm{ml}$ (noble agar, $0.5 \%$ ) and the top layer was $1.5 \mathrm{ml}$ (low-melting temperature agarose, $0.3 \%$ ), so the total volume was 3 $\mathrm{ml}$ in each well of a 6 well plate. Cells (6000 cells/well) were plated in triplicate in 6-well plates and grown for 2 weeks. Colonies were counted following staining with crystal violet. Three independent measurements $(\mathrm{N}=3)$ for MDA-MB-231 and four independent measurements $(\mathrm{N}=4)$ for MCF7 performed in triplicate were completed for each assay. The data are represented as means \pm SEM and were analyzed statistically by a one-way ANOVA and Bonferroni post hoc test.

\section{Anoikis Assay and Hanging Drop Assay}

The anoikis assay required the wells of 96 -well plates to be coated with a polymer known as poly-HEMA (Sigma). The poly-HEMA powder was dissolved in $95 \%$ ethanol at a concentration of $50 \mathrm{mg} / \mathrm{ml}$ to generate a stock solution. The working solution for poly-HEMA was made by diluting the $50 \mathrm{mg} / \mathrm{ml}$ stock at a $1: 10$ ratio in $100 \%$ ethanol to a final concentration of $5.0 \mathrm{mg} / \mathrm{ml}$. The wells of 96 well plates were coated with two layers of poly-HEMA, and the plates were dried overnight between each coating. Each experimental well, with or without poly- 
HEMA coating, was given $4.0 \times 10^{3}$ MDA-MB-231 cells in $100 \mu \mathrm{L}$ of complete media. Controls wells with or without poly-HEMA coating had no cells included. Cells were incubated overnight before recording the 0 hour reading. Number of cells within each well was quantified by AlmarBlue ${ }^{\circledR}$ cell quantitation assay. Briefly, each well received $10 \mu \mathrm{L}$ of AlmarBlue ${ }^{\circledR}$ and incubated for an additional 3 hours, and then fluorescence read on a plate reader for 0 to 96 hours measured at 24 hour time points. Three separate determinations performed in triplicate were made $(\mathrm{N}=3)$. The data are represented as means $\pm \mathrm{SEM}$, and were analyzed statistically by two-way ANOVA and Bonferroni post hoc test.

Hanging drop assay was performed by suspending $12.5 \mu \mathrm{l}$ complete culture media droplets containing 5000 MDA-MB-231 cells onto the inner surface of the lid of a $10 \mathrm{~cm}$ culture dish. Ten $\mathrm{ml}$ of PBS was placed into the dish to prevent evaporation of the hanging droplets. Cells within four individual droplets were counted by trypan blue exclusion for the number of dead cells compared to the number of live cells per individual determination $(N)$. The time points were 24 , 48 and 72 hours. Seven separate determinations performed in quadruplicate were made $(\mathrm{N}=7)$. The data are represented as means $\pm \mathrm{SEM}$, and were analyzed statistically by two-way ANOVA and Bonferroni post hoc test.

\section{Transwell Assays to Assess Relative Invasive Ability}

The inserts of permeable Transwell wells were either coated with or without $100 \mu \mathrm{l}$ of $0.5 \mathrm{mg} / \mathrm{ml}$ Matrigel (Life Technologies), and the Matrigel was 
allowed to solidify for $2 \mathrm{~h}$ at $37^{\circ} \mathrm{C}$. Upper chambers of the transwells were seeded with either $2.5 \times 10^{4}$ or $5 \times 10^{4}$ MDA-MB-231 cells in $100 \mu$ of media containing $0 \%$ FBS. The bottom chamber of the transwells contained $600 \mu \mathrm{L}$ of complete media. Cells were incubated at $37^{\circ} \mathrm{C}$ with $5 \% \mathrm{CO}_{2}$ and allowed to invade across the Matrigel for $24 \mathrm{~h}$. After incubation, cells on the topside of the transwell membrane were removed with a sterile cotton swab. Cells that invaded across the membrane were counted utilizing crystal violet staining. Four separate determinations performed in duplicate were made $(\mathrm{N}=4)$. The data are represented as means \pm SEM, and were analyzed statistically by one-way ANOVA and Bonferroni post hoc test.

\section{In Vitro Wound-Closure Assay}

The method is based on the previous protocol published by Peterson et al. in 2014 [146]. Silicone elastomer base (Sylgard 184 Elastomer; Dow Corning, Midland, MI, USA) was prepared per manufacturer's directions. A 2-mm biopsy punch was used to create five silicone plugs/well. The plugs were placed directly on the bottom of a 6-well plate. MDA-MB-231 and gRNA \#2 and \#5 clones were plated at a concentration of 600,000 cells/well and incubated for 48 hours so that the cells are confluent around the plugs. Plugs were removed to create a 2-mm diameter area and the remaining cells were washed twice with PBS. The cell free area created by the plug was photographed each day. The area free of cells was quantified for each time point using ImageJ software_(http://imagej.nih.gov/ij/; provided in the public domain by the National Institutes of Health (Bethesda, MD, 
USA) [147]. Data were plotted as the percentage of the initial area that was covered (wound closure) for each time point. Each data point represents means \pm SEM for three separate determinations performed in triplicate $(\mathrm{N}=3)$.

\section{Subcutaneous Xenograft of MDA-MB-231 Cells}

NOD-Rag1 ${ }^{\text {null }} \| 2 \mathrm{rg}^{\text {null }}(\mathrm{NRG})$ mice, provided by Dr. Levi Beverly's laboratory, were housed in the University of Louisville animal facility and the experiment was reviewed and approved by the University's Institutional Animal Care and Use Committee. The parental $(\mathrm{N}=10)$ and knockout $(\mathrm{N}=5$ for each knockout cell line) MDA-MB-231 cell lines $\left(1 \quad X \quad 10^{6}\right)$ were injected subcutaneously into the right or left flank, respectively, of 18 week old female NRG mice. Tumors where collected after six weeks, and weighed before being flash frozen. The data are represented as means \pm SEM, and were analyzed statistically by one-way ANOVA and Bonferroni post hoc test. 


\section{RESULTS}

\section{NAT1 Genomic and Amino Acid Sequence}

Sequencing for MDA-MB-231 cell lines characterized gRNA \#2 (clone 219) knockout cell line with a deletion in the open reading frame, which is the deletion of a cytosine nucleotide at base 96 of $870 \mathrm{bp}$ (table 5.1). This single nucleotide deletion resulted in a frameshift causing a premature stop codon after amino acid 49 of 290 (table 5.2). The gRNA \#5 (clone 5-50) knockout cell line had two nucleotides deleted at 43 and 44 bp downstream of the start codon (table 5.1). This deletion resulted in a premature stop codon after amino acid codon 14 of 290, which immediately terminates translation of NAT1 (table 5.2).

Sequencing results for MCF7 show that gRNA \#2 (clone 2-4) knockout cell line has a 34 bp deletion in the open reading frame, which spans from 95 to 129 bp (table 5.3). This deleted segment of DNA resulted in a frameshift causing a premature stop codon after 38 amino acids (table 5.4). The gRNA \#5 (clone 520) knockout cell line had two separate deletions. The first deletion was a single nucleotide deletion at bp 42 , and the other was a deletion of bp 43 to bp 48 with an adenine insertion in the same region (table 5.3). These indel deletions resulted in a premature stop codon after amino acid codon 23 for both sequences (table 5.4). 
Table 5.1 - Genomic sequence for the NAT1 gene in MDA-MB-231 Parental and NAT1 knockout clones

\begin{tabular}{|l|l|l|l|}
\hline Cell line & bp \# & Genomic Sequence & bp\# \\
\hline Parental & 76 & GACATTCTTCAACACCAGATCCGAGCTGTT & 105 \\
\hline gRNA \#2 clone & 76 & GACATTCTTCAACACCAGATC-GAGCTGTT & 105 \\
\hline Parental & 21 & TGAAAGAATTGGCTATAAGAAGTCTAGGAA & 50 \\
\hline gRNA \#5 clone & 21 & TGAAAGAATTGGCTATAAGAAG--TAGGAA & 50 \\
\hline
\end{tabular}


Table 5.2 - Resulting Amino Acid Sequence for MDA-MB-231 Parental and NAT1 knockout clones

\begin{tabular}{|c|c|c|}
\hline Cell line & Amino Acid Sequence & $\#$ of $A A$ \\
\hline Parental & $\begin{array}{llllllllllllllllllllllllllll}M & \mathrm{D} & I & \mathrm{E} & \mathrm{A} & \mathrm{Y} & \mathrm{L} & \mathrm{E} & \mathrm{R} & \mathrm{I} & \mathrm{G} & \mathrm{Y} & \mathrm{K} & \mathrm{K} & \mathrm{S} & \mathrm{R} & \mathrm{N} & \mathrm{K} & \mathrm{L} & \mathrm{D} & \mathrm{L} & \mathrm{E} & \mathrm{T} & \mathrm{L} & \mathrm{T} & \mathrm{D} & \mathrm{I} & \mathrm{L} \\
\mathrm{Q} & \mathrm{H} & \mathrm{Q} & \mathrm{I} & \mathrm{R} & \mathrm{A} & \mathrm{V} & \mathrm{P} & \mathrm{F} & \mathrm{E} & \mathrm{N} & \mathrm{L} & \mathrm{N} & \mathrm{I} & \mathrm{H} & \mathrm{C} & \mathrm{G} & \mathrm{D} & \mathrm{A} & \mathrm{M} & \mathrm{D} & \mathrm{L} & \mathrm{G} & \mathrm{L} & \mathrm{E} & \mathrm{A} & \mathrm{I} & \mathrm{F} \\
\mathrm{D} & \mathrm{Q} & \mathrm{V} & \mathrm{V} & \mathrm{R} & \mathrm{R} & \mathrm{N} & \mathrm{R} & \mathrm{G} & \mathrm{G} & \mathrm{W} & \mathrm{C} & \mathrm{L} & \mathrm{Q} & \mathrm{V} & \mathrm{N} & \mathrm{H} & \mathrm{L} & \mathrm{L} & \mathrm{Y} & \mathrm{W} & \mathrm{A} & \mathrm{L} & \mathrm{T} & \mathrm{T} & \mathrm{I} & \mathrm{G} & \mathrm{F} \\
\mathrm{E} & \mathrm{T} & \mathrm{T} & \mathrm{M} & \mathrm{L} & \mathrm{G} & \mathrm{G} & \mathrm{Y} & \mathrm{V} & \mathrm{Y} & \mathrm{S} & \mathrm{T} & \mathrm{P} & \mathrm{A} & \mathrm{K} & \mathrm{K} & \mathrm{Y} & \mathrm{S} & \mathrm{T} & \mathrm{G} & \mathrm{M} & \mathrm{I} & \mathrm{H} & \mathrm{L} & \mathrm{L} & \mathrm{L} & \mathrm{Q} & \mathrm{V} \\
\mathrm{T} & \mathrm{I} & \mathrm{D} & \mathrm{G} & \mathrm{R} & \mathrm{N} & \mathrm{Y} & \mathrm{I} & \mathrm{V} & \mathrm{D} & \mathrm{A} & \mathrm{G} & \mathrm{F} & \mathrm{G} & \mathrm{R} & \mathrm{S} & \mathrm{Y} & \mathrm{Q} & \mathrm{M} & \mathrm{W} & \mathrm{Q} & \mathrm{P} & \mathrm{L} & \mathrm{E} & \mathrm{L} & \mathrm{I} & \mathrm{S} & \mathrm{G} \\
\mathrm{K} & \mathrm{D} & \mathrm{Q} & \mathrm{P} & \mathrm{Q} & \mathrm{V} & \mathrm{P} & \mathrm{C} & \mathrm{I} & \mathrm{F} & \mathrm{R} & \mathrm{L} & \mathrm{T} & \mathrm{E} & \mathrm{E} & \mathrm{N} & \mathrm{G} & \mathrm{F} & \mathrm{W} & \mathrm{Y} & \mathrm{L} & \mathrm{D} & \mathrm{Q} & \mathrm{I} & \mathrm{R} & \mathrm{R} & \mathrm{E} & \mathrm{Q} \\
\mathrm{Y} & \mathrm{I} & \mathrm{P} & \mathrm{N} & \mathrm{E} & \mathrm{E} & \mathrm{F} & \mathrm{L} & \mathrm{H} & \mathrm{S} & \mathrm{D} & \mathrm{L} & \mathrm{L} & \mathrm{E} & \mathrm{D} & \mathrm{S} & \mathrm{K} & \mathrm{Y} & \mathrm{R} & \mathrm{K} & \mathrm{I} & \mathrm{Y} & \mathrm{S} & \mathrm{F} & \mathrm{T} & \mathrm{L} & \mathrm{K} & \mathrm{P} \\
\mathrm{R} & \mathrm{T} & \mathrm{I} & \mathrm{E} & \mathrm{D} & \mathrm{F} & \mathrm{E} & \mathrm{S} & \mathrm{M} & \mathrm{N} & \mathrm{T} & \mathrm{Y} & \mathrm{L} & \mathrm{Q} & \mathrm{T} & \mathrm{S} & \mathrm{P} & \mathrm{A} & \mathrm{S} & \mathrm{V} & \mathrm{F} & \mathrm{T} & \mathrm{S} & \mathrm{K} & \mathrm{S} & \mathrm{F} & \mathrm{C} & \mathrm{S} \\
\mathrm{L} & \mathrm{Q} & \mathrm{T} & \mathrm{P} & \mathrm{D} & \mathrm{G} & \mathrm{V} & \mathrm{H} & \mathrm{C} & \mathrm{L} & \mathrm{V} & \mathrm{G} & \mathrm{F} & \mathrm{T} & \mathrm{L} & \mathrm{T} & \mathrm{H} & \mathrm{R} & \mathrm{R} & \mathrm{F} & \mathrm{N} & \mathrm{Y} & \mathrm{K} & \mathrm{D} & \mathrm{N} & \mathrm{T} & \mathrm{D} & \mathrm{L} \\
\mathrm{I} & \mathrm{E} & \mathrm{F} & \mathrm{K} & \mathrm{T} & \mathrm{L} & \mathrm{S} & \mathrm{E} & \mathrm{E} & \mathrm{E} & \mathrm{I} & \mathrm{E} & \mathrm{K} & \mathrm{V} & \mathrm{L} & \mathrm{K} & \mathrm{N} & \mathrm{I} & \mathrm{F} & \mathrm{N} & \mathrm{I} & \mathrm{S} & \mathrm{L} & \mathrm{Q} & \mathrm{R} & \mathrm{K} & \mathrm{L} & \mathrm{V} \\
\mathrm{P} & \mathrm{K} & \mathrm{H} & \mathrm{G} & \mathrm{D} & \mathrm{R} & \mathrm{F} & \mathrm{F} & \mathrm{T} & \mathrm{I} & \mathrm{St} & \mathrm{SP} & & & & & & & & & & & & & & & \end{array}$ & 290 \\
\hline $\begin{array}{l}\text { gRNA \#2 } \\
\text { clone }\end{array}$ & $\begin{array}{llllllllllllllllllllllllllll}M & D & I & E & A & Y & L & E & R & I & G & Y & K & K & S & R & N & K & L & D & L & E & T & L & T & D & I & L \\
Q & H & Q & I & E & L & F & P & L & R & T & L & T & S & I & V & G & M & P & W & T & S t & 0 p & & & & \end{array}$ & 49 \\
\hline $\begin{array}{l}\text { gRNA \# } 5 \\
\text { clone }\end{array}$ & M D I $E$ A $\quad Y$ L E $E$ R I G $Y$ K K Stop & 14 \\
\hline
\end{tabular}


Table 5.3 - Genomic sequence for the NAT1 gene in MCF7 Parental and NAT1 knockout clones

\begin{tabular}{|l|l|l|l|}
\hline Cell line & bp \# & Genomic Sequence & bp\# \\
\hline Parental & 91 & CAGATCCGAGCTGTTCCCTTTGAGAACCTTAACATCCATTGTGGG & 135 \\
\hline $\begin{array}{l}\text { gRNA \#2 } \\
\text { clone }\end{array}$ & 91 & CAGAT-----------------------TGTGGG & 135 \\
\hline Parental & 31 & GGCTATAAGAAGTCTAGGAACAAATTGGAC & 60 \\
\hline $\begin{array}{l}\text { gRNA \#5 } \\
\text { lone }\end{array}$ & 31 & GGCTATAAGAA-TCTAGGAACAAATTGGAC & 60 \\
\hline $\begin{array}{l}\text { gRNA \#5 } \\
\text { clone }\end{array}$ & 31 & GGCTATAAGAAGA-----AACAAATTGGAC & 60 \\
\hline
\end{tabular}


Table 5.4 - Resulting Amino Acid Sequence for MCF7 Parental and NAT1 knockout clones

\begin{tabular}{|c|c|c|}
\hline Cell line & Amino Acid Sequence & $\#$ of $A A$ \\
\hline Parental & $\begin{array}{llllllllllllllllllllllllllll}M & \mathrm{D} & I & \mathrm{E} & \mathrm{A} & \mathrm{Y} & \mathrm{L} & \mathrm{E} & \mathrm{R} & \mathrm{I} & \mathrm{G} & \mathrm{Y} & \mathrm{K} & \mathrm{K} & \mathrm{S} & \mathrm{R} & \mathrm{N} & \mathrm{K} & \mathrm{L} & \mathrm{D} & \mathrm{L} & \mathrm{E} & \mathrm{T} & \mathrm{L} & \mathrm{T} & \mathrm{D} & \mathrm{I} & \mathrm{L} \\
\mathrm{Q} & \mathrm{H} & \mathrm{Q} & \mathrm{I} & \mathrm{R} & \mathrm{A} & \mathrm{V} & \mathrm{P} & \mathrm{F} & \mathrm{E} & \mathrm{N} & \mathrm{L} & \mathrm{N} & \mathrm{I} & \mathrm{H} & \mathrm{C} & \mathrm{G} & \mathrm{D} & \mathrm{A} & \mathrm{M} & \mathrm{D} & \mathrm{L} & \mathrm{G} & \mathrm{L} & \mathrm{E} & \mathrm{A} & \mathrm{I} & \mathrm{F} \\
\mathrm{D} & \mathrm{Q} & \mathrm{V} & \mathrm{V} & \mathrm{R} & \mathrm{R} & \mathrm{N} & \mathrm{R} & \mathrm{G} & \mathrm{G} & \mathrm{W} & \mathrm{C} & \mathrm{L} & \mathrm{Q} & \mathrm{V} & \mathrm{N} & \mathrm{H} & \mathrm{L} & \mathrm{L} & \mathrm{Y} & \mathrm{W} & \mathrm{A} & \mathrm{L} & \mathrm{T} & \mathrm{T} & \mathrm{I} & \mathrm{G} & \mathrm{F} \\
\mathrm{E} & \mathrm{T} & \mathrm{T} & \mathrm{M} & \mathrm{L} & \mathrm{G} & \mathrm{G} & \mathrm{Y} & \mathrm{V} & \mathrm{Y} & \mathrm{S} & \mathrm{T} & \mathrm{P} & \mathrm{A} & \mathrm{K} & \mathrm{K} & \mathrm{Y} & \mathrm{S} & \mathrm{T} & \mathrm{G} & \mathrm{M} & \mathrm{I} & \mathrm{H} & \mathrm{L} & \mathrm{L} & \mathrm{L} & \mathrm{Q} & \mathrm{V} \\
\mathrm{T} & \mathrm{I} & \mathrm{D} & \mathrm{G} & \mathrm{R} & \mathrm{N} & \mathrm{Y} & \mathrm{I} & \mathrm{V} & \mathrm{D} & \mathrm{A} & \mathrm{G} & \mathrm{F} & \mathrm{G} & \mathrm{R} & \mathrm{S} & \mathrm{Y} & \mathrm{Q} & \mathrm{M} & \mathrm{W} & \mathrm{Q} & \mathrm{P} & \mathrm{L} & \mathrm{E} & \mathrm{L} & \mathrm{I} & \mathrm{S} & \mathrm{G} \\
\mathrm{K} & \mathrm{D} & \mathrm{Q} & \mathrm{P} & \mathrm{Q} & \mathrm{V} & \mathrm{P} & \mathrm{C} & \mathrm{I} & \mathrm{F} & \mathrm{R} & \mathrm{L} & \mathrm{T} & \mathrm{E} & \mathrm{E} & \mathrm{N} & \mathrm{G} & \mathrm{F} & \mathrm{W} & \mathrm{Y} & \mathrm{L} & \mathrm{D} & \mathrm{Q} & \mathrm{I} & \mathrm{R} & \mathrm{R} & \mathrm{E} & \mathrm{Q} \\
\mathrm{Y} & \mathrm{I} & \mathrm{P} & \mathrm{N} & \mathrm{E} & \mathrm{E} & \mathrm{F} & \mathrm{L} & \mathrm{H} & \mathrm{S} & \mathrm{D} & \mathrm{L} & \mathrm{L} & \mathrm{E} & \mathrm{D} & \mathrm{S} & \mathrm{K} & \mathrm{Y} & \mathrm{R} & \mathrm{K} & \mathrm{I} & \mathrm{Y} & \mathrm{S} & \mathrm{F} & \mathrm{T} & \mathrm{L} & \mathrm{K} & \mathrm{P} \\
\mathrm{R} & \mathrm{T} & \mathrm{I} & \mathrm{E} & \mathrm{D} & \mathrm{F} & \mathrm{E} & \mathrm{S} & \mathrm{M} & \mathrm{N} & \mathrm{T} & \mathrm{Y} & \mathrm{L} & \mathrm{Q} & \mathrm{T} & \mathrm{S} & \mathrm{P} & \mathrm{A} & \mathrm{S} & \mathrm{V} & \mathrm{F} & \mathrm{T} & \mathrm{S} & \mathrm{K} & \mathrm{S} & \mathrm{F} & \mathrm{C} & \mathrm{S} \\
\mathrm{L} & \mathrm{Q} & \mathrm{T} & \mathrm{P} & \mathrm{D} & \mathrm{G} & \mathrm{V} & \mathrm{H} & \mathrm{C} & \mathrm{L} & \mathrm{V} & \mathrm{G} & \mathrm{F} & \mathrm{T} & \mathrm{L} & \mathrm{T} & \mathrm{H} & \mathrm{R} & \mathrm{R} & \mathrm{F} & \mathrm{N} & \mathrm{Y} & \mathrm{K} & \mathrm{D} & \mathrm{N} & \mathrm{T} & \mathrm{D} & \mathrm{L} \\
\mathrm{I} & \mathrm{E} & \mathrm{F} & \mathrm{K} & \mathrm{T} & \mathrm{L} & \mathrm{S} & \mathrm{E} & \mathrm{E} & \mathrm{E} & \mathrm{I} & \mathrm{E} & \mathrm{K} & \mathrm{V} & \mathrm{L} & \mathrm{K} & \mathrm{N} & \mathrm{I} & \mathrm{F} & \mathrm{N} & \mathrm{I} & \mathrm{S} & \mathrm{L} & \mathrm{Q} & \mathrm{R} & \mathrm{K} & \mathrm{L} & \mathrm{V} \\
\mathrm{P} & \mathrm{K} & \mathrm{H} & \mathrm{G} & \mathrm{D} & \mathrm{R} & \mathrm{F} & \mathrm{F} & \mathrm{T} & \mathrm{I} & \mathrm{St} & \mathrm{S} & & & & & & & & & & & & & & & \end{array}$ & 290 \\
\hline $\begin{array}{l}\text { gRNA \#2 } \\
\text { clone }\end{array}$ & $\begin{array}{lllllllllllllllllllllllllllll}M & D & I & E & A & Y & L & E & R & I & G & Y & K & K & S & R & N & K & L & D & L & E & T & L & T & D & I & L \\
Q & H & Q & I & V & G & M & P & W & T & S t & 0 p & & & & & & & & & & & & & & \end{array}$ & 38 \\
\hline $\begin{array}{l}\text { gRNA \#5 } \\
\text { clone }\end{array}$ & 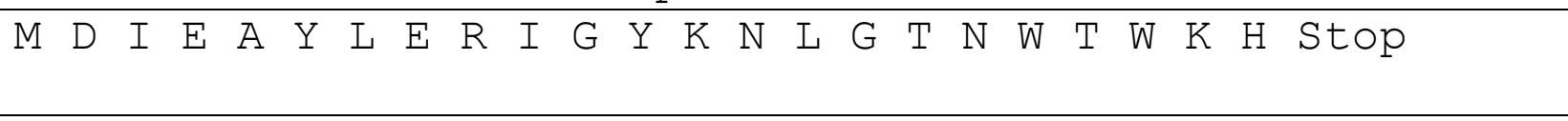 & 23 \\
\hline $\begin{array}{l}\text { gRNA \# } 5 \\
\text { clone }\end{array}$ & 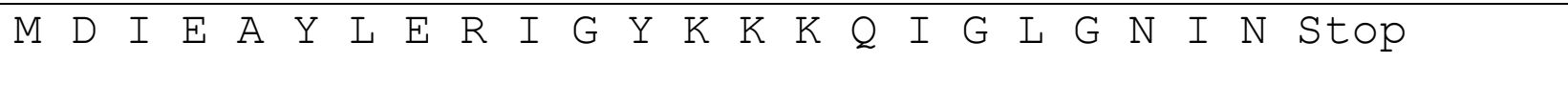 & 23 \\
\hline
\end{tabular}




\section{In Vitro and In Situ PABA Acetylation Activity}

The in vitro $\mathrm{N}$-acetylation of PABA in MDA-MB-231 parental cell was 14.4 $\pm 1.63 \mathrm{nmoles} / \mathrm{min} / \mathrm{mg}$ of protein (figure $5.1 \mathrm{~A}$ ). The CRISPR gRNA \#2 and \#5 clones reduced levels of activity to below a detectable level, with the limit of detection $0.05 \mathrm{nmoles} / \mathrm{min} / \mathrm{mg}$ of protein (figure $5.1 \mathrm{~A}$ ). The $\mathrm{N}$-acetylation of PABA in situ per hour per million cells followed the same pattern as the in vitro activity. $\mathrm{N}$-acetylation of PABA in the parental MDA-MB-231 cell line activity was $1.15 \pm 0.022 \mathrm{nmoles} / \mathrm{hr} / \mathrm{million}$ cells (figure $5.1 \mathrm{C}$ ). In the gRNA \#2 and \#5 clones, levels of PABA $N$-acetylation in situ were reduced to below a detectable level, with the limit of detection $0.20 \mathrm{nmoles} / \mathrm{hr} / \mathrm{million}$ cells (figure $5.1 \mathrm{C}$ ).

The in vitro acetylation of PABA activity for MCF7 parental cell lysates was $39.0 \pm 3.42 \mathrm{nmoles} / \mathrm{min} / \mathrm{mg}$ of protein (figure 5.1B). The CRISPR gRNA \#2 and \#5 clones had levels of activity reduced to below a detectable level, with the limit of detection $0.05 \mathrm{nmoles} / \mathrm{min} / \mathrm{mg}$ of protein (figure $5.1 \mathrm{~B}$ ). The $\mathrm{N}$-acetylation of PABA in situ per hour per million cells followed the same pattern as the in vitro activity. $\mathrm{N}$-acetylation of PABA in the parental MCF7 cell line was $2.20 \pm 0.357$ nmoles/hr/million cells (figure 5.1D). In the gRNA \#2 and \#5 clones, levels of PABA $N$-acetylation in situ were reduced to below a detectable level, with the limit of detection 0.20 nmoles $/ \mathrm{hr} /$ million cells (figure 5.1D). 


\section{Endogenous AcCoA Levels}

The endogenous level of AcCoA within the MDA-MB-231 parental cell line

was $17.8 \pm 1.1$ pmoles/million cells (figure $5.1 \mathrm{E}$ ). The endogenous level of AcCoA within the cells of the gRNA \#2 and \#5 NAT1 knockout clones was $33.1 \pm$ 1.8 and $35.5 \pm 2.6$ pmoles/million cells, respectively (figure 5.1E). Overall endogenous levels of AcCoA within the gRNA \#2 and \#5 NAT1 knockout clones were significantly elevated compared to their MDA-MB-231 parental cell line $(N=8 ; p<0.05)$ (figure 5.1E).

MCF7 parental cell line had an endogenous level of AcCoA of $18.7 \pm$ $0.897 \mathrm{pmoles} / \mathrm{million}$ cells (figure 5.1F). The endogenous levels of AcCoA within the cells of the gRNA \#2 and \#5 NAT1 knockout clones were $27.6 \pm 2.60$ and $27.0 \pm 2.72 \mathrm{pmoles} / \mathrm{million}$ cells, respectively (figure 5.1F). Overall endogenous levels of AcCoA within the gRNA \#2 and \#5 NAT1 knockout clones were significantly elevated compared to their MCF7 parental cell line $(N=12 ; p<0.05)$ (figure 5.1F). 
FIGURE 5.1

A

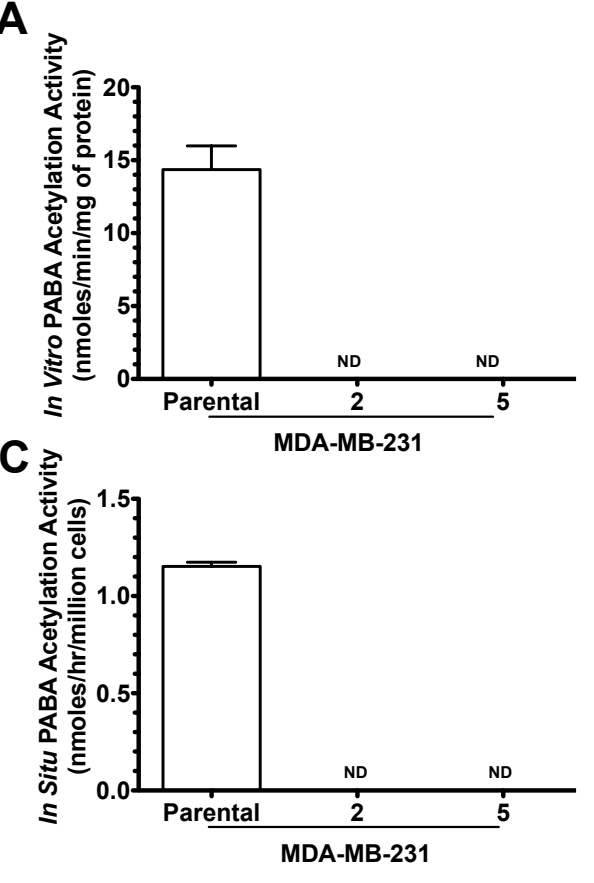

E

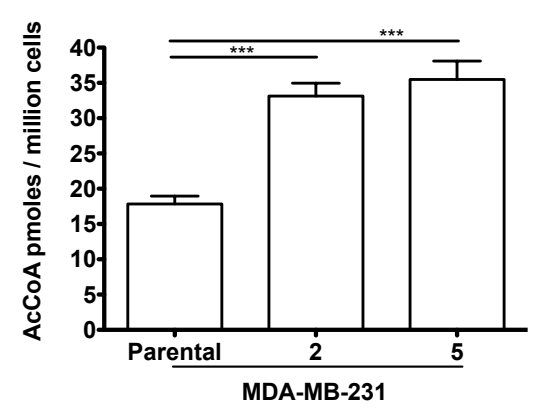

B

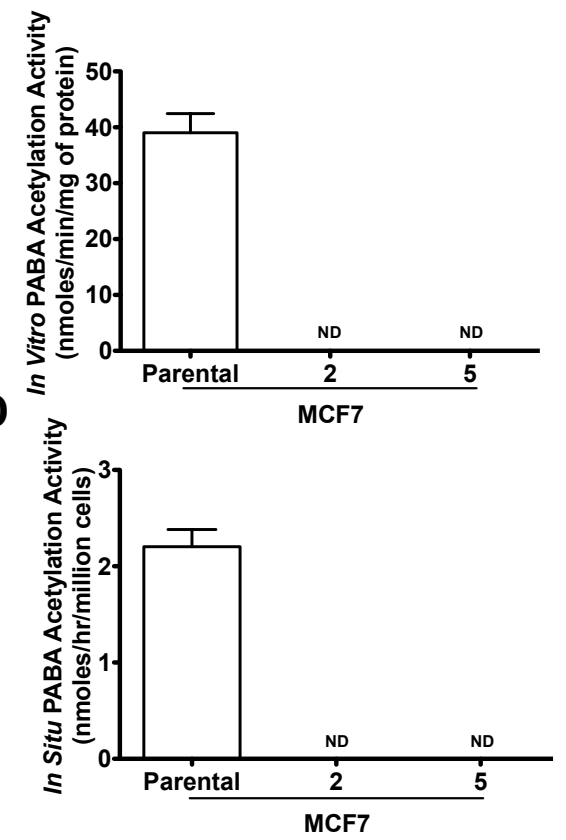

$\mathbf{F}$

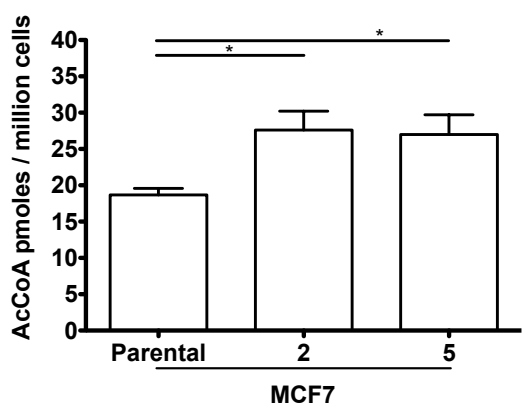

Figure 5.1 - NAT1 PABA acetylation activity and endogenous AcCoA concentration level in genomic modified MDA-MB-231 and MCF7 cell lines. Each bar illustrates mean \pm SEM. The in vitro PABA $N$-acetylation $(A-B)$ activity in cell line lysates $(\mathrm{N}=3)$. The in situ PABA N-acetylation ( $\mathrm{C}-\mathrm{D})$ in MDA-MB-231 $(\mathrm{N}=3)$ and MCF7 $(\mathrm{N}=4)$ cell lines cultured in PABA spiked media. The endogenous AcCoA levels (E-F) for MDA-MB-231 $(\mathrm{N}=8)$ and MCF7 $(\mathrm{N}=12)$ cell lines.

Differences between cell lines were significantly different $\left({ }^{*} p \leq 0.05 ;{ }^{* * *} p \leq 0.001\right)$ following one-way ANOVA with a Bonferroni post-test. 


\section{Cell Line Doubling Times}

The doubling times for the parental cell line and gRNA \#2 and \#5 NAT1 knockout cell lines were $30.5 \pm 1.0,29.3 \pm 1.1$, and $29.8 \pm 0.7$ hours, respectively $(\mathrm{N}=3)$ (figure 5.2A). Neither of the gRNA NAT1 knockout clone cell lines significantly altered the doubling time compared to the parental MDA-MB-231 cell line. Differences were tested for statistical significance by one-way ANOVA ( $p>$ $0.05)$.

MCF7 parental cell line and gRNA \#2 and \#5 NAT1 knockout cell lines exhibited doubling times of $41.4 \pm 0.4,45.3 \pm 6.2$, and $38.8 \pm 8.5$ hours, respectively ( $\mathrm{N}=3$ )(figure $5.2 \mathrm{~B})$. Neither of the gRNA NAT1 knockout clone cell lines significantly affected the doubling time compared to the parental MCF7 cell line. Differences were tested for statistical significance by one-way ANOVA ( $p>$ $0.05)$.

\section{Anchorage-Dependent and -Independent Colony Formation Assay}

The ability of colony formation by anchorage-dependent manner was quantified for MDA-MB-231 parental $(40.7 \pm 2.54$ colonies $)$ and gRNA \#2 (51.3 \pm 1.61 colonies) and \#5 (54.8 \pm 6.76 colonies) NAT1 knockout modified cell lines. Anchorage-dependent colonies among the MDA-MB-231 and NAT1 knockout cell lines did not differ statistically from each other tested by a one-way ANOVA followed by Bonferroni post hoc test ( $p>0.05 ; \mathrm{N}=6$ ) (figure $5.2 \mathrm{C}$ ). 
MCF7 parental and gRNA \#2 and \#5 NAT1 knockout modified cell lines ability of colony formation by anchorage-dependent manner was quantified as $50.7 \pm 5.2,80.6 \pm 6.4$, and $41.5 \pm 6.2$ colonies, respectively. MCF7 gRNA \#2 clone cell line formed statistically more colonies than the parental and gRNA \#5 clone cell lines when tested by a one-way ANOVA followed by Bonferroni post hoc test $(p<0.0005 ; N=7)$ (figure $5.2 D)$.

Anchorage-independent colony formation assays (also known as "soft agar assays") allow for the determination of cancer cell ability to form colonies in the absence of cellular attachment to a surface. The MDA-MB-231 parental cell line formed anchorage-independent colonies at markedly higher levels than the NAT1 knockout clones (figure 5.2E). The number of colonies formed by MDAMB-231 parental and gRNA \#2 and \#5 NAT1 knockout modified cell lines were $1070 \pm 76,48.3 \pm 17.2$, and $23.4 \pm 7.0$ colonies, respectively. The anchorageindependent colony formation of MDA-MB-231 parental cell line was significantly higher than their CRISPR NAT1 knockout peers when tested by one-way ANOVA followed by Bonferroni post hoc test $(p<0.0001 ; N=3)$. The same Bonferroni post test showed that the two CRISPR NAT1 knockout cell lines were not statistically $(p>0.05)$ different from each other.

MCF7 parental cell line formed anchorage-independent colonies at a higher level than the NAT1 knockout MCF7 cell line clones (figure 5.2F). The number of colonies formed by MCF7 parental and gRNA \#2 and \#5 NAT1 
knockout cell lines were $195 \pm 9,33.7 \pm 6.8$, and $13.8 \pm 6.6$, respectively. Anchorage-independent colonies formed by the MCF7 parental cell line were significantly higher than gRNA \#2 and \#5 NAT1 knockout clones by one-way ANOVA followed by Bonferroni post hoc test $(p<0.0001 ; N=4)$. The MCF7 gRNA \#2 and \#5 NAT1 knockout clones were not statistically different $(p>0.05)$ from each other. 


\section{FIGURE 5.2}

A

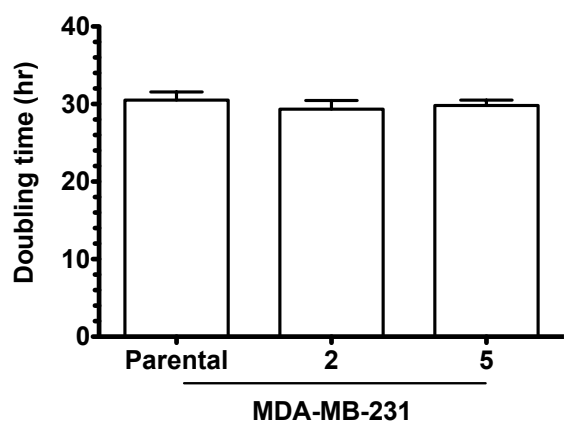

C

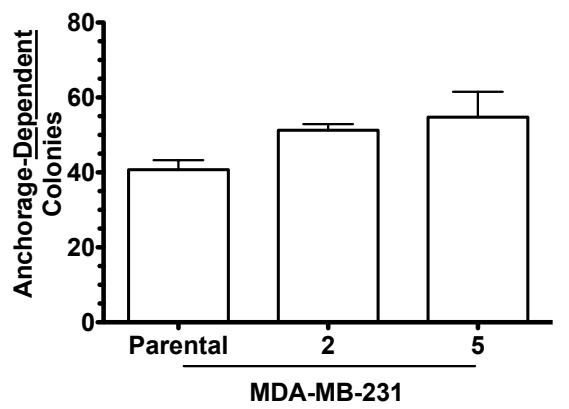

E

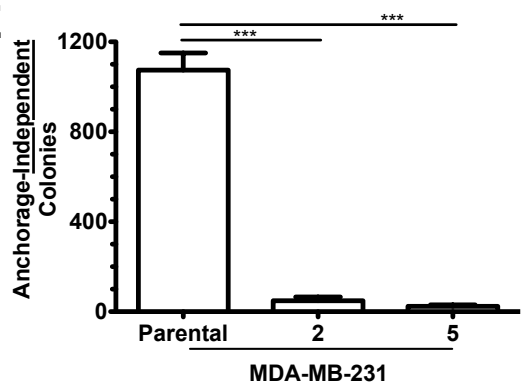

B
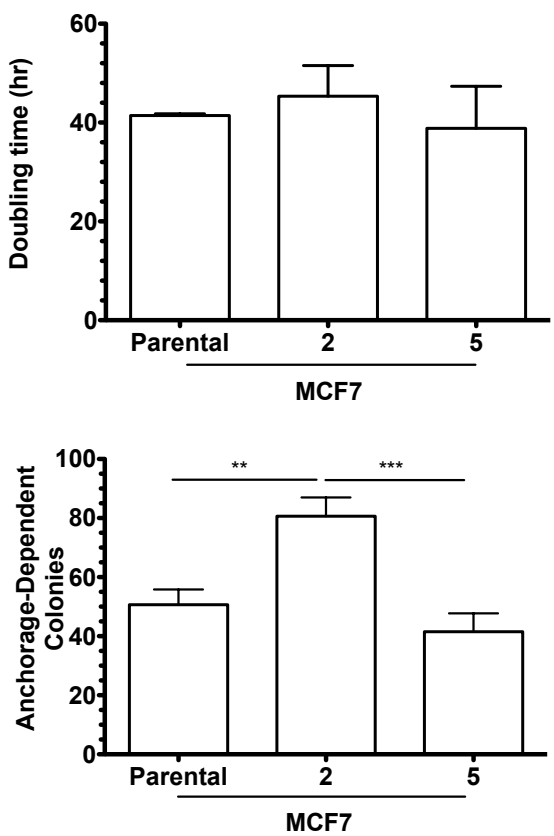

$\mathbf{F}$

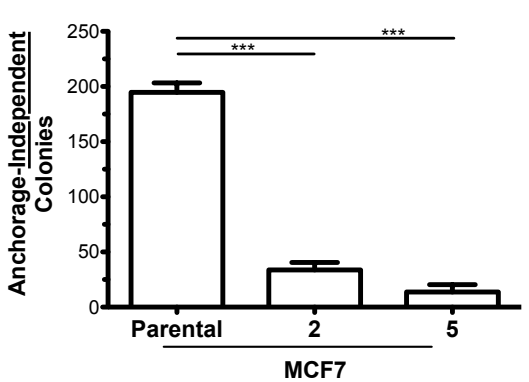

Figure 5.2 - Cell growth properties in genomic modified MDA-MB-231 and MCF7 cell lines. Each bar illustrates mean \pm SEM. Cell doubling times $(A-B)$ in MDAMB-231 and MCF7 NAT1 knockout cell lines did not differ significantly from parental cell lines following one-way ANOVA $(p>0.05)(N=3)$. The anchoragedependent growth $(\mathrm{C})$ did not differ significantly among the MDA-MB-231 cell lines following one-way ANOVA ( $p>0.05)(N=6)$. MCF7 CRISPR gRNA \#2 clone cell line formed more anchorage-dependent colonies than the parental and CRISPR gRNA \#5 clone cell lines (D) according to an one-way ANOVA followed by a Bonferroni post-test $\left({ }^{* *} p \leq 0.001\right.$ and $\left.{ }^{* * *} p \leq 0.001\right)(N=7)$. The NAT1 knockout cell lines formed significantly less anchorage-independent colonies compared to parental cell lines (E-F) for both MDA-MB-231 (N=3) and MCF7 $(\mathrm{N}=4)$ determined by one-way ANOVA followed by a Bonferroni post-test $\left({ }^{* * *} p \leq\right.$ $0.001)$. No significant differences in anchorage-independent colonies between the gRNA \#2 and \#5 of MDA-MB-231 ( $N=3)$ and MCF7 ( $N=4)(p>0.05)$. 


\section{Anoikis Assay and Hanging Drop Assay}

Cancer cells were measured for anoikis resistance by being cultured under anchorage independent conditions. Anchorage independent growth conditions were achieved by coating wells of a 96-well plate with poly-HEMA, which keeps cells from attaching to the bottom of the well. In anchorage independent growth conditions the growth curves of MDA-MB-231 parental and gRNA \#2 and \#5 knockout cell lines do not significantly differ from their respective cells grown in anchorage dependent conditions ( $N=3$ )(figure $5.3 \mathrm{~A}-\mathrm{C}$ ). When parental and NAT1 knockout clones are compared between each growth condition there was no significant difference observed (figure 5.3D and E).

To address the growth of MDA-MB-231 parental and knockout cell lines in anchorage independent growth conditions and in close cellular proximity a hanging drop assay was conducted. The results suggest that over the course of time knockout of NAT1 within MDA-MB-231 cancer cells results in aggregating and forming a mass of cells sooner that the parental cell line (figure 5.4A). If the ratio of dead cells to live cells is measured by trypan blue exclusion, the gRNA \#2 and \#5 NAT1 knockout clone cell lines developed a higher ratio of dead cells to live cells compared to the parental MDA-MB-231 cell line according to a twoway ANOVA (figure 5.4B) (interaction $p<0.0001, N=7$ ). At the 72 hour time point both the gRNA \#2 and \#5 NAT1 knockout clone cell lines had significantly higher

ratio of dead cells to live cells compared to the parental cell line (figure 5.4B) $(p<0.01, N=7)$. 


\section{Invasion Assay}

The relative invasion ability of MDA-MB-231 parental and gRNA \#2 and \#5 NAT1 knockout clones were found not to differ significantly when compared by a by one-way ANOVA and Bonferroni post hoc test ( $p>0.05 ; \mathrm{N}=4$ )(figure $5.5 \mathrm{~B}$ ).

\section{Wound Closure for MDA-MB-231 Cell Lines}

MDA-MB-231 gRNA \#2 and \#5 NAT1 knockout clone cell lines closed more of a wound than the MDA-MB-231 parental cell line parental cell lines (figure 5.6A). The linear slopes for the NAT1 knockout cell lines were found to be significantly higher than the linear slope of the parental cell line $(p<0.01 ; N=3)$ (figure 5.6B).

\section{Subcutaneous Xenograft of MDA-MB-231 Cell Lines}

The removed xenograft tumors of MDA-MB-231 cells weighed $0.448 \pm$ 0.0696 grams for parental cell line, $0.308 \pm 0.0515$ grams for gRNA \#2 NAT1 knockout clone, and $0.463 \pm 0.128$ grams for gRNA \#5 NAT1 knockout clone. There was no difference in the total tumor weights of the isolated tumors between the parental and CRISPR clones ( $p>0.05)$ (figure 5.7). 


\section{FIGURE 5.3}
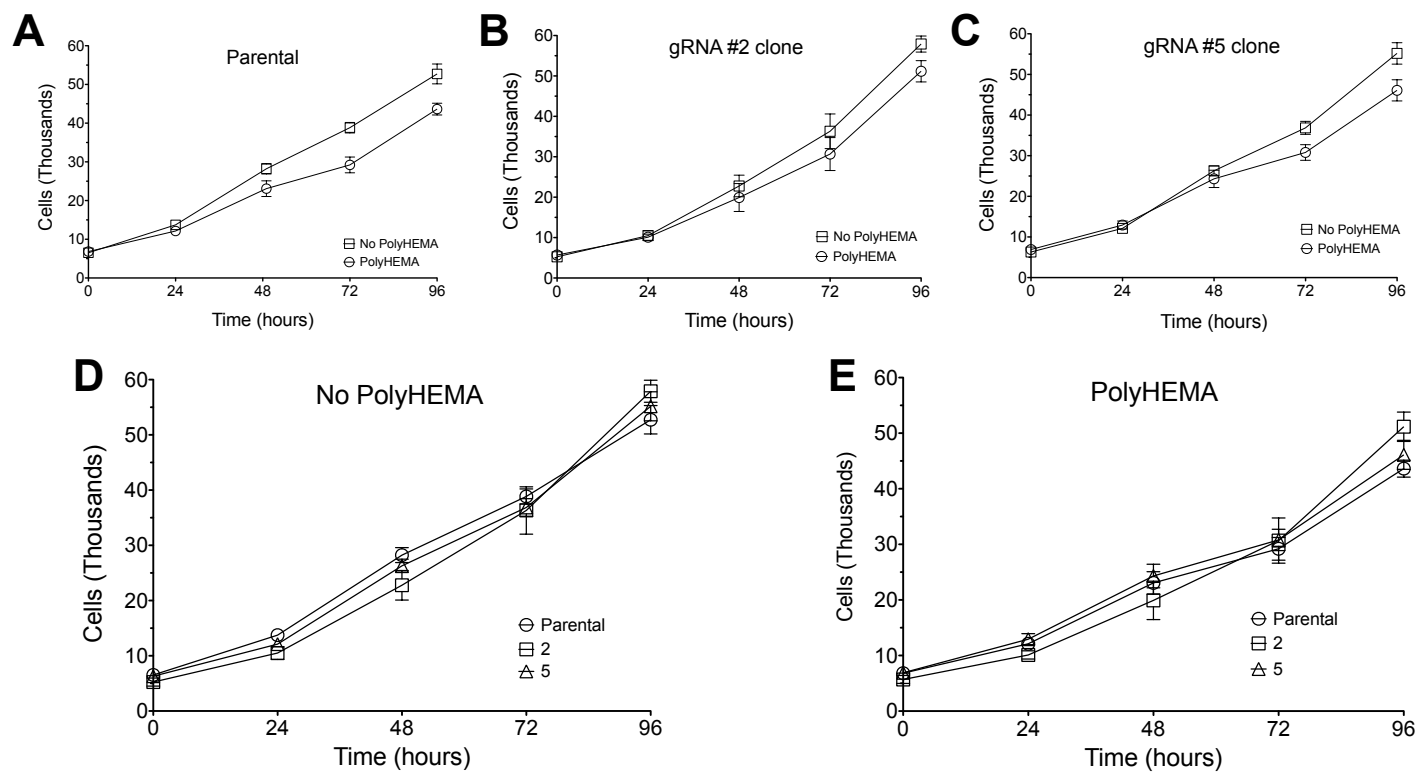

Figure 5.3 - Growth curves for MDA-MB-231 cell lines with standard adhesion or in anchorage-independent conditions. Parental and CRISPR gRNA knockout clone cell lines growth curves comparing their ability to grow in standard noncoated wells versus poly-HEMA coated wells (anchorage independent conditions) (A-C). Parental and the CRISPR/Cas9-mediated NAT1 knockouts display a level of anoikis resistance when compared to standard anchorage growth. Comparisons of the two different conditions for each cell line found no statistical difference ( $A, p=0.63 ; N=3$ / $B . p=0.88 ; N=3$ / $C, p=0.72 ; N=3$ ). The NAT1 knockout cell lines have comparable growth and anoikis resistance to the parental MDA-MB-231 cell lines over the course of 96 hours (D-E). 
FIGURE 5.4
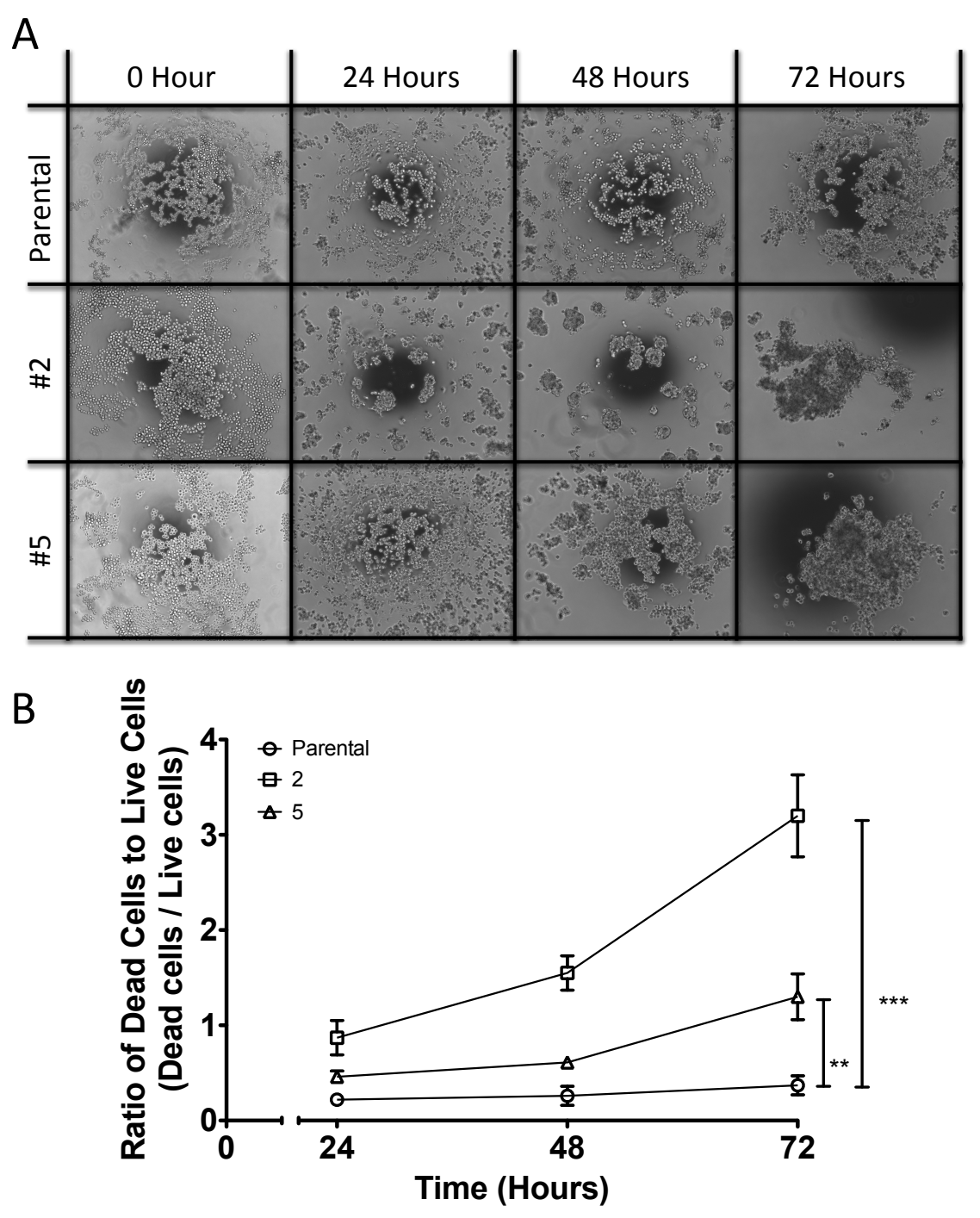

Figure 5.4 - Comparison of representative photomicrographs taken of the hanging drops showing the cells four days (A). The CRISPR knockout MDA-MB231 clone cell lines (\#2 and \#5) each form tightly packed, often singular, cellular masses. However the parental MDA-MB-231 cells remain relatively diffused by the fourth day. The cells are collected and counted using trypan blue exclusion to determine the ratio of "dead cells" to "live cells" within a drop (B). The parental MDA-MB-231 cells seem to remain at the same ratio of dead to live cells over the course of three days. However NAT1 knockout clones increase in the ratio of dead cells to live cells over the course of days. This is found to be significantly different by two-way ANOVA (interaction $\mathrm{p}<0.0001 ; \mathrm{N}=7$ ) followed by a Bonferroni post hoc test ( ${ }^{* *} p \leq 0.01$; ${ }^{* * *} p \leq 0.001$ for the 72 hour time point). 
FIGURE 5.5
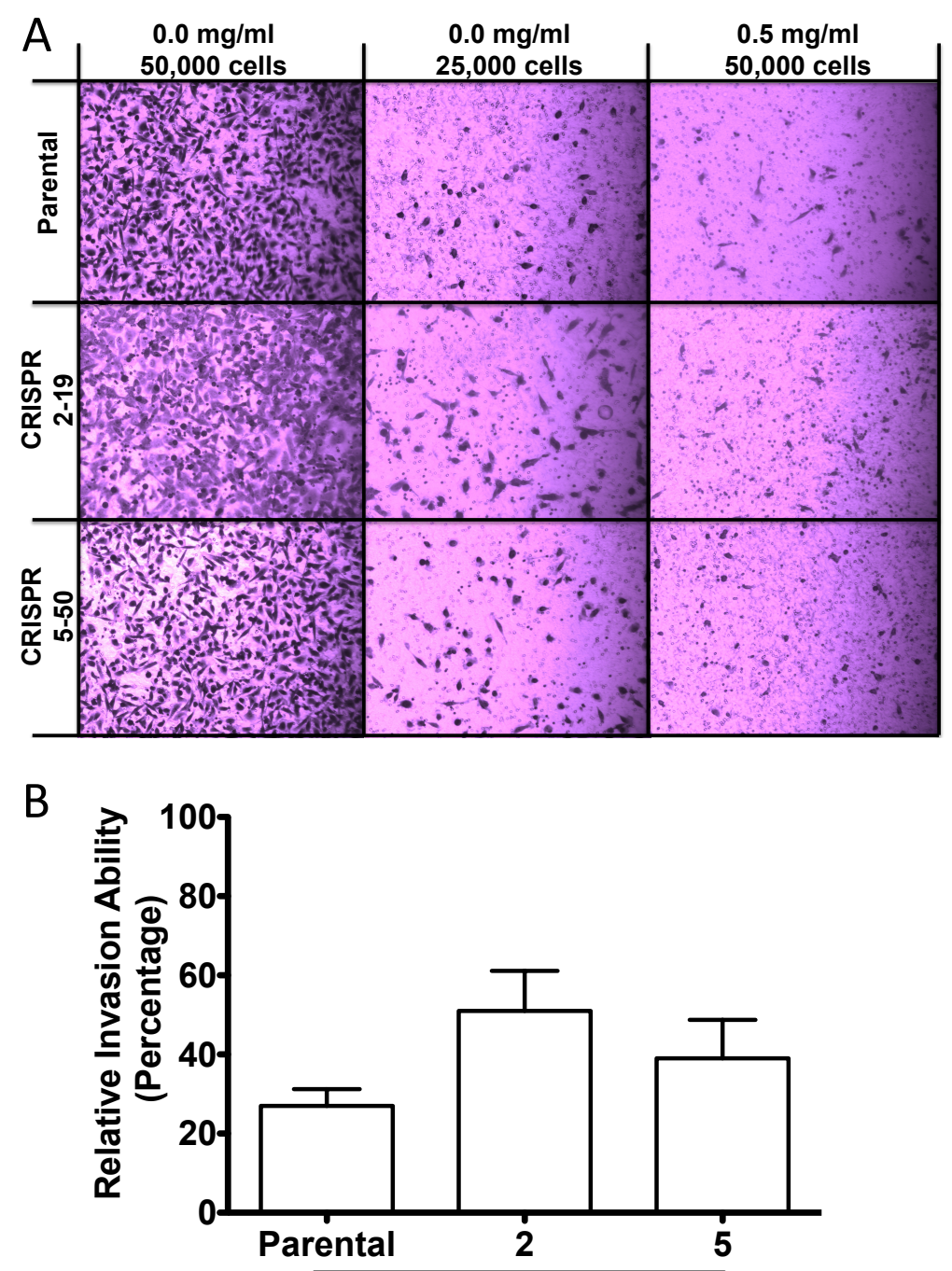

MDA-MB-231

Figure 5.5 -Comparison of photomicrographs taken of Transwell ${ }^{\circledR}$ membranes illustrating the different number of cells that were able to reach the bottom side of the membrane either with or without Matrigel for parental or NAT1 knockout cell lines (A). The gel concentration is given along the top of the columns as $\mathrm{mg} / \mathrm{ml}$, and then directly below is the number of cells that were seeded into the Transwell ${ }^{\circledR}$ insert. Relative Invasion ability for either MDA-MB-231 parental or NAT1 knockout cell lines (B). Relative invasiveness was calculated by dividing the cells that invaded thru the $0.5 \mathrm{mg} / \mathrm{ml}$ gel matrix (insert seeded with 50,000 cells) by the number of cells that migrated through no gel (insert seeded with 25,000 cells). The relative invasiveness ability for each cell line was nonsignificant different $(p=0.19 ; N=4)$. 


\section{FIGURE 5.6}

A

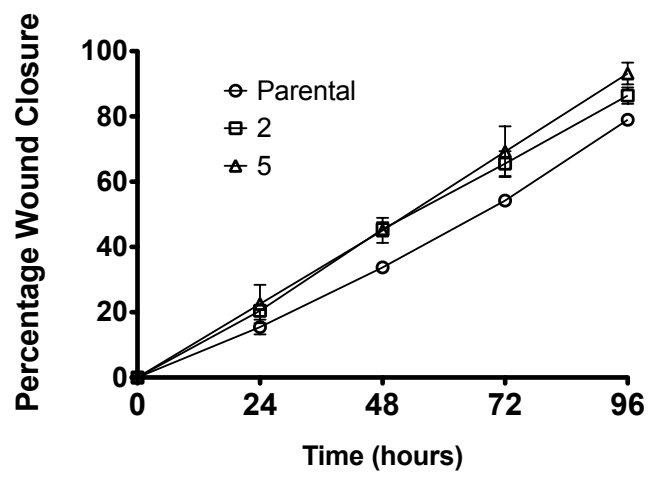

B

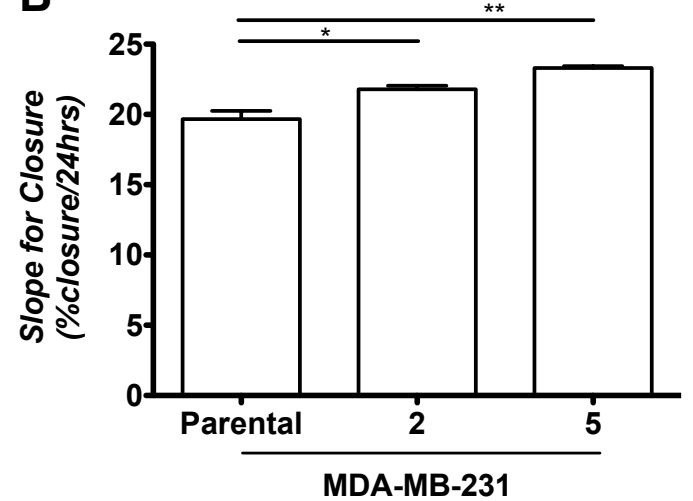

Figure 5.6 - Percentage of closure for a $2 \mathrm{~mm}$ diameter wound over the course 96 hours. The CRISPR gRNA \#2 and \#5 NAT1 knockout clone cell lines have a higher percentage of closure that the MDA-MB-231 parental cell line over the 96 hours (A). The rate of closure is elevated in the NAT1 knockout cell lines compared to the rate for the parental MDA-MB-231 cell line (B). This elevated rate for NAT1 knock out cells was found to be significant by a one-way ANOVA followed by a Bonferroni post hoc test $\left({ }^{*} p \leq 0.05 ;{ }^{* *} p \leq 0.01 ; N=3\right)$. 


\section{FIGURE 5.7}

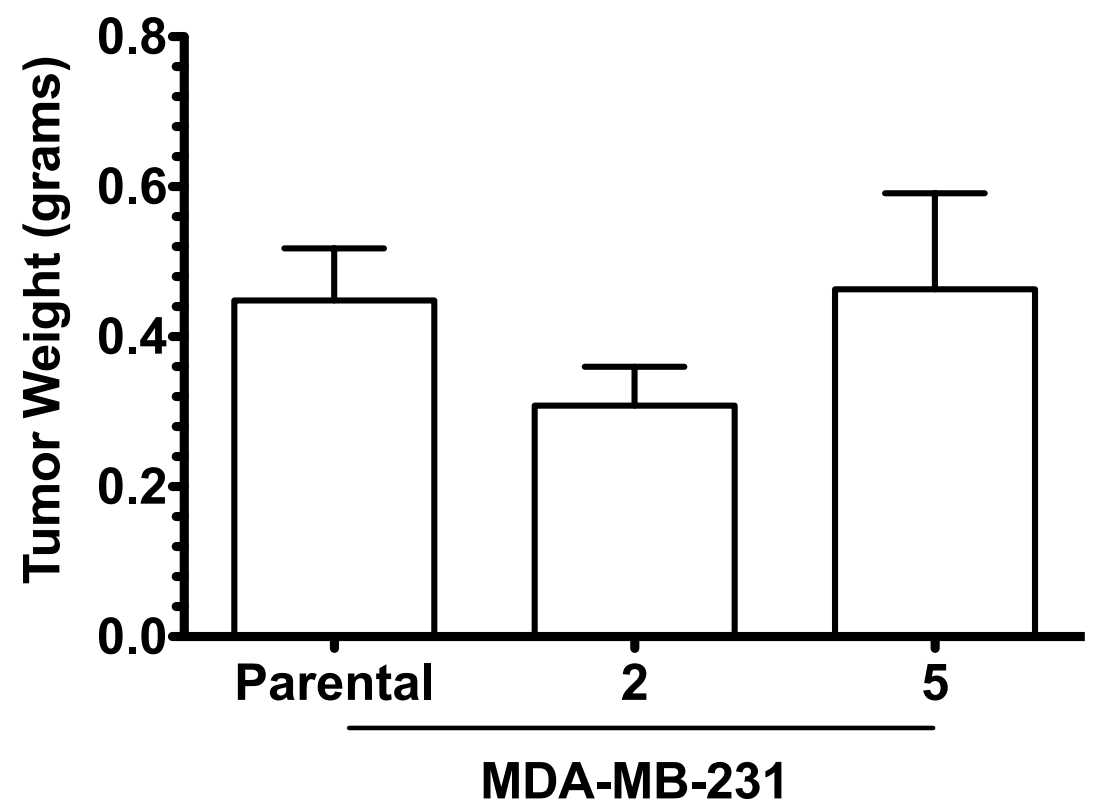

Figure 5.7 - The removed xenograft tumor weights for MDA-MB-231 parental $(\mathrm{N}=10)$, gRNA \#2 clone $(\mathrm{N}=5)$ and gRNA \#5 clone $(\mathrm{N}=5)$ were not significantly different from each other as determined by a one-way ANOVA $(p=0.454)$. 


\section{DISCUSSION}

CRISPR/Cas9 was used to produce cloned cell lines with a stable knockout of NAT1 in human MDA-MB-231 and MCF7 breast cancer cell lines. This study served to replicate previous findings with partial shRNA knockdowns, and confirmed differences in human NAT1 expression effects within breast cancer cell lines. Differences in human NAT1 expression have been reported to alter cancer cell growth properties, and understanding how NAT1 gene expression affects cancer cell growth characteristics is very important.

MDA-MB-231 and MCF7 gRNA \#2 and \#5 NAT1 knockout clones resulted in no measurable PABA acetylation either in vitro or in situ assays, at least a $45 \%$ increase of endogenous AcCoA levels, and at least a 6 -fold decrease in anchorage-independent growth compared to the parental MDA-MB-231 and MCF7 cell lines. However knockout of NAT1 produced no significant changes $(p>0.05)$ in cell doubling time, anchorage-dependent growth, or relative invasion ability compared to parental MDA-MB-231 cells. MCF7 parental and knockout clone cell lines showed no significant difference $(p>0.05)$ in doubling time. The MCF7 gRNA \#2 clone formed more anchorage-dependent colonies that the MCF7 parental and gRNA \#5 clone cell lines. This elevation of colonies in MCF7 gRNA \#2 clone is not related to the knockout of NAT1 since it is not found in the MCF7 gRNA \#5 clone, and the results from other model systems show no 
increase in anchorage-dependent colonies. So this increase can be the result of an off target effect.

The combined results with NAT1 knockout cell lines show no difference in doubling time compared to the parental cell lines. The number of anchoragedependent colonies was found to be independent of the NAT1 activity level in these breast cancer cell lines. The relative cellular invasion ability was found to be non-significantly different between MDA-MB-231 parental cells and NAT1 knockout cells. These findings suggest that NAT1 does not play a role in growth rates, anchorage-dependent colony formation, or relative invasion ability for breast cancer cells under cell culture conditions. This conclusion is different from that of previous reports $[11,12]$.

NAT1 hydrolysis of AcCoA in the presence of folate compounds suggests that NAT1 may affect endogenous levels of AcCoA [54, 103]. Consistent with this concept, NAT1 knockout elevated AcCoA levels in both the MDA-MB-231 and MCF7 cell line model systems. Rat embryonic fibroblasts from rapid acetylator congenic rats have lower levels of AcCoA than rat embryonic fibroblasts derived from slow acetylator congenic rats [65]. Partial knockdown of NAT1 in MDA-MB231 also showed elevated levels of AcCoA compared to the wildtype (scramble shRNA) MDA-MB-231 cell line. A direct connection for physiological differences in AcCoA levels drawn to NAT1 AcCoA hydrolysis requires further investigation. 
However the current accumulating data show that NAT1 influences endogenous AcCoA levels.

Anchorage-independent growth decreased 12-fold in MDA-MB-231 and 6fold in MCF7 cells when NAT1 activity was knocked out. Based on this result, it is hypothesized that the removal of NAT1 activity reestablished anoikis ability within the cell lines. Anoikis is an anchorage-related apoptosis that results from the loss of integrin-mediated cell-matrix contact. In the absence of attachment to extracellular matrix $(\mathrm{ECM})$ or upon cell adhesion to inappropriate location, cells undergo this type of apoptosis. Integrin receptors mediate the cell to ECM interactions providing physical links with the cytoskeleton and transduce signals from the ECM to the cell. The transduction of signals is mandatory for several cellular processes including migration, proliferation and survival [148-151]. Anoikis serves as a defense mechanism within an organism. The defense mechanism prevents detached cells reattaching to incorrect ECM locations and proliferating. Cells that lack or have a reduced anoikis response can result in cells surviving under suspension conditions and/or proliferating at ectopic sites with a different ECM. Decreased regulation of anoikis is emerging as a hallmark of cancer cells and contributes to the formation of metastasis in distant organs [148-151].

However testing for reestablishment of anoikis revealed that anchorage independent growth rates, determined from growth in poly-HEMA coated plates, 
were not different between MDA-MB-231 parental and NAT1 knockout clone cell lines. This finding means that anoikis is unlikely the cause of the dramatic differences in anchorage-independent colony formation. A hanging drop assay revealed an elevated ratio of dead to live NAT1 knockout cells compared to the parental cell line. In the hanging drop assay, the cells grow in anchorageindependent conditions, but are forced to gradually come into contact with each other. This result is suggestive that the NAT1 knockout cell lines are more sensitive to the cell-cell contacts than the parental cell line. So instead of anoikis reestablishment, the close proximity of other cells may be the cause for a lower number of anchorage-independent colonies. The wound closure assay with MDA-MB-231 cells showed that NAT1 knockout cell lines enter an open growth area at higher rates compared to the parental cell line, which was observed in the closure rates for each cell line.

Subcutaneous xenograft of MDA-MB-231 NAT1 knockout cells developed into a tumor with the same masses as the parental cells. This result is consistent with cell culture results showing no difference in anchorage-dependent growth. A future experiment with tail vein injections of cancer cells and measuring lung metastasis may result in the NAT1 knockout cells producing lower tumor rates than parental cells. This theory is based on published data using similar methods [12]. Also this methodology of tail vein injection requires cancer cells to flow through the blood stream and grow from individual cells into a lung metastasis, 
which is a better representation of the cell culture anchorage-independent findings.

In summary, our findings compliment but do not fully replicate previous reports regarding the effect of reducing NAT1 activity on cancer cell properties. In our studies, complete removal of NAT1-catalyzed N-acetylation in the MDA-MB231 and MCF7 breast cancer cell line by CRISPR/Cas9 resulted in a significant decrease in anchorage-independent colony formation without affecting overall cell growth and relative invasion ability. NAT1 knockout cell lines had increased endogenous AcCoA levels, about 45\%, compared to the parental cell line. The results warrant further studies to determine mechanisms to understand how reduced NAT1 activity is related to reduced formation of anchorage-independent colonies. Use of this model system further suggests that human NAT1 could serve as a target for the prevention and/or treatment of breast cancer. 
CHAPTER VI

\section{SUMMARY AND CONCLUSIONS}

The results presented within this dissertation show the possible role of NAT1 in tumorigenesis and cell biology. To come upon these results experiments were conducted using in vitro enzymatic reactions, in vivo studies with homozygous high (rapid) or low (slow) NAT2 activity congenic rats, and genetically modified cancer cell lines. The second chapter shows that human NAT1 and rodent NAT2 hydrolyze AcCoA in a folate dependent manner. The third chapter shows that rapid NAT2 congenic rats develop more tumors than the slow NAT2 congenic strain following administration of MNU and DMBA carcinogens, which are both not metabolized by rat NAT2. The fourth and fifth chapters are studies performed with partial NAT1 knockdown and complete NAT1 knockout human breast cancer cell lines, respectively. The findings conflict with some previous findings on knockdown cell lines, but also share a common result. In both the partial knockdown and complete knockout cell lines anchorage-independent colony formation ability in soft agar is greatly diminished compared to parental cell lines. Endogenous AcCoA levels in congenic slow NAT2 rat embryonic fibroblasts, partial NAT1 knockdown cell line, and complete NAT1 knockout cell lines show increased AcCoA when NAT activity is reduced within the cell. The "complete mechanism/role" of NAT1 is still debatable, 
however this dissertation provides evidence that NAT1 influences mammary cancer susceptibility and has an endogenous role within a cell.

The second chapter, first results section, shows human NAT1 and the rodent ortholog NAT2 can perform AcCoA hydrolysis in the presence of folate but absence of xenobiotic substrate (e.g. PABA). The human NAT2 and the rodent Nat1 have no detectable AcCoA hydrolysis activity. A HPLC method was developed to measure the level of CoA and AcCoA. We determined the Michaelis-Menton kinetic constants (Vmax and $\mathrm{Km}$ ) for both AcCoA and folate using human NAT1 as well as three rodent Nat2 enzymes. The fact that folate and DHF support the AcCoA hydrolysis activity makes it a possible endogenous activity within a cell. MTX, a folate analog, was not able to support hydrolysis of AcCoA to any considerable degree. All these in vitro studies strengthen the position that NAT1 can perform an endogenous reaction independent of a xenobiotic substrate.

The third chapter suggests that human NAT1, with the use of the ortholog rat Nat2 in congenic rats, plays an important role in tumorigenic incidence and onset. The strengths of this study are the congenic rat model and the similarity of human NAT1 and rat NAT2. The Hein laboratory made the congenic Fischer 344 rat strains several years ago, and characterized the differences between rapid and slow Nat2 congenic rats in previous publications. The rapid and slow NAT2 congenic F344 rat stains were derived by the same breeding approach, so the 
genetic background of rapid and slow congenic rats is more than $99.9 \%$ similar. This very close similarity allows us to compare rapid and slow NAT2 with minimal influence of strain differences besides the NAT2 gene. As mentioned in the introduction, human NAT1 and rat NAT2 share over $83 \%$ amino acid sequence homology, with no differences in the active site or the C-terminal tail. The rat breast cancer model is a strength because we can measure palpable tumors in live animals over time. In theory this study could be conducted on almost any form of cancer.

Chemically induced tumors are affected by variable, yet controllable, factors like the inducing carcinogen, age of administration, reproductive history, and diet. Diet and reproductive history of these rats are the same for both rapid and slow congenic rats. Administration of $\mathrm{MNU}$ is an approached used for several decades to induce mammary tumors in rodents. MNU is a direct acting DNA alkylating agent that does not need biotransformation to form DNA adducts. It has been shown that sexually immature F344 rats (at 3 weeks of age) are more susceptible to mammary carcinogenesis by MNU than mature rats ( 8 weeks of age) [77]. In chapter three, MNU was given at both 3 and 8 weeks of age to ensure no possible developmental differences were affecting the results. Additionally, rats were treated with another well-studied and utilized carcinogen, DMBA, at eight weeks of age. DMBA is a procarcinogen that requires enzymatic metabolism to become an active carcinogen. The enzymes that activate DMBA have been characterized and do not involve human NAT1/rat NAT2. The use of 
DMBA shows that tumorigenic differences between rapid and slow NAT2 congenic rats are not carcinogen related. The study in chapter three is strengthened by the different approaches to address the factors that can influence chemically induced tumors.

The use of rat embryonic fibroblasts (REFs) to measure the endogenous AcCoA levels of rapid and slow congenic strains is necessary in this study. The ability to normalize the small amount of detectable AcCoA from HPLC to the number of cells is considerably more reliable and reproducible than the extensive trials using whole tissue from congenic rats. Whole tissue suffered from considerable variability in the data from tissue weights and tissue composition. REFs serve to strengthen this study by greatly increasing the reliability of the data.

The results in the fourth and fifth chapters use two separate models: a partial knockdown and a knockout of NAT1. In both of these model systems, no effect on doubling time, number of anchorage-dependent colonies, relative cellular invasion ability were found to be non-significantly different between wildtype NAT1 activity cells and NAT1 knockout breast cancer cell lines. These repetitive findings suggest that NAT1 does not play a role in growth rates, anchorage-dependent colony formation, or relative invasion ability for breast cancer cells under cell culture conditions. This conclusion differs from that of 
previous studies by others [11, 12], but is strongly supported by the different models and cell lines used within this dissertation.

In the fourth chapter despite a 12-fold overexpression of NAT1 in vitro activity, significant $(p<0.05)$ changes in endogenous AcCoA levels, cell doubling time, anchorage-dependent growth, anchorage-independent cell growth, or relative invasion ability were not observed. In contrast, a previous study using HB4a cells reported that NAT1 overexpression resulted in enhanced growth properties [8]. The MDA-MB-231 cells used in the present study are a claudinlow, triple-negative breast cancer cell line whereas the HB4a cell line is derived from normal luminal mammary epithelial cells. Thus, the lack of differences between scrambled shRNA and NAT1 overexpression MDA-MB-231 cell lines may be a result of the cell line utilized. It is also possible that NAT1 has a type of threshold effect where increasing NAT1 activity within a cell does not result in a significant difference as with knockdown of NAT1 activity. The reduced NAT1 activity studies could be further strengthened with the inclusion of reestablishing the NAT1 activity once it has been completely knocked out. Theoretically the difference in anchorage-independent colony formation and the endogenous AcCoA level should be restored to that of the parental cell line. The reestablished NAT1 activity cell lines are currently being developed and explored within the Hein laboratory. 
Chapters III, IV, and V all explore the concept presented in chapter II, which is that in the presence of folate, NAT1 is able to hydrolyze AcCoA. Consistent with this concept, endogenous AcCoA levels in congenic rat embryonic fibroblasts, partial NAT1 knockdown cell line, and complete NAT1 knockout cell lines showed increased AcCoA when the level of NAT1 activity is reduced within the cell. The complete NAT1 knockout in MDA-MB-231 cell lines elevated endogenous AcCoA levels by $86 \%$ to $99 \%$. The complete NAT1 knockout in MCF7 elevated endogenous AcCoA levels by $45 \%$ to $48 \%$. These findings are consistent with folate-dependent AcCoA hydrolysis catalyzed by NAT1. However the findings do not provide conclusive evidence that the folatedependent hydrolysis is the primary or sole mechanism for the elevation of AcCoA.

Differences in AcCoA levels could provide an explanation for differences in metabolites of fatty acid synthesis and amino acids [131]. The effects of NAT1 on anchorage-independent cell growth and endogenous AcCoA levels may provide insight into why congenic rapid NAT2 rats developed more mammary tumors than congenic slow NAT2 rats following administration of mammary carcinogens that are not metabolized by rat NAT2 [65].

This dissertation provides evidence that NAT1 influences mammary cancer susceptibility and has an endogenous role within a cell. The "complete mechanism/role" of NAT1 is still debatable. The mechanism/role discussed within 
this dissertation focused on NAT1 influence over AcCoA concentrations. Future experiments will need to be done to fully understand the ramifications and benefits of removing NAT1 activity from a cell. 


\section{CHAPTER VII}

\section{FUTURE DIRECTIONS}

This chapter serves to provide future experiments to expand upon the results within this dissertation. The results of this dissertation indicate NAT1 has a role in tumorigenesis, anchorage-independent colony formation, and cellular AcCoA concentrations. The future directions based off these findings are diverse in scope from exploring the role NAT1 might play in DNA damage to exploring how altered levels of one of the most important biology compounds, AcCoA, can affect cellular functions.

In chapter three, slow NAT2 congenic rats had fewer mammary tumors than rapid NAT2 congenic rats following administration carcinogens (MNU and DMBA) that are not metabolized by rat NAT2. The difference in tumor incidence between the congenic rat strains is hypothesized to be the result of difference in DNA damage repair. The first possible experiment is measuring total DNA damage in the rapid and slow congenic rats from MNU by alkaline comet assay. The other experiment could be measuring the level of H-Ras and K-Ras mutations resulting from MNU exposure. While measuring the frequency of mutations is not a measure of DNA damage, the mutations are a result of 
inappropriate DNA repair. These experiments will inform how rat NAT2 activity can influence tumorigenic differences.

The comet assay, also known as single-cell gel electrophoresis assay, is a simple and sensitive technique for the detection of DNA damage and repair in cell lines. A commonly used comet assay is the alkaline comet assay, which is performed under high $\mathrm{pH}(>13)$. The alkaline comet assay is optimal for assessing agents with genotoxic activity [152]. The alkaline comet assay is able to detect single-strand breaks, double-strand breaks, and other damage to DNA. As discussed in the chapter three, the methylnitrosourea (MNU) mechanism to cause cancer is DNA damage resulting from the alkylation of nitrogen and oxygen in DNA leading to mutations (figure 3.2). MNU exposure strategy for cell lines has been established, and analyzed by alkaline comet assay [153]. The rat embryonic fibroblasts (REFs) isolated from the congenic rat model in chapter three can be used with an alkaline comet assay. The REFs could be exposed to MNU in situ and DNA damage quantified over time. The expected result is that slow NAT2 REFs would have reduced levels of DNA damage compared to the rapid NAT2 REFs. The parental and NAT1 modified MDA-MB-231 and MCF7 breast cancer cell lines could also be used with the alkaline comet assay following MNU exposure. Preliminary studies have been performed with the MDA-MB-231 parental and NAT1 knockout clone cell lines. Currently there is a trend of the NAT1 knockout MDA-MB-231 clones having less DNA damage than 
the parental cells at 24 hours post MNU exposure. Additional experiments are needed to confirm that NAT1 knockout serves to reduce DNA damage.

In classical chemical carcinogenesis studies, MNU is shown to commonly target the second base of codon 12 of H-Ras and K-Ras to generate a G12D mutation [97, 154-158]. This common mutation on codon 12 of $\mathrm{H}$-Ras and K-Ras caused by MNU can be used to assess the frequency of mutation between rapid and slow NAT2 congenic rats. A study using isolated rapid and slow NAT2 REFs to assess the mutation frequency of Ras codon 12 following in situ MNU exposure would determine any mutation frequency difference. The expected result would be the slow NAT2 REFs have a lower frequency of the mutation compared to the rapid NAT2 REFs after MNU exposure. The use of MDA-MB231 and MCF7 NAT1 knockout clones could also be used instead of REFs to quantify the frequency of codon 12 mutations. MCF7 cell line does not contain any mutations at the codon 12 for H-RAS and K-Ras [159]. MDA-MB-231 cell line also has no mutations for the codon 12 in H-Ras and K-Ras, however there is a known mutation in K-Ras codon 13 (G13D) [159]. The quantification of MNU induced mutation at codon 12 can be done with competitive, allele-specific TaqMan $^{\text {TM }}$ PCR (castPCR) (Life Technologies ${ }^{\text {TM }}$, California, USA) [160]. This experiment would answer if NAT1 knockout could help cells repair DNA damage with a lower frequency of DNA mutations. 
Additional experiments in relationship to the finding in chapter three range from repeat experiments in new animal models to use of new carcinogens. While considerable effort was put forward to minimize the differences between rapid and slow NAT2 congenic rats, it is still only one animal model. This use of only one animal model is a weakness in the study from chapter three. The addition of different animal models with altered rodent NAT2 activity, such as mouse and hamster, would serve to strengthen tumorigenic study findings [52, 57-59, 161]. Another interesting study would be the effect of mammary tumor mastectomies on tumor re-occurrence between the rapid and slow NAT2 congenic rats. Mammary tumors would be induced with MNU or DBMA, and upon the first palpable mass perform a mastectomy to remove the mammary gland to subsequently observe if the mastectomy provided increased tumor free periods for either the rapid or slow NAT2 congenic rats. The results of this study could help guide clinical decisions, when a woman with higher or lower levels of NAT1 activity is diagnosed with breast cancer. Also since rodent NAT2 is known to have wide tissue distribution, conducting chemically induced tumorigenic experiments in other tissues should show similar results to the mammary gland tumor incidence. There are numerous published chemically induced tumor animal models with detailed mechanism information. As with the MNU and DMBA, carcinogens should be selected that do not require metabolic activation or deactivation by human NAT1/rat NAT2. 
In chapter four and five, anchorage-independent colony formation is decreased whenever NAT1 activity is reduced. This raises the question as to how NAT1 is able to influence this anchorage-independent colony formation finding. The proteins involved for this result are wide ranging, and information is lacking to help directly address the mechanistic role of NAT1. To direct future research efforts proteomic and acetylomic analysis of MDA-MB-231 parental and NAT1 knockout clone cell lines are being conducted. The results of these studies will guide future research into proteins that could be involved in the observed differences in anchorage-independent colony formation. In addition, proteomics and acetylomics will allow for greater understanding of NAT1's role in cellular biology.

The mammalian cell contains more than 8,000 unique acetylation sites on proteins [162-164]. Protein acetylation occurs both co-translationally onto the $N$ terminal residue of a protein and post-translationally onto the $N^{\varepsilon}$ amino group of lysine residues. Lysine acetylation is catalyzed by multiple families of lysine acetyltransferases (KATs) and reversed by lysine deacetylases (KDACs). AcCoA is an essential donor of acetyl groups for acetylation in eukaryotic cells. Reduced AcCoA carboxylase (ACC1) expression decreases the amount of AcCoA that moves through the fatty acid synthesis pathway, resulting in an increased cellular level of AcCoA, globally increased histone acetylation, and altered transcriptional regulation [165, 166]. Increased conversion of AcCoA into malonyl-CoA reduces 
the pool of cellular acetyl-CoA, and globally decreased histone acetylation [166]. Although acetylation correlates with the level of AcCoA, it is unclear whether AcCoA is rate-limiting for the activity of all KATs. The results from chapter three, four, and five show decreased NAT1 activity increases the concentration of AcCoA within a cell. This control of AcCoA by NAT1 may mean that NAT1 can control the level of protein and histone acetylation.

The growing amount of literature on the importance of protein acetylation underscores the importance of understanding how NAT1 influences AcCoA concentration, protein post translation modifications, and histone acetylation. The use of mass spectrometry can be used to explore how NAT1 activity can affect the protein post translation modification landscape, also known as acetylomics. Also, NAT1 activity control of cellular AcCoA could provide interesting research in spermatogenesis. During the formation of sperm, cells go through a period of hyperacetylation. During the hyperacetylation stage, cells could repress NAT1 expression, so AcCoA levels increase. The NAT1 activity can be determined for tissues from different stages of spermatogenesis. The possible repression of NAT1 activity should align with the period of hyperacetylation. As discussed in chapter four, overexpression NAT1 does not seem to affect the AcCoA concentration compared to the parental cell line. The reason for this result is still unclear, and could benefit from additional investigations.

As this chapter highlights, there are various experiments that can be 
pursued as an extension of work presented in this dissertation. The extended research should reveal interesting roles for NAT1 in tumorigenesis, anchorageindependent colony formation, and cellular AcCoA concentrations. The future of NAT1 research should prove to be of considerable interest as the massive voids in understanding of NAT1's endogenous role is further elucidated. 


\section{REFERENCES}

1. Blum, M., et al., Human Arylamine N-Acetyltransferase Genes - Isolation, Chromosomal Localization, and Functional Expression. DNA and Cell Biology, 1990. 9(3): p. 193-203.

2. Boukouvala, S. and E. Sim, Structural analysis of the genes for human arylamine $\mathrm{N}$-acetyltransferases and characterisation of alternative transcripts. Basic \& Clinical Pharmacology \& Toxicology, 2005. 96(5): p. 343-351.

3. Pacifici, G.M., C. Bencini, and A. Rane, Acetyltransferase in Humans Development and Tissue Distribution. Pharmacology, 1986. 32(5): p. 283291.

4. Windmill, K.F., et al., The role of xenobiotic metabolizing enzymes in arylamine toxicity and carcinogenesis: Functional and localization studies. Mutation Research-Fundamental and Molecular Mechanisms of Mutagenesis, 1997. 376(1-2): p. 153-160.

5. Sim, E., et al., Arylamine N-acetyltransferases: structural and functional implications of polymorphisms. Toxicology, 2008. 254(3): p. 170-83.

6. Hein, D.W., et al., Changes in consensus arylamine N-acetyltransferase gene nomenclature. Pharmacogenetics and Genomics, 2008. 18(4): p. 367-368.

7. Hein, D.W., et al., Molecular genetics and epidemiology of the NAT1 and NAT2 acetylation polymorphisms. Cancer Epidemiol Biomarkers Prev, 2000. 9(1): p. 29-42.

8. Adam, P.J., et al., Arylamine N-Acetyltransferase-1 Is Highly Expressed in Breast Cancers and Conveys Enhanced Growth and Resistance to Etoposide in Vitro. Molecular Cancer Research, 2003. 1(11): p. 826-835.

9. Tooker, P., et al., Bexarotene (LGD1069, Targretin), a selective retinoid X receptor agonist, prevents and reverses gemcitabine resistance in NSCLC cells by modulating gene amplification. Cancer Res, 2007. 67(9): p. 442533. 
10. Wakefield, L., et al., Arylamine $\mathrm{N}$-acetyltransferase I expression in breast cancer cell lines: A potential marker in estrogen receptor-positive tumors. Genes Chromosomes \& Cancer, 2008. 47(2): p. 118-126.

11. Tiang, J.M., N.J. Butcher, and R.F. Minchin, Small molecule inhibition of arylamine $\mathrm{N}$-acetyltransferase Type $I$ inhibits proliferation and invasiveness of MDA-MB-231 breast cancer cells. Biochemical and Biophysical Research Communications, 2010. 393(1): p. 95-100.

12. Tiang, J.M., N.J. Butcher, and R.F. Minchin, Effects of human arylamine $\mathrm{N}$-acetyltransferase I knockdown in triple-negative breast cancer cell lines. Cancer Medicine, 2015. 4(4): p. 565-574.

13. Tiang, J.M., et al., RNAi-Mediated Knock-Down of Arylamine Nacetyltransferase-1 Expression Induces E-cadherin Up-Regulation and Cell-Cell Contact Growth Inhibition. Plos One, 2011. 6(2).

14. Butcher, N.J. and R.F. Minchin, Arylamine N-Acetyltransferase 1: A Novel Drug Target in Cancer Development. Pharmacological Reviews, 2012. 64(1): p. 147-165.

15. Perou, C.M., et al., Molecular portraits of human breast tumours. Nature, 2000. 406(6797): p. 747-52.

16. Sorlie, T., et al., Gene expression patterns of breast carcinomas distinguish tumor subclasses with clinical implications. Proceedings of the National Academy of Sciences of the United States of America, 2001. 98(19): p. 10869-74.

17. van 't Veer, L.J., et al., Gene expression profiling predicts clinical outcome of breast cancer. Nature, 2002. 415(6871): p. 530-6.

18. Weigelt, B., et al., Gene expression profiles of primary breast tumors maintained in distant metastases. Proceedings of the National Academy of Sciences of the United States of America, 2003. 100(26): p. 15901-5.

19. Bertucci, F., et al., Identification and validation of an ERBB2 gene expression signature in breast cancers. Oncogene, 2004. 23(14): p. 256475.

20. Abba, M.C., et al., Gene expression signature of estrogen receptor alpha status in breast cancer. BMC Genomics, 2005. 6: p. 37.

21. Knuutila, S., et al., DNA copy number losses in human neoplasms. American Journal of Pathology, 1999. 155(3): p. 683-694.

22. Farmer, P., et al., Identification of molecular apocrine breast tumours by microarray analysis. Oncogene, 2005. 24(29): p. 4660-71. 
23. Alimonti, A., et al., Subtle variations in Pten dose determine cancer susceptibility. Nature Genetics, 2010. 42(5): p. 454-U136.

24. Smid, M., et al., Genes associated with breast cancer metastatic to bone. Journal of Clinical Oncology, 2006. 24(15): p. 2261-2267.

25. Casey, T., et al., Molecular signatures suggest a major role for stromal cells in development of invasive breast cancer. Breast cancer research and treatment, 2009. 114(1): p. 47-62.

26. Badawi, A.F., et al., Role of Aromatic Amine Acetyltransferases, Nat1 and Nat2, in Carcinogen-DNA Adduct Formation in the Human UrinaryBladder. Cancer Research, 1995. 55(22): p. 5230-5237.

27. Bell, D.A., et al., Polymorphism in the N-acetyltransferase 1 (NAT1) polyadenylation signal: association of NAT1*10 allele with higher $\mathrm{N}$ acetylation activity in bladder and colon tissue. Cancer Research, 1995. 55(22): p. 5226-9.

28. Wang, D., et al., Human N-acetyltransferase $1{ }^{*} 10$ and ${ }^{*} 11$ alleles increase protein expression through distinct mechanisms and associate with sulfamethoxazole-induced hypersensitivity. Pharmacogenetics and Genomics, 2011. 21(10): p. 652-664.

29. Millikan, R.C., et al., Cigarette smoking, $\mathrm{N}$-acetyltransferases 1 and 2, and breast cancer risk. Cancer Epidemiology, Biomarkers \& Prevention, 1998. 7(5): p. 371-378.

30. Lilla, C., et al., Effect of NAT1 and NAT2 genetic polymorphisms on colorectal cancer risk associated with exposure to tobacco smoke and meat consumption. Cancer Epidemiology, Biomarkers \& Prevention, 2006. 15(1): p. 99-107.

31. Bell, D.A., et al., Polyadenylation Polymorphism in the Acetyltransferase-1 Gene (Nat1) Increases Risk of Colorectal-Cancer. Cancer Research, 1995. 55(16): p. 3537-3542.

32. Gemignani, F., et al., Development of lung cancer before the age of 50: the role of xenobiotic metabolizing genes. Carcinogenesis, 2007. 28(6): p. 1287-1293.

33. Li, D., et al., Polymorphisms of cytochrome P4501A2 and Nacetyltransferase genes, smoking, and risk of pancreatic cancer. Carcinogenesis, 2006. 27(1): p. 103-11.

34. Taylor, J.A., et al., The role of N-acetylation polymorphisms in smokingassociated bladder cancer: Evidence of a gene-gene-exposure three-way interaction. Cancer Research, 1998. 58(16): p. 3603-3610. 
35. Gu, J., et al., Effects of $\mathrm{N}$-acetyl transferase 1 and 2 polymorphisms on bladder cancer risk in Caucasians. Mutation Research-Genetic Toxicology and Environmental Mutagenesis, 2005. 581(1-2): p. 97-104.

36. Gong, C.M., et al., A meta-analysis of the NAT1 and NAT2 polymorphisms and prostate cancer: a huge review. Medical Oncology, 2011. 28(1): p. 365-376.

37. Dhaini, H.R. and G.N. Levy, Arylamine N-acetyltransferase 1 (NAT1) genotypes in a Lebanese population. Pharmacogenetics, 2000. 10(1): p. 79-83.

38. Walraven, J.M., J.O. Trent, and D.W. Hein, Structure-function analyses of single nucleotide polymorphisms in human $N$-acetyltransferase 1. Drug Metabolism Reviews, 2008. 40(1): p. 169-184.

39. Bouchardy, C., et al., N-acetyltransferase NAT1 and NAT2 genotypes and lung cancer risk. Pharmacogenetics, 1998. 8(4): p. 291-8.

40. Millner, L.M., et al., Phenotype of the most common "slow acetylator" arylamine $N$-acetyltransferase 1 genetic variant (NAT1*14B) is substratedependent. Drug Metab Dispos, 2012. 40(1): p. 198-204.

41. Hein, D.W., et al., Molecular genetics and epidemiology of the NAT1 and NAT2 acetylation polymorphisms. Cancer Epidemiology, Biomarkers \& Prevention, 2000. 9(1): p. 29-42.

42. Hein, D.W., Molecular genetics and function of NAT1 and NAT2: role in aromatic amine metabolism and carcinogenesis. Mutation ResearchFundamental and Molecular Mechanisms of Mutagenesis, 2002. 506: $p$. 65-77.

43. de Leon, J.H., K.P. Vatsis, and W.W. Weber, Characterization of naturally occurring and recombinant human $\mathrm{N}$-acetyltransferase variants encoded by NAT1. Molecular Pharmacology, 2000. 58(2): p. 288-99.

44. Fretland, A.J., et al., Functional characterization of nucleotide polymorphisms in the coding region of N-acetyltransferase 1. Pharmacogenetics, 2001. 11(6): p. 511-20.

45. Evans, D.A.P., K.A. Manley, and V.A. McKusick, Genetic Control of Isoniazid Metabolism in Man. Bmj, 1960. 2(5197): p. 485-491.

46. Parker, J.M., Human Variability in the Metabolism of Sulfamethazine. Human Heredity, 1969. 19(4): p. 402-409.

47. Weber, W.W. and D.W. Hein, N-Acetylation Pharmacogenetics. Pharmacological Reviews, 1985. 37(1): p. 25-79. 
48. Goodfellow, G.H., J.M. Dupret, and D.M. Grant, Identification of amino acids imparting acceptor substrate selectivity to human arylamine acetyltransferases NAT1 and NAT2. Biochemical Journal, 2000. 348: p. 159-166.

49. Mushtaq, A., M. Payton, and E. Sim, The $\mathrm{COOH}$ terminus of arylamine Nacetyltransferase from Salmonella typhimurium controls enzymic activity. Journal of Biological Chemistry, 2002. 277(14): p. 12175-12181.

50. Walraven, J.M., M.A. Doll, and D.W. Hein, Identification and characterization of functional rat arylamine $\mathrm{N}$-acetyltransferase 3 : Comparisons with rat arylamine $\mathrm{N}$-acetyltransferases 1 and 2 . Journal of Pharmacology and Experimental Therapeutics, 2006. 319(1): p. 369-375.

51. Wakefield, L., et al., Mouse arylamine N-acetyltransferase 2 (Nat2) expression during embryogenesis: a potential marker for the developing neuroendocrine system. Biomarkers, 2008. 13(1): p. 106-18.

52. Witham, K.L., et al., 5-methyl-tetrahydrofolate and the Sadenosylmethionine cycle in C57BL/6J mouse tissues: gender differences and effects of arylamine N-acetyltransferase-1 deletion. PLoS One, 2013. 8(10): p. e77923.

53. Minchin, R.F., Acetylation of P-Aminobenzoylglutamate, a Folic-Acid Catabolite, by Recombinant Human Arylamine N-Acetyltransferase and U937 Cells. Biochemical Journal, 1995. 307: p. 1-3.

54. Laurieri, N., et al., From Arylamine N-Acetyltransferase to FolateDependent Acetyl CoA Hydrolase: Impact of Folic Acid on the Activity of (HUMAN)NAT1 and Its Homologue (MOUSE)NAT2. PLoS One, 2014. 9(5): p. e96370.

55. Hein, D.W., et al., Metabolic activation and deactivation of arylamine carcinogens by recombinant human NAT1 and polymorphic NAT2 acetyltransferases. Carcinogenesis, 1993. 14(8): p. 1633-8.

56. Doll, M.A. and D.W. Hein, Cloning, sequencing and expression of NAT1 and NAT2 encoding genes from rapid and slow acetylator inbred rats. Pharmacogenetics, 1995. 5(4): p. 247-51.

57. Fretland, A.J., et al., Cloning, sequencing, and recombinant expression of NAT1, NAT2, and NAT3 derived from the C3H/HeJ (rapid) and A/HeJ (slow) acetylator inbred mouse: Functional characterization of the activation and deactivation of aromatic amine carcinogens. Toxicology and Applied Pharmacology, 1997. 142(2): p. 360-366. 
58. Ferguson, R.J., et al., Syrian hamster monomorphic $\mathrm{N}$-acetyltransferase (NAT1) alleles: amplification, cloning, sequencing, and expression in $E$. coli. Pharmacogenetics, 1994. 4(2): p. 82-90.

59. Ferguson, R.J., et al., Cloning, expression, and functional characterization of rapid and slow acetylator polymorphic $\mathrm{N}$-acetyl-transferase encoding genes of the Syrian hamster. Pharmacogenetics, 1996. 6(1): p. 55-66.

60. Hein, D.W., N-acetyltransferase 2 genetic polymorphism: effects of carcinogen and haplotype on urinary bladder cancer risk. Oncogene, 2006. 25(11): p. 1649-58.

61. Deghan Manshadi, S., et al., Folic acid supplementation promotes mammary tumor progression in a rat model. PLoS One, 2014. 9(1): $p$. e84635.

62. Folate, in Dietary Reference Intakes for Thiamin, Riboflavin, Niacin, Vitamin B6, Folate, Vitamin B12, Pantothenic Acid, Biotin, and Choline. 1998, National Academies Press (US): Washington (DC).

63. Llanos, A.A., et al., Relationships among folate, alcohol consumption, gene variants in one-carbon metabolism and p16INK4a methylation and expression in healthy breast tissues. Carcinogenesis, 2014. 36(1): p. 6067.

64. Hein, D.W., et al., Systemic functional expression of $\mathrm{N}$-acetyltransferase polymorphism in the F344 Nat2 congenic rat. Drug metabolism and disposition: the biological fate of chemicals, 2008. 36(12): p. 2452-9.

65. Stepp, M.W., et al., Congenic rats with higher arylamine Nacetyltransferase 2 activity exhibit greater carcinogen-induced mammary tumor susceptibility independent of carcinogen metabolism. BMC Cancer, 2017. 17(1): p. 233.

66. Millner, L.M., et al., Phenotype of the Most Common "Slow Acetylator" Arylamine N-Acetyltransferase 1 Genetic Variant (NAT1*14B) Is Substrate-Dependent. Drug Metabolism and Disposition, 2011. 40(1): p. 198-204.

67. Endo, Y., et al., Immunohistochemical determination of the miR-1290 target arylamine $\mathrm{N}$-acetyltransferase 1 (NAT1) as a prognostic biomarker in breast cancer. BMC Cancer, 2014. 14: p. 990.

68. Kim, S.J., et al., Promoter hypomethylation of the $N$-acetyltransferase 1 gene in breast cancer. Oncology Reports, 2008. 19(3): p. 663-668.

69. Butcher, N.J., A. Arulpragasam, and R.F. Minchin, Proteasomal degradation of $\mathrm{N}$-acetyltransferase 1 is prevented by acetylation of the 
active site cysteine - A mechanism for the slow acetylator phenotype and substrate-dependent down-regulation. Journal of Biological Chemistry, 2004. 279(21): p. 22131-22137.

70. Butcher, N.J., K.F. Ilett, and R.F. Minchin, Substrate-dependent regulation of human arylamine $\mathrm{N}$-acetyltransferase-1 in cultured cells. Molecular Pharmacology, 2000. 57(3): p. 468-73.

71. Butcher, N.J. and R.F. Minchin, Arylamine N-acetyltransferase 1 gene regulation by androgens requires a conserved heat shock element for heat shock factor-1. Carcinogenesis, 2010. 31(5): p. 820-6.

72. Bonamassa, B., Y.J. Ma, and D.X. Liu, Glucocorticoid Receptor-Mediated Transcriptional Regulation of N-acetyltransferase 1 Gene Through Distal Promoter. AAPS Journal, 2012. 14(3): p. 581-590.

73. Hein, D.W., et al., Rodent models of the human acetylation polymorphism: comparisons of recombinant acetyltransferases. Mutation research, 1997. 376(1-2): p. 101-6.

74. Wick, M.J. and P.E. Hanna, Bioactivation of N-arylhydroxamic acids by rat hepatic $\mathrm{N}$-acetyltransferase. Detection of multiple enzyme forms by mechanism-based inactivation. Biochemical pharmacology, 1990. 39(6): p. 991-1003.

75. Hein, D.W., et al., Extrahepatic Expression of the $\mathrm{N}$-Acetylation Polymorphism toward Arylamine Carcinogens in Tumor Target Organs of an Inbred Rat Model. Journal of Pharmacology and Experimental Therapeutics, 1991. 258(1): p. 232-236.

76. Hein, D.W., et al., Acetylator phenotype-dependent and -independent expression of arylamine $\mathrm{N}$-acetyltransferase isozymes in rapid and slow acetylator inbred rat liver. Drug metabolism and disposition: the biological fate of chemicals, 1991. 19(5): p. 933-7.

77. Ariazi, J.L., et al., Mammary glands of sexually immature rats are more susceptible than those of mature rats to the carcinogenic, lethal, and mutagenic effects of $\mathrm{N}$-nitroso- $\mathrm{N}$-methylurea. Mol Carcinog, 2005. 43(3): p. $155-64$.

78. Pegg, A.E., Methylation of the O6 position of guanine in DNA is the most likely initiating event in carcinogenesis by methylating agents. Cancer Invest, 1984. 2(3): p. 223-31.

79. Shrivastav, N., D. Li, and J.M. Essigmann, Chemical biology of mutagenesis and DNA repair: cellular responses to DNA alkylation. Carcinogenesis, 2010. 31(1): p. 59-70. 
80. Fortini, P., et al., The base excision repair: mechanisms and its relevance for cancer susceptibility. Biochimie, 2003. 85(11): p. 1053-71.

81. Engelward, B.P., et al., A chemical and genetic approach together define the biological consequences of 3-methyladenine lesions in the mammalian genome. Journal of Biological Chemistry, 1998. 273(9): p. 5412-5418.

82. Loechler, E.L., C.L. Green, and J.M. Essigmann, In vivo mutagenesis by O6-methylguanine built into a unique site in a viral genome. Proceedings of the National Academy of Sciences of the United States of America, 1984. 81(20): p. 6271-5.

83. Margison, G.P. and M.F. Santibanez-Koref, O6-alkylguanine-DNA alkyltransferase: role in carcinogenesis and chemotherapy. Bioessays, 2002. 24(3): p. 255-66.

84. York, S.J. and P. Modrich, Mismatch Repair-dependent Iterative Excision at Irreparable O6-Methylguanine Lesions in Human Nuclear Extracts. Journal of Biological Chemistry, 2006. 281(32): p. 22674-22683.

85. Karran, P. and M.G. Marinus, Mismatch correction at O6-methylguanine residues in E. coli DNA. Nature, 1982. 296(5860): p. 868-9.

86. Delaney, J.C. and J.M. Essigmann, Effect of sequence context on O(6)methylguanine repair and replication in vivo. Biochemistry, 2001. 40(49): p. $14968-75$.

87. Fu, D., J.A. Calvo, and L.D. Samson, Balancing repair and tolerance of DNA damage caused by alkylating agents. Nature Reviews: Cancer, 2012. 12(2): p. 104-120.

88. Ethier, S.P. and R.L. Ullrich, Induction of mammary tumors in virgin female $B A L B / c$ mice by single low doses of 7,12-dimethylbenz[a]anthracene. Journal of the National Cancer Institute, 1982. 69(5): p. 1199-203.

89. Huberman, E., M.W. Chou, and S.K. Yang, Identification of 7,12dimethylbenz[a]anthracene metabolites that lead to mutagenesis in mammalian cells. Proceedings of the National Academy of Sciences of the United States of America, 1979. 76(2): p. 862-866.

90. Slaga, T.J., et al., Importance of the Bay Region Diol-Epoxide in 7,12Dimethylbenz[a]Anthracene Skin Tumor Initiation and Mutagenesis. Cancer Letters, 1979. 6(4-5): p. 213-220.

91. Gonzalez, F.J., The use of gene knockout mice to unravel the mechanisms of toxicity and chemical carcinogenesis. Toxicology Letters, 2001. 120(1-3): p. 199-208. 
92. Buters, J., et al., CYP1B1 determines susceptibility to low doses of 7,12dimethylbenz[a]anthracene-induced ovarian cancers in mice: correlation of CYP1B1-mediated DNA adducts with carcinogenicity. Carcinogenesis, 2003. 24(2): p. 327-34.

93. Nebert, D.W., D.D. Petersen, and A.J. Fornace, Cellular-Responses to Oxidative Stress - the [Ah] Gene Battery as a Paradigm. Environmental Health Perspectives, 1990. 88: p. 13-25.

94. Rundle, A., et al., The relationship between genetic damage from polycyclic aromatic hydrocarbons in breast tissue and breast cancer. Carcinogenesis, 2000. 21(7): p. 1281-9.

95. Weinkam, R.J. and M.E. Dolan, Intracellular activation of cytotoxic agents: kinetic models for methylnitrosoureas and N-methyl-N'-nitro- $N$ nitrosoguanidine in cell culture. Chemical Research in Toxicology, 1989. 2(3): p. 157-161.

96. Pegg, A.E., Methylation of the O6Position of Guanine in DNA is the Most Likely Initiating Event in Carcinogenesis by Methylating Agents. Cancer Investigation, 2009. 2(3): p. 223-231.

97. Budan, F., et al., Early modification of c-myc, Ha-ras and p53 expressions by chemical carcinogens (DMBA, MNU). In Vivo, 2009. 23(4): p. 591-8.

98. Thompson, H.J., et al., Rapid induction of mammary intraductal proliferations, ductal carcinoma in situ and carcinomas by the injection of sexually immature female rats with 1-methyl-1-nitrosourea. Carcinogenesis, 1995. 16(10): p. 2407-11.

99. Ariazi, J.L., et al., Mammary glands of sexually immature rats are more susceptible than those of mature rats to the carcinogenic, lethal, and mutagenic effects of $\mathrm{N}$-nitroso- $\mathrm{N}$-methylurea. Molecular Carcinogenesis, 2005. 43(3): p. 155-164.

100. Thompson, H.J., et al., Temporal sequence of mammary intraductal proliferations, ductal carcinomas in situ and adenocarcinomas induced by 1-methyl-1-nitrosourea in rats. Carcinogenesis, 1998. 19(12): p. 2181-5.

101. Samuelson, D.J., et al., Fine mapping reveals multiple loci and a possible epistatic interaction within the mammary carcinoma susceptibility quantitative trait locus, Mcs5. Cancer Research, 2005. 65(21): p. 96379642.

102. Samuelson, D.J., et al., Rat Mcs5a is a compound quantitative trait locus with orthologous human loci that associate with breast cancer risk. Proceedings of the National Academy of Sciences of the United States of America, 2007. 104(15): p. 6299-6304. 
103. Stepp, M.W., et al., Folate-dependent hydrolysis of acetyl-coenzyme $A$ by recombinant human and rodent arylamine $N$-acetyltransferases. Biochemistry and Biophysics Reports, 2015. 3: p. 45-50.

104. Warner, D.R., et al., Altered signal transduction in Folr1(-/-) mouse embryo fibroblasts. Cell Biology International, 2011. 35(12): p. 1253-1259.

105. Miyazono, Y., et al., Toxicological characterization of $\mathrm{N}$-methyl-Nnitrosourea-induced cataract in rats by LC/MS-based metabonomic analysis. Journal of Applied Toxicology, 2011. 31(7): p. 655-662.

106. Bieche, I., et al., Relationship between intratumoral expression of genes coding for xenobiotic-metabolizing enzymes and benefit from adjuvant tamoxifen in estrogen receptor alpha-positive postmenopausal breast carcinoma. Breast Cancer Research, 2004. 6(3): p. R252-R263.

107. Andres, S.A., G.N. Brock, and J.L. Wittliff, Interrogating differences in expression of targeted gene sets to predict breast cancer outcome. BMC Cancer, 2013. 13: p. 326.

108. Ronckers, C.M., C.A. Erdmann, and C.E. Land, Radiation and breast cancer: a review of current evidence. Breast Cancer Research, 2005. 7(1): p. 21-32.

109. Imaoka, T., et al., Radiation-Induced Mammary Carcinogenesis in Rodent Models: What's Different from Chemical Carcinogenesis? Journal of Radiation Research, 2009. 50(4): p. 281-293.

110. Program), N.N.T., N-Nitrosamines (15 listings): N-Nitroso-N-methylurea. Rep Carcinog, 2011. 12: p. 318.

111. Cai, L., et al., Acetyl-CoA Induces Cell Growth and Proliferation by Promoting the Acetylation of Histones at Growth Genes. Molecular Cell, 2011. 42(4): p. 426-437.

112. Marino, G., et al., Regulation of Autophagy by Cytosolic Acetyl-Coenzyme A. Molecular Cell, 2014. 53(5): p. 710-725.

113. Galdieri, L. and A. Vancura, Acetyl-CoA Carboxylase Regulates Global Histone Acetylation. Journal of Biological Chemistry, 2012. 287(28): p. 23865-23876.

114. Wellen, K.E., et al., ATP-citrate lyase links cellular metabolism to histone acetylation. Science, 2009. 324(5930): p. 1076-80.

115. Siudeja, K., et al., Impaired Coenzyme A metabolism affects histone and tubulin acetylation in Drosophila and human cell models of pantothenate 
kinase associated neurodegeneration. Embo Molecular Medicine, 2011. 3(12): p. 755-766.

116. Siegel, R.L., K.D. Miller, and A. Jemal, Cancer statistics, 2016. CA: A Cancer Journal for Clinicians, 2016. 66(1): p. 7-30.

117. Savci-Heijink, C.D., et al., A novel gene expression signature for bone metastasis in breast carcinomas. Breast Cancer Res Treat, 2016. 156(2): p. 249-59.

118. Bonifas, J., et al., Characterization of N-Acetyltransferase 1 Activity in Human Keratinocytes and Modulation by para-Phenylenediamine. Journal of Pharmacology and Experimental Therapeutics, 2010. 334(1): p. 318326.

119. Dairou, J., et al., Peroxynitrite irreversibly inactivates the human xenobiotic-metabolizing enzyme arylamine $N$-acetyltransferase 1 (NAT1) in human breast cancer cells - A cellular and mechanistic study. Journal of Biological Chemistry, 2004. 279(9): p. 7708-7714.

120. Atmane, N., et al., Redox regulation of the human xenobiotic metabolizing enzyme arylamine N-acetyltransferase 1 (NAT1) - Reversible inactivation by hydrogen peroxide. Journal of Biological Chemistry, 2003. 278(37): p. 35086-35092.

121. Ragunathan, $\mathrm{N}$., et al., Identification of the xenobiotic-metabolizing enzyme arylamine $N$-acetyltransferase 1 as a new target of cisplatin in breast cancer cells: Molecular and cellular mechanisms of inhibition. Molecular Pharmacology, 2008. 73(6): p. 1761-1768.

122. Kukongviriyapan, V., et al., Inhibitory effects of polyphenolic compounds on human arylamine N-acetyltransferase 1 and 2. Xenobiotica, 2006. 36(1): p. 15-28.

123. Chen, Y.S., et al., Curcumin inhibited the arylamines $N$-acetyltransferase activity, gene expression and DNA adduct formation in human lung cancer cells (A549). Toxicology in Vitro, 2003. 17(3): p. 323-333.

124. Malka, F., et al., Mechanisms and kinetics of human arylamine Nacetyltransferase 1 inhibition by disulfiram. Febs Journal, 2009. 276(17): p. $4900-4908$.

125. Tiang, J.M., N.J. Butcher, and R.F. Minchin, Small molecule inhibition of arylamine $\mathrm{N}$-acetyltransferase Type $I$ inhibits proliferation and invasiveness of MDA-MB-231 breast cancer cells. Biochem Biophys Res Commun, 2010. 393(1): p. 95-100. 
126. Russell, A.J., et al., Selective small molecule inhibitors of the potential breast cancer marker, human arylamine $\mathrm{N}$-acetyltransferase 1 , and its murine homologue, mouse arylamine $\mathrm{N}$-acetyltransferase 2. Bioorganic \& Medicinal Chemistry, 2009. 17(2): p. 905-918.

127. Millner, L.M., et al., NATb/NAT1*4 promotes greater arylamine $N$ acetyltransferase 1 mediated DNA adducts and mutations than NATa/NAT1*4 following exposure to 4-aminobiphenyl. Molecular Carcinogenesis, 2012. 51(8): p. 636-646.

128. Metry, K.J., et al., 2-amino-1-methyl-6-phenylimidazo [4,5-b] pyridineinduced DNA adducts and genotoxicity in Chinese hamster ovary (CHO) cells expressing human CYP1A2 and rapid or slow acetylator $\mathrm{N}$ acetyltransferase 2. Molecular Carcinogenesis, 2007. 46(7): p. 553-563.

129. Hein, D.W., et al., Tissue distribution of $\mathrm{N}$-acetyltransferase 1 and 2 catalyzing the $\mathrm{N}$-acetylation of 4-aminobiphenyl and O-acetylation of $\mathrm{N}$ hydroxy-4-aminobiphenyl in the congenic rapid and slow acetylator Syrian hamster. Molecular Carcinogenesis, 2006. 45(4): p. 230-238.

130. Millner, L.M., et al., Functional analysis of arylamine $N$-acetyltransferase 1 (NAT1) NAT1*10 haplotypes in a complete NATb mRNA construct. Carcinogenesis, 2012. 33(2): p. 348-55.

131. Carlisle, S.M., et al., Untargeted polar metabolomics of transformed MDAMB-231 breast cancer cells expressing varying levels of human arylamine $\mathrm{N}$-acetyltransferase 1. Metabolomics, 2016. 12(7).

132. Ishino, Y., et al., Nucleotide sequence of the iap gene, responsible for alkaline phosphatase isozyme conversion in Escherichia coli, and identification of the gene product. J Bacteriol, 1987. 169(12): p. 5429-33.

133. Bolotin, A., et al., Clustered regularly interspaced short palindrome repeats (CRISPRs) have spacers of extrachromosomal origin. Microbiology, 2005. 151(8): p. 2551-2561.

134. Pourcel, C., G. Salvignol, and G. Vergnaud, CRISPR elements in Yersinia pestis acquire new repeats by preferential uptake of bacteriophage DNA, and provide additional tools for evolutionary studies. Microbiology, 2005. 151(3): p. 653-663.

135. Mojica, F.J., et al., Intervening sequences of regularly spaced prokaryotic repeats derive from foreign genetic elements. J Mol Evol, 2005. 60(2): p. 174-82.

136. Brouns, S.J., et al., Small CRISPR RNAs guide antiviral defense in prokaryotes. Science, 2008. 321(5891): p. 960-4. 
137. Deltcheva, E., et al., CRISPR RNA maturation by trans-encoded small RNA and host factor RNase III. Nature, 2011. 471(7340): p. 602-7.

138. Jinek, M., et al., A programmable dual-RNA-guided DNA endonuclease in adaptive bacterial immunity. Science, 2012. 337(6096): p. 816-21.

139. Kim, D., et al., Digenome-seq: genome-wide profiling of CRISPR-Cas9 offtarget effects in human cells. Nat Methods, 2015. 12(3): p. 237-43, 1 p following 243.

140. Hsu, P.D., et al., DNA targeting specificity of RNA-guided Cas9 nucleases. Nat Biotechnol, 2013. 31(9): p. 827-32.

141. Frock, R.L., et al., Genome-wide detection of DNA double-stranded breaks induced by engineered nucleases. Nat Biotechnol, 2015. 33(2): p. $179-86$.

142. Bolukbasi, M.F., et al., DNA-binding-domain fusions enhance the targeting range and precision of Cas9. Nat Methods, 2015. 12(12): p. 1150-6.

143. Lin, Y., et al., CRISPR/Cas9 systems have off-target activity with insertions or deletions between target DNA and guide RNA sequences. Nucleic Acids Res, 2014. 42(11): p. 7473-85.

144. Fu, Y., et al., High-frequency off-target mutagenesis induced by CRISPRCas nucleases in human cells. Nat Biotechnol, 2013. 31(9): p. 822-6.

145. Tsai, S.Q., et al., GUIDE-seq enables genome-wide profiling of off-target cleavage by CRISPR-Cas nucleases. Nat Biotechnol, 2015. 33(2): p. 18797.

146. Peterson, J.L., et al., The role of endogenous epidermal growth factor receptor ligands in mediating corneal epithelial homeostasis. Invest Ophthalmol Vis Sci, 2014. 55(5): p. 2870-80.

147. Schneider, C.A., W.S. Rasband, and K.W. Eliceiri, NIH Image to ImageJ: 25 years of image analysis. Nat Methods, 2012. 9(7): p. 671-5.

148. Frisch, S.M. and E. Ruoslahti, Integrins and anoikis. Curr Opin Cell Biol, 1997. 9(5): p. 701-6.

149. Reddig, P.J. and R.L. Juliano, Clinging to life: cell to matrix adhesion and cell survival. Cancer Metastasis Rev, 2005. 24(3): p. 425-39.

150. Jin, K., et al., Molecular insights into tumour metastasis: tracing the dominant events. J Pathol, 2017. 241(5): p. 567-577. 
151. Paoli, P., E. Giannoni, and P. Chiarugi, Anoikis molecular pathways and its role in cancer progression. Biochim Biophys Acta, 2013. 1833(12): p. 3481-98.

152. Tice, R.R., et al., Single cell gel/comet assay: guidelines for in vitro and in vivo genetic toxicology testing. Environ Mol Mutagen, 2000. 35(3): p. 20621.

153. Schreiber, V., et al., Poly(ADP-ribose) polymerase-2 (PARP-2) is required for efficient base excision DNA repair in association with PARP-1 and XRCC1. J Biol Chem, 2002. 277(25): p. 23028-36.

154. Zarbl, H., et al., Direct mutagenesis of Ha-ras-1 oncogenes by N-nitroso$\mathrm{N}$-methylurea during initiation of mammary carcinogenesis in rats. Nature, 1985. 315(6018): p. 382-5.

155. Sukumar, S., et al., Induction of mammary carcinomas in rats by nitrosomethylurea involves malignant activation of $\mathrm{H}$-ras-1 locus by single point mutations. Nature, 1983. 306(5944): p. 658-61.

156. Newcomb, E.W., W. Bayona, and S. Pisharody, N-methylnitrosoureainduced Ki-ras codon 12 mutations: early events in mouse thymic lymphomas. Mol Carcinog, 1995. 13(2): p. 89-95.

157. Calvert, R.J., et al., K-ras codon 12 and 61 point mutations in bromodeoxyuridine- and $N$-nitrosomethylurea-induced rat renal mesenchymal tumors. Cancer Lett, 1996. 109(1-2): p. 1-7.

158. Barbacid, M., ras oncogenes: their role in neoplasia. Eur J Clin Invest, 1990. 20(3): p. 225-35.

159. Torbett, N.E., et al., A chemical screen in diverse breast cancer cell lines reveals genetic enhancers and suppressors of sensitivity to PI3K isoformselective inhibition. Biochem J, 2008. 415(1): p. 97-110.

160. Bolton, L., et al., KRAS mutation analysis by PCR: a comparison of two methods. PLoS One, 2015. 10(1): p. e0115672.

161. Sugamori, K.S., et al., Generation and functional characterization of arylamine $N$-acetyltransferase Nat1/Nat2 double-knockout mice. Mol Pharmacol, 2003. 64(1): p. 170-9.

162. Choudhary, C., et al., Lysine acetylation targets protein complexes and co-regulates major cellular functions. Science, 2009. 325(5942): p. 83440. 
163. Chen, Y., et al., Quantitative acetylome analysis reveals the roles of SIRT1 in regulating diverse substrates and cellular pathways. Mol Cell Proteomics, 2012. 11(10): p. 1048-62.

164. Scholz, C., et al., Acetylation site specificities of lysine deacetylase inhibitors in human cells. Nat Biotechnol, 2015. 33(4): p. 415-23.

165. Galdieri, L. and A. Vancura, Acetyl-CoA carboxylase regulates global histone acetylation. J Biol Chem, 2012. 287(28): p. 23865-76.

166. Zhang, M., L. Galdieri, and A. Vancura, The yeast AMPK homolog SNF1 regulates acetyl coenzyme $A$ homeostasis and histone acetylation. Mol Cell Biol, 2013. 33(23): p. 4701-17. 


\section{ABBREVIATIONS}

\begin{tabular}{ll} 
A & Adenine \\
ACC1 & AcCoA carboxylase \\
AcCoA & Acetyl-Coenzyme A \\
Arg & Analysis of variance \\
cDNA & Arginine \\
CO 2 & Complementary deoxyribonucleic acid \\
Cas9 & CRISPR-associated 9 enzyme \\
CRISPR & Clustered Regularly Interspaced Palindromic Repeats \\
DHF & Dihydrofolate \\
DMBA & 7,12-dimethylbenzanthracene \\
ER & Estrogen receptor \\
F344 & Fischer 344 rat \\
G & Guanine \\
H\&E & Hematoxylin and eosin \\
KATs & lysine acetyltransferases \\
KDACs & lysine deacetylases \\
kg & kilogram \\
mg & milligram \\
ml & milliliter \\
\hline
\end{tabular}




\begin{tabular}{ll} 
MNU & Methyl-nitrosourea/N-methylnitrosourea/1-nitroso-1-methylurea \\
MTX & Methotrexate \\
NAT1 & Nitrogen \\
NAT2 & Arylamine N-Acetyltransferase 1 \\
O & Arylamine N-Acetyltransferase 2 \\
PABG & Oxygen \\
PAM & p-aminobenzoylglutamate \\
PCR & protospacer adjacent motif \\
qPCR & Real-time quantitative polymerase chain reation \\
Phe & Phenylalanine \\
RNA & Ribonucleic acid \\
SEM & Standard error mean \\
shRNA & Short hairpin ribonucleic acid \\
T & Thymine \\
THF & Tetrahydrofolate \\
Tyr & Tyrosine \\
Val & Valine \\
WKY & Wistar Kyoto rat \\
${ }^{\circ} \mathrm{N}$ & Degrees Celsius \\
\hline & Micro \\
\hline
\end{tabular}




\title{
CURRICULUM VITAE
}

\author{
Marcus W. Stepp
}

University of Louisville, School of Medicine

Department of Pharmacology and Toxicology

Louisville, KY 40202

Personal Contact Information:

marcus.stepp@gmail.com

1-812-786-3449
Academic Contact Information: mwstep03@louisville.edu 1-502-852-6284
EDUCATION

2014-2017

2011-2014

2006-2010
University of Louisville, Louisville, Kentucky

Doctor of Philosophy, Department of Pharmacology and

Toxicology

National Institute of Environmental Health Sciences

Training Grant (T32-ES011564)

Graduate Dean's Citation

University of Louisville, Louisville, Kentucky

Master of Science, Department of Pharmacology and

Toxicology

Graduate Dean's Citation

Rose-Hulman Institute of Technology, Terre Haute, Indiana

Bachelors of Science, Applied Biology and Biochemistry \& Molecular Biology

\section{PROFESSIONAL EXPERIENCE \\ 2011-2017 Graduate Research Fellow, University of Louisville, Department of Pharmacology and Toxicology, Louisville, Kentucky \\ 2010-2011 Research Technician, University of Louisville, Division of Pulmonary, Critical Care, and Sleep Disorders Medicine, Louisville, Kentucky \\ 2009-2010 Undergraduate Senior Research, Rose-Hulman Institute of Technology, Terre Haute, Indiana \\ 2009 Praktikum researcher, Universitatsklinikum Essen, Institut für Transfusionsmedizin, Essen, Germany \\ 2007, 2008 Internship Researcher, Cincinnati Children's Hospital, Division of Experimental Hematology, Cincinnati, Ohio \\ LEADERSHIP (MOST RECENT) \\ 2013-2016 Class Representative, Department of Pharmacology and Toxicology, University of Louisville}


2014-2015 President, Pharmacology and Toxicology Graduate Student Organization, University of Louisville

2014-2015 Student representative, Pharmacology and Toxicology Graduate Admissions Committee, University of Louisville

2014-2015 Student representative, Graduate Student Council, University of Louisville

2013-2015 Student Representative, Student Affairs Committee, Department of Pharmacology and Toxicology, University of Louisville

2013-2014 Vice President, Pharmacology and Toxicology Graduate Student Organization, University of Louisville

MENTORSHIP (MOST RECENT)

G. Mamaliga (2014); M. Chang (2015); M. Furnish (2016);

J. Gardner (2017)

PROFESSIONAL SOCIETIES

2013-present Society of Toxicology (SOT)

2013-present Ohio Valley Chapter of the Society of Toxicology (OVSOT)

2013-present American Society for Pharmacology and Experimental Therapeutics (ASPET)

2008-present Alpha Chi Sigma (Colligate and Professional)

2007-2009 International Society for Pharmaceutical Engineering (ISPE)

\section{PUBLICATIONS}

\section{Manuscripts - Published}

1. Stepp, M. W., M. A. Doll, D. J. Samuelson, M. G. Sanders, J. C. States, D. W. Hein. (2017) "Congenic rats with higher arylamine Nacetyltransferase 2 activity exhibit greater carcinogen-induced mammary tumor susceptibility independent of carcinogen metabolism." BMC Cancer 17: 233.

2. Carlisle, S. M., P. J. Trainor, X. M. Yin, M. A. Doll, M. W. Stepp, J. C. States, X. Zhang, D. W. Hein. (2016) "Untargeted polar metabolomics of transformed MDA-MB-231 breast cancer cells expressing varying levels of human arylamine $\mathrm{N}$-acetyltransferase 1." Metabolomics 12.

3. Stepp, M. W., G. Mamaliga, M. A. Doll, J. C. States, D. W. Hein (2015). "Folate-dependent hydrolysis of acetyl-coenzyme A by recombinant human and rodent arylamine $\mathrm{N}$-acetyltransferases." Biochem Biophys Rep 3: $45-50$.

4. Stepp, M. W., R. J. Folz, J. Yu, I. N. Zelko (2014). "The c10orf10 gene product is a new link between oxidative stress and autophagy." Biochimica et Biophysica Acta (BBA) - Molecular Cell Research, 1843(6): 1076-1088,

5. Zelko, I. N., M. W. Stepp, R. J. Folz (2013). "A bioluminescent transgenic mouse model: real-time in vivo imaging of antioxidant EC-SOD gene expression and regulation by interferon gamma." Gene 530(1): 75-82. 
6. Millner, L. M., M. A. Doll, M. W. Stepp, J. C. States, D. W. Hein (2012). "Functional analysis of arylamine $\mathrm{N}$-acetyltransferase 1 (NAT1) NAT1*10 haplotypes in a complete NATb mRNA construct." Carcinogenesis 33(2): 348-355.

7. Zelko, I. N., M. W. Stepp, A. L. Vorst, R. J. Folz (2011). "Histone acetylation regulates the cell-specific and interferon-gamma-inducible expression of extracellular superoxide dismutase in human pulmonary arteries." Am J Respir Cell Mol Biol 45(5): 953-961.

\section{Manuscripts - Unpublished}

8. Stepp, M. W., M. A. Doll, S. M. Carlisle, J. C. States, D. W. Hein. "Inhibition of arylamine $\mathrm{N}$-acetyltransferase 1 reduces anchorageindependent growth in human breast cancer cell line MDA-MB-231." Submitted.

9. Carlisle, S.M., P. J. Turner, M. A. Doll, M. W. Stepp, C. M. Klinge, D. W. Hein. "Knockout of human arylamine $\mathrm{N}$-acetyltransferase 1 (NAT1) in MDA-MB-231 breast cancer cells leads to increased reserve capacity, maximum mitochondrial capacity, and glycolytic reserve capacity." Submitted.

\section{Abstracts - National//nternational}

1. Stepp, M. W., M. A. Doll, D. W. Hein (2017). Decreased Human Arylamine N-Acetyltransferase 1 (NAT1) Elevates Cellular AcetylCoenzyme A Levels. Poster presentation. Society of Toxicology $56^{\text {th }}$ Annual Meeting, Baltimore, MD

2. Stepp, M. W., M. A. Doll,D. J. Samuelson, M. G. Sanders, J. C. States, D. W. Hein. 2016. Chemically Induced Mammary Tumor Differences Between Rapid and Slow Arylamine N-Acetyltransferase Congenic Fischer 344 Rats. Oral presentation. $7^{\text {th }}$ International Workshop on Nacetyltransferase (NAT), Trier, Germany

3. Stepp, M. W., M. A. Doll, M. Y. Chang, J. C. States, D. W. Hein. 2016. CRISPR/Cas9 Knockout of Arylamine $\mathrm{N}$-acetyltransferase 1 in Human Breast Cancer Cell Lines. Oral presentation. $7^{\text {th }}$ International Workshop on $\mathrm{N}$-acetyltransferase (NAT), Trier, Germany

4. Carlisle, S. M., P. J. Trainor, X. M. Yin, M. A. Doll, M. W. Stepp, J. C. States, X. Zhang, D. W. Hein. 2016. Untargeted Polar Metabolomics of Transformed MDA-MB-231 Breast Cancer Cells Expressing Varying Levels of Human Arylamine $\mathrm{N}$-Acetyltransferase 1. Oral presentation. $7^{\text {th }}$ International Workshop on N-acetyltransferase (NAT), Trier, Germany

5. Carlisle, S. M., M. A. Doll, M. W. Stepp, J. C. States, D. W. Hein. 2016. Construction and characterization of MDA-MB-231 Breast cancer cells stably expressing Varying Arylamine $\mathrm{N}$-acetyltransferase 1. Oral presentation. $7^{\text {th }}$ International Workshop on $\mathrm{N}$-acetyltransferase (NAT), Trier, Germany 
6. Stepp, M. W., M. A. Doll,D. J. Samuelson, M. G. Sanders, J. C. States, D. W. Hein. 2016. Chemically Induced Mammary Tumor Differences Between Rapid and Slow Arylamine N-Acetyltransferase Congenic Fischer 344 Rats Administered 7,12-Dimethylbenzanthracene (DMBA). Poster presentation. Society of Toxicology $55^{\text {th }}$ Annual Meeting, New Orleans, LA

7. Stepp, M. W., M. A. Doll, J. C. States, D. W. Hein. 2015. More Frequent Breast Tumors in Rapid Compared to Slow Rat nat2 Congenic Fischer 344 Rats Administered Methylnitrosourea. Poster presentation. Society of Toxicology $54^{\text {th }}$ Annual Meeting, San Diego, CA

8. Doll, M. A., M. W. Stepp, J. C. States, D. W. Hein. 2015. RNAi- and Small Molecule-Induced Inhibition of Arylamine N-Acetyltransferase 1 Reduce Anchorage Independent Growth in Breast cancer. Poster presentation. Society of Toxicology $54^{\text {th }}$ Annual Meeting, San Diego, CA

9. Stepp, M. W., M. A. Doll, M. G. Sanders, D. W. Hein. 2013. Rapid Arylamine $N$-Acetyltransferase Congenic Rats Show Increase of Chemically Induced Breast Tumors by $\mathrm{N}$-methylnitrosourea. Oral presentation. Sixth International Workshop on Arylamine Nacetyltransferases, Toronto, ON

\section{Abstracts - Regional (20 most recent)}

1. Stepp, M. W., J. Q. Gardner, D. W. Wilkey, M. L. Merchant, D. W. Hein. 2017. Acetylomic Analysis of Arylamine N-Acetyltransferase 1 Knockout in the MDA-MB-231 Triple Negative Breast Cancer Line. Poster presentation. Research! Louisville 2017, Louisville, KY

2. Gardner, J. Q., M. W. Stepp, D. W. Wilkey, M. L. Merchant, D. W. Hein. 2017. Identification of the Endogenous Role of Arylamine NAcetyltransferase 1 in Cancer Related Cellular Processes through Proteomic Analysis. Poster presentation. Research! Louisville 2017, Louisville, KY

3. Furnish, M., M. W. Stepp, M. A. Doll, M. Y. Chang, D. W. Hein. 2017. Investigation of arylamine $\mathrm{N}$-acetyltransferase 1 CRISR/Cas9 knockout in MDA-MB-231 cell lines via anoikis and invasion assays. Poster presentation. Posters at the Capitol, Frankfort, KY

4. Furnish, M., M. W. Stepp, M. A. Doll, M. Y. Chang, D. W. Hein. 2016. Investigation of arylamine $\mathrm{N}$-acetyltransferase $1 \mathrm{CRISR} / \mathrm{Cas} 9$ knockout in MDA-MB-231 cell lines via anoikis and invasion assays. Oral presentation. Proceedings of the Kentucky Academy of Science, Louisville, KY

5. Stepp, M. W., M. A. Doll, D. W. Hein. 2016. Decreased Human NAT1 or Rat NAT2 activity Elevates Cellular Acetyl-coenzyme A Levels. Poster presentation. Ohio Valley Society of Toxicology 2016 Annual Meeting, Eli Lilly Company, Indianapolis, IN

6. Stepp, M. W., M. A. Doll, D. W. Hein. 2016. Decreased Human NAT1 or Rat NAT2 activity Elevates Cellular Acetyl-coenzyme A Levels. Poster presentation. Research! Louisville 2016, Louisville, KY 
7. Furnish, M., M. W. Stepp, M. A. Doll, M. Y. Chang, D. W. Hein. 2016. Investigation Of CRISPR/Cas9 Arylamine N-Acetyltransferase 1 Knockouts In MDA-MB-231 Cell Lines Via Anoikis And Invasion Assays. Poster presentation. Research! Louisville 2016, Louisville, KY

8. Stepp, M. W., M. A. Doll, D. J. Samuelson, M. G. Sanders, J. C. States, D. W. Hein. 2015. Differences Between Rapid and Slow Arylamine Nacetyltransferase Fischer 344 Congenic Rats in Methylnitrosoureainduced Mammary Tumors. Oral presentation. Ohio Valley Society of Toxicology 2015 Annual Meeting, Northern Kentucky University, Highland Heights, Louisville, KY

9. Stepp, M. W., M. A. Doll, M. G. Sanders, D. W. Hein. 2015. Differences between rapid and slow arylamine $\mathrm{N}$-acetyltransferase Fischer 344 congenic rats in methylnitrosourea-induced breast tumors. Poster presentation. Research! Louisville 2015, Louisville, KY

10. Chang, M. Y., M. W. Stepp, M. A. Doll, D. W. Hein. 2015. Effect of Arylamine $\mathrm{N}$-acetyltransferase 1 Knockout by CRISPR/Cas 9 on Doubling Time in MDA-MB-231, MCF-7, \& ZR-75-1 Breast Cancer Cell Lines. Poster presentation. Research! Louisville 2015, Louisville, KY

11.Stepp, M. W., G. Mamaliga, M. A. Doll, J. C. States, D. W. Hein. 2015. Folate-Dependent Hydrolysis of Acetyl-Coenzyme A by Recombinant Human and Rodent Arylamine N-Acetyltransferases. Poster presentation. Ohio Valley Society of Toxicology 2015 Graduate Student/Postdoc Annual Summer Meeting, Cincinnati, $\mathrm{OH}$

12. Stepp, M. W., G. Mamaliga, M. A. Doll, J. C. States, D. W. Hein. 2015. Folate-Dependent Hydrolysis of Acetyl-Coenzyme A by Recombinant Human and Rodent Arylamine N-Acetyltransferases. Poster presentation. Great Lakes Drug Metabolism and Disposition Group 2015 Meeting, Ann Arbor, MI

13.Stepp, M. W., M. A. Doll, J. C. States, D. W. Hein. 2014. Methylnitrosourea tumorigenesis differences between rapid and slow rat Nat2 congenic Fischer 344 rats exposed at 8 weeks of age. Poster presentation. James Graham Brown Cancer Center Annual Retreat 2014, Louisville, KY

14. Mamaliga, G., M. W. Stepp, M. A. Doll, D. W. Hein. 2014. FolateDependent Acetyl CoA Hydrolysis by Human and Rodent Nacetyltransferases. Poster presentation. James Graham Brown Cancer Center Annual Retreat 2014, Louisville, KY

15.Stepp, M. W., M. A. Doll, J. C. States, D. W. Hein. 2014. Methylnitrosourea tumorigenesis differences between rapid and slow rat Nat2 congenic Fischer 344 rats exposed at 8 weeks of age. Poster presentation. Research! Louisville 2014, Louisville, KY

16. Mamaliga, G., M. W. Stepp, M. A. Doll, D. W. Hein. 2014. FolateDependent Acetyl CoA Hydrolysis by Human and Rodent Nacetyltransferases. Poster presentation. Research! Louisville 2014, Louisville, KY

17. Barve, A. S., M. W. Stepp, M. A. Doll, J. Zhang, G. E. Arteel, S. S. Barve, 
D. W. Hein. 2014. Hepatocarcinogenic Effects of 4,4 methylenedianaline (MDA) and Obesogenic Dietary Components. Poster presentation. Research! Louisville 2014, Louisville, KY

18. Stepp, M. W., M. A. Doll, J. C. States, D. W. Hein. 2014. Incidence of Nmethylnitrosourea-induced breast tumors differ between rapid and slow acetylator congenic rat strains. Poster presentation. Great Lakes Drug Metabolism and Disposition Group 2014 Meeting, Indianapolis, IN

19. Stepp, M. W., M. A. Doll, M. G. Sanders, D. W. Hein. 2013. Fischer 344 rat strains congenic at arylamine $\mathrm{N}$-acetyltransferase differ in breast tumorigenesis induced by 1-methyl-1-nitrosourea. Poster presentation. James Graham Brown Cancer Center Annual Retreat 2013, Louisville, KY

20. Stepp, M. W., M. A. Doll, M. G. Sanders, D. W. Hein. 2013. Fischer 344 rat strains congenic at arylamine $\mathrm{N}$-acetyltransferase differ in breast tumorigenesis induced by $\mathrm{N}$-methylnitrosourea. Oral and poster presentation. Ohio Valley Society of Toxicology 2013 Annual Meeting, Louisville, $\mathrm{KY}$

\section{PRESENTATIONS (20 MOST RECENT)}

1. Poster presentation, 09/2017, Research! Louisville 2017, Louisville, KY

2. Oral presentation, 06/2017, PhD Dissertation Defense, Louisville, KY

3. Poster presentation, $3 / 2017$, Society of Toxicology $56^{\text {th }}$ Annual Meeting, Baltimore, MD

4. Poster Presentation, 10/2016, Ohio Valley Society of Toxicology 2016 Annual Meeting, Eli Lilly Company, Indianapolis, IN

5. Poster presentation, 10/2016, Research! Louisville 2016, Louisville, KY

6. Oral Presentation, 6/2016, $7^{\text {th }}$ International Workshop on Arylamine Nacetyltransferases, Tier, Germany

7. Oral Presentation, 6/2016, $7^{\text {th }}$ International Workshop on Arylamine Nacetyltransferases, Trier, Germany

8. Oral Presentation, 6/2016, Colloquia on Cancer Biology and Therapeutics, Louisville, KY

9. Poster presentation, $3 / 2016$, Society of Toxicology $55^{\text {th }}$ Annual Meeting, New Orleans, LA

10. Oral Presentation, 11/2015, Ohio Valley Society of Toxicology 2015 Annual Meeting, Northern Kentucky University, Highland Heights, KY

11. Poster presentation, 10/2015, Research! Louisville 2015, Louisville, KY

12. Poster presentation, 6/2015, Ohio Valley Society of Toxicology 2015 Graduate Student/Postdoc Annual Summer Meeting, Cincinnati, OH

13. Poster presentation, 5/2015, Great Lakes Drug Metabolism and Disposition Group 2015 Meeting, Ann Arbor, MI

14. Poster presentation, $3 / 2015$, Society of Toxicology $54^{\text {th }}$ Annual Meeting, San Diego, CA

15. Poster presentation, 10/2014, James Graham Brown Cancer Center Annual Retreat 2014, Louisville, KY,

16. Poster presentation, 9/2014, Research! Louisville 2014, Louisville, KY 
17. Oral presentation, 08/2014, Masters Defense/PhD Proposal Defense, Louisville, KY

18. Poster presentation, 5/2014, Great Lakes Drug Metabolism and Disposition Group 2014 Meeting, Indianapolis, IN

19. Poster presentation, 10/2013, James Graham Brown Cancer Center Annual Retreat 2013, Louisville, KY

20. Oral Presentation, 10/2013, Sixth International Workshop on Arylamine $\mathrm{N}$-acetyltransferases, Toronto, ON 